\author{
Universidade de São Paulo \\ Instituto de Física \\ FINPE
}

\title{
Algumas Aplicações de Campos Escalares em Cosmologia
}

\author{
Jackson Max Furtunato Maia
}

Banca Examinadora:

Prof. Dr. Gil C. Marques

Prof. Dr. Oscar J. P. Éboli

Prof. Dr. Adolfo Maia Jr.

Prof. Dr. Reuven Opher

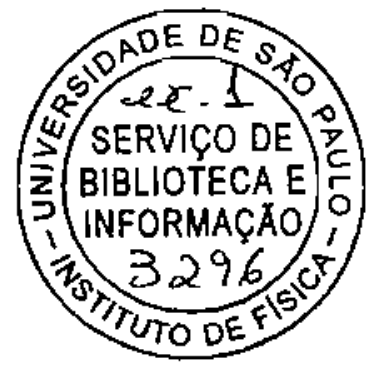

Prof. Dr. Rudnei O. Ramos

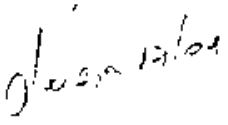

Tese de doutorado submetida ao Instituto de Física da Universidade de São Paulo.

Orientadores:

Prof. Dr. Gil da Costa Marques

Prof. Dr. José Ademir Sales de Lima

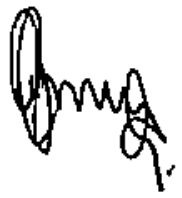

São Paulo - 2000 


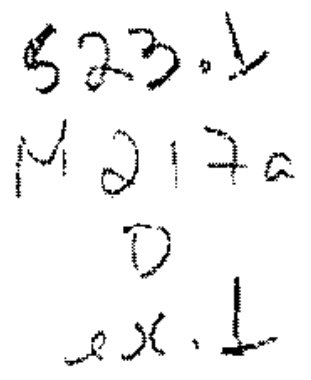

FICHA CATALOGRÁFICA

Preparada pelo Serviço de Biblioteca e Informação do Instituto de Física da Universidade de São Paulo

Maia, Jackson Max Furtunato

Algumas Aplicaçōes de Campos Escalares em Cosmologia. Săo Paulo, 2000.

Tese (Doutoramento) - Universidade de Săo Paulo. Instituto de Fisica - Departamento de Fisica Experimental

Orientador: Prof. Dr. Gil da Costa Marques

Área de Concentração: Fisica de Particulas Elementares

Unitermos: 1. Cosmologia; 2. Campo Escalar;

3. Gravitação; 4. Teoria de Cordas. 
oxin

-ow o ogp ow onb epuemy

a lotry som[y snat soy 
ร. 


\section{Agradecimentos:}

- aos meus co-orientadores Prof. Gil da Costa Marques, pela orientação, pela liberdade e confiança depositada e por me abrir novos caminhos; Prof. José Ademir Sales de Lima, pelo exemplo de trabalho, generosidade intelectual e paciencia;

- Prof, Robert Brandenberger, pelo exemplo e oportunidade;

- a Carenina, Ariel e Amanda pela inspíração, pelo amor e pela imensa felicidade, novidade e sentimento de completude que trouxeram para a minha vida;

- aos meus pais, por toda a liberdade e apoio irrestrito;

- a Ettore Baldini Neto, pela amizade, hospedagem, revisäo do texto e traqüilidade trasmitida nos estágios finais deste trabalho;

- a Oscar Bordon Alvares, pela ajuda no início do doutorado;

- a Richard Easther, pelas conversas e dicas durante a nossa colaboraçäo;

- a Eduardo, Ceiça, Katiane, Ana, Fătima e Denis, minha família estendida, que tantas vezes partilharam conosco o cuidado com as crianças, em particular a Catarina, sempre presente;

- a Jonatan e Amarildes e Adolfo, Goreti, Igor, Aron e Bia, pelas acolhidas;

- aos varios e preciosos amigos que fiz pelos caminhos, principalmente os que de alguma forma participaram deste doutorado: Alexandre Gadelha, os Amaldos (Gammal e Maccarone), Francisco Durâtes, os Franks (Antonucci e Smith), Isabela Porto, Jaime Merino, Joel Pupin, Mara Varela (em particular, pela revisẵo do estilo), Pedrag Stojkov, Raquel de Carvalho, Raul Abramo, Shan-Wen Tsai, Varese Timóteo e Wendy Sigle; 
- aos colegas do FINPE em S等o Paulo, do grupo de altas energias em Providence, e do grupo de astrofisica em Natal, pelas atmosferas estimulantes;

- aos funcionários e funcionárias que mantiveram as estruturas necessárias para un bom andamento do trabalho e, em particular, a Cláudia Barone, que vánias vezes me salvou das ameacas da selva burocrática;

- aAPES e ao CNPq pelas bolsas concedidas, a aos contribuintes que sustentam a academia contemplativa. 
Três aplicaçōes de campos escalares a cosmologias homogêneas e isotrópicaș săo aprosentadas, com motivacões e resultados diversos.

No primeiro caso, uma tểenica de multiplicadores de Lagrange é usada para estabelecer vínculos fisicos sobre os invariantes de curvatura possivelmente presentes na açâo efetiva de baixas energias da teoria de cordas. Um modelo näo-singular é obtido em um caso particular, sugerindo uma possível correção ua ação da gravitação compatível com as simetrias das cosmoloyias de cordas.

Numa outra abordagem, é proposto um modelo fenomenológico não-singular baseado no decaimento do termo cosmológico. O modelo tem como principal caracteristica uma passagem suave entre uma fase inflacionária do tipo de Sitter e uma fase com dinămica do tipo Friedmann-Robertson-Walker.

Como últímo exemplo, ê considerado um campo escalar acoplado termicamente ao fluido cósmico. Adotando um termo dissipativo específico, mas usual, é definido um espaşo de parametros contendo as cosmologias com campos escalares mais comuns e o modelo padräo como casos particulares. As condições de rolamento lento são obtidas e é apresentado um modelo cosmológico simples para exemplificar o potencial heurístico dos parâmetros propostos. 


\begin{abstract}
Three applications of scalar fields to homogeneous and isotropic cosmologies are presented, with distinct motivations and results.

In the first case, a Lagrange multiplier technique is used in order to set physical constraints on the curvature invariants possibly present in the low energy effective action of string theory. In a particular case, a nonsingular model is obtained, suggesting a possible correction in the gravity action which is compatible to the symmetries of string cosmology.

In another approach, a nonsingular model based on the decay of the cosmological term is proposed. The model has as a major feature a smooth transition between an inflationary de Sitter phase and a phase with FRW-type dynamics.

As a last example, a scalar field thermally coupled to the cosmic fluid is considered. By adopting a specific but usual dissipative term, it is defined a parameter space encompassing the most common scalar field cosmologies, as well as the standard model, as limiting cases. Slow roll conditions are obtained and it is presented a simple toy model to illustrate the heuristic potential of the proposed parameters.
\end{abstract}




\section{Conteúdo}

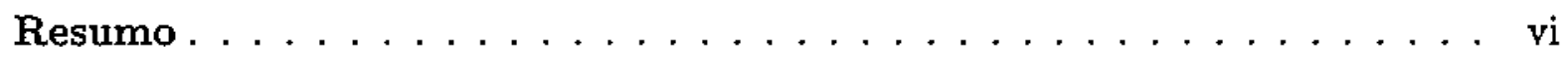

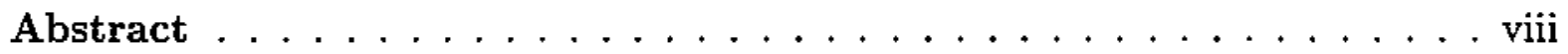

Lista de figuras . . . . . . . . . . . . . . xii

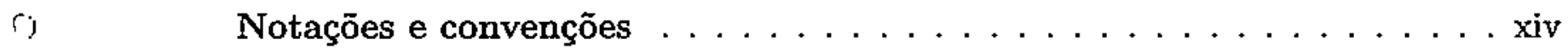

$\begin{array}{ll}\text { Apresentação } & 1\end{array}$

1 O Big Bang e seus problemas 5

1.1 Um pouco de história . . . . . . . . . . . . . . 5

1.2 O modelo cosmológico padrāo . . . . . . . . . . . . . . . 10

1.3 Situação observacional . . . . . . . . . . . . . . . . 15

1.4 Problemas do modelo padrão $\ldots \ldots \ldots \ldots$

2 Campos escalares e inflação $\quad 23$

2.1 Introdução . . . . . . . . . . . . . . . . 23

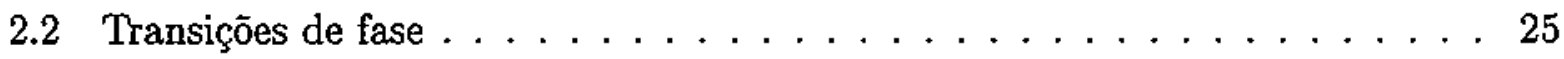

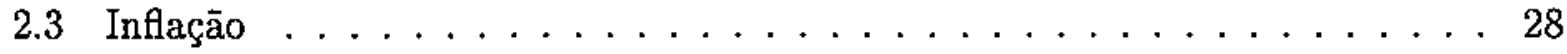

2.4 Soluçōes para os problemas do modelo padrão $\ldots \ldots \ldots$. . . . . . 30

2.5 Alguns tipos de inflaçāo $\ldots \ldots \ldots$. . . . . . . . . . . 31

2.6 Problemas da inflação $\ldots \ldots \ldots \ldots \ldots \ldots \ldots \ldots$

3 Cosmologia dilatônica não-singular 35 


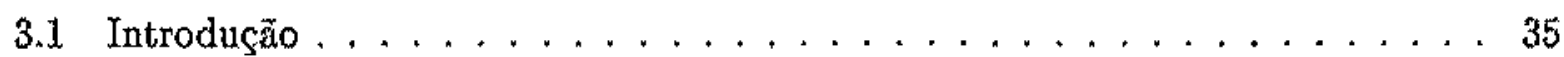

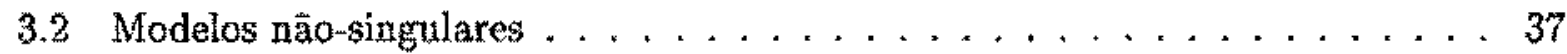

3.3 Açāo e equaçöes de movimento $\ldots \ldots \ldots \ldots \ldots \ldots \ldots$

3.4 Diagramas de fase das soluçoes sem o dilaton . . . . . . . . . . 42

3.5 Efeitos do dilaton $\ldots \ldots \ldots \ldots \ldots \ldots \ldots$

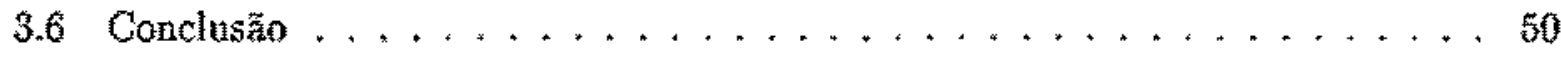

4 Cosmologias com decaimento do vácuo 53

4.1 Termo cosmológico variável $\ldots \ldots \ldots \ldots \ldots \ldots$

4.2 Um caso geral $\ldots \ldots \ldots \ldots \ldots \ldots \ldots \ldots$

4.3 Modelo deflacionário nä́-singular $\ldots \ldots \ldots \ldots \ldots$

4.4 Consequências observacionais $\ldots \ldots \ldots \ldots \ldots \ldots$

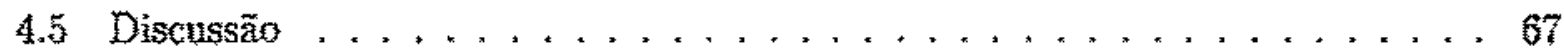

5 Campos escalares acoplados $\quad 71$

5.1 Introdução . . . . . . . . . . . . . . 71

5.2 Equaçòes básicas . . . . . . . . . . . . . . . 73

5.3 Inflação morna: um exemplo $\ldots \ldots \ldots \ldots \ldots \ldots$

5 Inflação morna generalizada $\ldots \ldots \ldots \ldots \ldots \ldots$

5.5 Dissipaçăo e condiçóes de rolamento lento $\ldots \ldots \ldots \ldots$

5.6 Um modelo simples $\ldots \ldots \ldots \ldots \ldots \ldots \ldots$. . . . . . . . . .

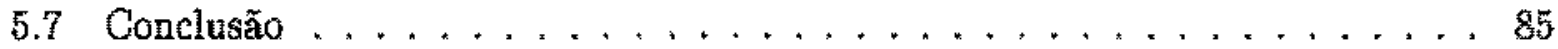

$\begin{array}{lr}\text { Consideraçöes finais } & 87\end{array}$

$\begin{array}{ll}\text { Apêndice A } & 89\end{array}$

$\begin{array}{ll}\text { Apêndice B } & 91\end{array}$

$\begin{array}{lc}\text { Referências } & 93\end{array}$ 


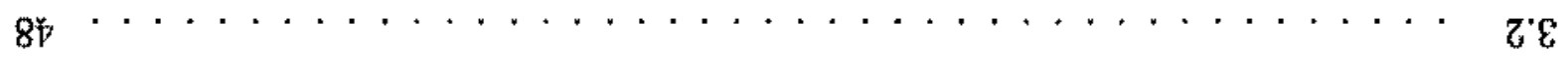

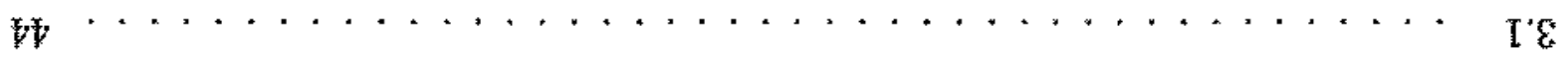


$\operatorname{IITX}$ 


\section{Notaçōes e convençōes}

- Assinatura da métrica: $(+\cdots)$

- Sinal do tensor de Riemann: $+R_{\nu \alpha \beta}^{\mu \alpha}=\partial_{\alpha} \Gamma_{\nu \beta}^{\mu \beta}-\partial_{\beta} \Gamma_{\nu \alpha}^{\mu}+\Gamma_{\alpha \alpha}^{\mu} \Gamma_{\nu \beta}^{\alpha}-\Gamma_{\alpha \beta}^{\mu} \Gamma_{\nu \alpha}^{\sigma}$

- Os índices gregos variam de 0 a 3 . Índices repetidos obedecem a convenção de Einstein.

- Derivada parcial: $\frac{\partial \phi}{\partial x^{a}} \equiv \phi_{, \alpha}$

- Derivada covariante: $A_{; \beta}^{\alpha}=A_{\beta}^{\alpha}+\Gamma_{\beta \lambda}^{\alpha} A^{\lambda}$

- Usaremos aqui unidades naturais, on seja, $\hbar=c=k_{B}=1$, a menos que unidades de outro sistema sejam explicitamente escritas por conveniência ou tradição. Em unidades naturais, a dimensăo fundarnental é a energia, de modo que

$$
[\text { energia }]=[\text { massa }]=[\text { temperatura }]=[\text { comprimento }]^{-1}=[\text { tempo }]^{-1}
$$

Como unidade de energia usaremos os múltiplos do elétron-volt (eV), particularmente o GeV:

$$
1 \mathrm{GeV}=1,60 \times 10^{-3} \mathrm{erg}=1,26 \times 10^{33} \mathrm{~K}=1,78 \times 10^{-24} \mathrm{~g},
$$

de modo que a unidade da densidade de energia, extensamente utrilizada no texto, é o GeVt: $1 \mathrm{GeV}^{4}=2,32 \times 10^{17} \mathrm{~g} \cdot \mathrm{cm}^{-3}$

- Quantidades de Planck: $\tau_{\mathrm{pl}} \equiv\left(\hbar G / c^{3}\right)^{1 / 2}=1,82 \times 10^{-33} \mathrm{~cm} ; E_{\mathrm{pl}} \equiv\left(\hbar c^{5} / G\right)^{1 / 2}=$ $1,22 \times 10^{19} \mathrm{GeV} ; m_{\mathrm{pl}} \equiv(h c / C)^{1 / 2}=2,18 \times 10^{-5} \mathrm{~g} ; \rho_{\mathrm{pl}} \equiv c^{5} / h \mathrm{G}^{2}=2,22 \times 10^{76} \mathrm{GeV}^{4}$ $t_{\mathrm{pl}} \equiv\left(\hbar G / c^{5}\right)^{1 / 2}=5,39 \times 10^{-4 t_{\mathrm{seg}}} T_{\mathrm{ph}} \equiv\left(\hbar c^{5} / k_{B} G\right)^{1 / 2}=1,42 \times 10^{32} \mathrm{~K}$

- Ocasionalmente o megaparsec (Mpe) será usado como unidade de distância: $1 \mathrm{Mpc}=$ $3,26 \times 10^{f} \operatorname{anos}-\mathrm{luz}=3,09 \times 10^{24} \mathrm{~cm}$ 


\section{Apresentação}

A cosmologia atual passa por um intenso processo de reciclagem. Devido a novas observações, velhos e novos parâmetros cosmológicos estāo sendo medidos com uma precisão sem precedentes e o espaço para especulação pura ou para a crença paradigmática vem ficando cada vez menor. A tendência histórica de seguir apenas o modelo mais simples e depois adicionar a este cadeias cada vez mais complexas de hipóteses esta dando lugar a outras práticas, nas quais novas hipóteses são consideradas à luz dos novos dados observacionais.

Tomando-se como exemplo o "paradigma" inflacionário: após mais de uma década de buscas, ainda não há qualquer teoria fundamental que justifique o inflaton (o campo escalar elementar supostamente responsável pela inflação). Já começa-se a pensar em mecanismos que possam, ou prover alguma outra forma de inflação que não seja fundamentada em campos escalares, ou resolver os problemas clássicos do modelo cosmológico padrão por vias não inflacionárias.

Um outro exemplo, talvez mais definitivo, é o relativo enfraquecimento de modelos baseados em defeitos topológicos como origem das sementes que geraram as estruturas em larga escala do universo. Após as observações das flutuações térmicas da radiação cósmica de fundo pelo satélite COBE (Cosmic Background Explorer) e outros experimentos em terra cada vez mais precisos, verificou-se que os espectros de perturbações previstos por modelos baseados em defeitos topológicos são de difícil compatibilidade com os últimos resultados observacionais.

Um último exemplo, desta vez não envolvendo o universo primitivo: há não muito 
tempo, diversas observafoes erarn interpretadas de modo a darem como certo que o termo cosmológico $A$ era zero on irrelevante. Tudo isso esta tendo que ser revisto sob luz das novas observagöes de curvas de luminosidade das supernovas do tipo Ia (SNIa), que indicam que - universo está numa fase de expansào acelerada. Os dados observacionais revelaram-se compativeis com a existência de um temo cosmológico que seria responsával por mais da metade da densidade de energia do universo atual. Como resultado, já há quern fale da um nowo modelo padrão, desta vez inciuindo a constante cosmológica.

Claro, näo se quer dizer com isto que os modelos tradicionais devam ser descartados, mas é certo que este final de decada tem testemunhado um crescinento de interesse em modelos novos, e a prática relativamente comum de desconsiderar prematuramente tudo o que não é pertinente à corrente dominante parece estar mudando. Se há tapaço para explorar novas idecias, há também para pensar as antigas sob novos pontos de vista. $\vec{E}$ o que se tenta fazer nesta tese, na qual o campo escalar, fo utilizado am inumeras situacoes

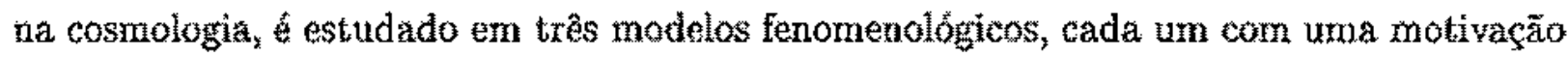
diferente. O plano do trabalho é descrito a seguir.

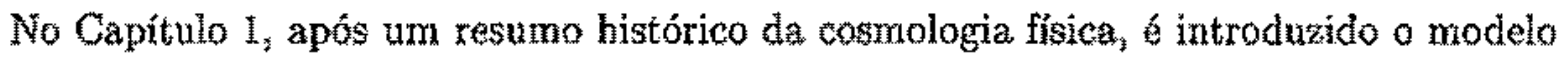
padräo, seus sucessos e problemas. $O$ Capítulo 2 trata do exemplo mais bern sucedido de apliząão de campos escalares em cosmologia: a infaçấo. Neste capítulo é dada mais

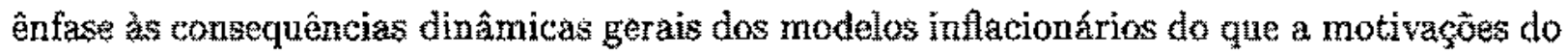
ponto de vista da teoria de camposs. Estes dois capitulos constituem a primeira parte, de contextualizagāo, desta tese.

A segunda parte tratarse de aplicaçôes de campos escalares a modelos fenomenológicos nos quais são tentadas soluçōes ou indicasỏes de novos tratumentos para problerias em aberto do modelo cosmológico padrāo. Como ocorre em qualquẹ abordagem fenomenológica, a expectativa é de se obter fundamentos para a construção de teorias mais completas, baseadas em primeiros prineípios.

Dentre os velhos problemas ainda sem solução no contexto do modelo padräo, há o 
problema da singularidade. A Relatividade Geral (RG) estabelece a seguinte relaçäo:

(geometria) $G^{\mu t} \propto T^{\prime k t}$ (conteúdo material).

Os teoremas de Penrose e Hawking, demonstram a existência de singularidades para uma gama bastante ampla de condições na RG. A partir desses teoremas, considera-se que a teoria nâo pode ser válida nos instantes iniciais da formaçäo do universo (para energias maiores do que a energia de Planck, $\left.E_{\mathrm{p}}\right) .{ }^{1}$ Normalmente considera-se que ou algum mecanismo físico entra en açăo para valores muito altos da curvatura do espaço-tempo, evitando assim as divergêneias na densidade de energia da matéria, ou se propõem correçöes na própria RG que previnam a ocorrência de singularidades. Nesta tese, apresentamos uma proposta de cada tipo, uma com termo cosmológico variável e outra inspirada pela ação efetiva de baixas energias das teorias de cordas fundanentais.

No Capitulo 3 a necessidade de prevençäo da singularidade é usada como vínculo físico na construção de um modelo não-singular inspirado pelas simetrias presentes nà teoria de cordas fundamentais, quando estudadas no domínio de baixas energias que caracterizam a cosmologia (no contexto das cordas fundamentais, isto significa abaixo da energia de Planck). O capítulo apresenta resultados originais publicados na Ref. [42].

No Capítulo 4 discutem-se modelos fenomenológicos com decaimento do vácuo, assumto que ultimamente yem levantando muito interesse, após a descoberta de que o universo está acelerando. A intenção desses modelos é fornecer indicaçóes de solução para o problema da discrepância de dezenas de ordens de grandeza entre as estimativas teóricas da densidade de energia do vácuo e o seu valor observado hoje, um mistério usualmerte conhecido como - problema da constante cosmológica. Os modelos apresentados no capítulo podem ter consequências tanto no universo primitivo, pois dependendo dos valores dos parämetros fenomenológicos os modelos sảo não-singulares, guanto na dinâmica atual do universo, com o văcuo participando como componente da matéria escura. A base deste capitulo săo as Refs. $[63,65,66]$.

\footnotetext{
${ }^{1}$ As definiröes das quantidades de Planck poden ser encontradas na p. ix acima.
} 
Uma proposta alternativa e interessante de inflação é supor que o contato térmíco do inflaton com os demais campos nầo se perde ao longo da expansão acelerada que caracteriza os cenários inflacionảios. Modelos deste hipo, chamados de inflação morna (uarm inflation) têm sido propostos como concorrentes dos modelos inflacionários mais consagrados. $O$ Capitulo 5 traz una análise de modelos com campos escalares acoplados baseada em um espaço de parametros convenientemente escolhido. Entendido como uma ferramenta no estudo das consequências dinâmicas de campos escalares com acoplamentos, o espactco de parâmetros foi usado para estabelecter um modelo simples, mas abrungente, que comporta dinhmicas compativeis com a expansäo acelerada descoberta com as observaçôs das SNIa e sugere a possibilidade de conexäo entre esses modelos acoplados a aqueles com decaimento do vácuo. A maior parte dos resultados deste capitulo foi publicada na Ref. [83]. 


\section{Capítulo 1}

\section{O Big Bang e seus problemas}

\subsection{Um pouco de história}

Em 1917, logo após completar a sua formulaçăo da teoria da relatividade geral (TRG), Einstein inaugurou a era da cosmologia relativística ao publicar o artigo no qual as suas equações do campo gravitacional eram aplicadas pela primeira vez ao universo como urn todo. Ele tinha três propósitos em mente ao formular o seu modelo cosmológico [1]: de monstrar que se poderia extrair da TRG uma descrição consistente do universo, algo em que a física newtoniana vinha falhando atế então, descrever um univesso estático, o que estava de acordo com as crenças da época, e mostrar que a TRG satisfazia o Princípio de Mach.

No modelo de Einstein o universo é entendido como um gấs de galáxias, homogêneo e isotrópico em larga escala (Principio Cosmológico). Alêm disso, é suposto que a energia cinética das partículas desse gás é desprezivel com relação a sua energia inercial (massa de repouso), o que significa considerá-lo um fuido com pressão nula. No eutanto, usando apenas estas hipóteses e partindo de um estado inicial estático, o fluido colapsaria em virtude da atração gravitacional. Este fato levou Einstein a introduzir un parantmetro livre nas equaçóes de carnpo que, além de não violar a covariăncia da TRG, seria importante apenas em escalas cosmológicas. Tal parâmetro, denominado por ele de termo cosmológico 
$(\Lambda)$, proveria a força repulsiva necessária para equilibrar a atração gravitacional. Usando a condição de estaticidade como vínculo entre o termo cosmológico e a densidade de matéria, Einstein obteve uma relaçẫo de proporcionalidade entre a massa total do universo (caracteristica global) e a sua geonetria (que determina o movimento local de partículas de teste), sugerindo desta forma, a validade do Principio de Mach.

Entretanto, poucos meses apớs a publicaçâo do artigo de Einstein, de Sitter apresentou urn modelo [2] com constante cosmológica no qual a densidade de matéria era zero. Neste modelo, partículas de teste se afastam entre si sob ação apenas da força repulsiva devida ao termo cosmológico. Se isto por um lado poderia ser considerado um primeiro exemplo de modelo cosmológico com expansäo, ${ }^{1}$ por outro, apresentava partículas de teste com propriedades inerciais em um espaço vazio, mostrando assim que a TRC admitia soluçöes que aparentemente violawam o Princípio de Mach.

Em 1922 e 1924 Friedmann [4] mostrou que as Equaçôes de Binstein admitem soluçōes dinâmicas (algo que näo era claro na época) e que a constante cosmológica não era imprescindivel para a elaboraçäo de um modelo do universo. Nesta mesma época Shipher [5] apresentou as primeiras evidências em favor de urn desvio para o vermelho cosmológico. Tais resultados, juntamente com os de Hubble [6] em 1929, sugeriam um universo em expansảo, descartando definitivamente o modelo estático. Isso fez com que o próprio Einstein propusesse a eliminação do termo cosmológico das equaçôes de campo.

Na mesma época em que o criador renegava a criatura, Lemaitre [7] a regeneraya para apresentar um modelo também expansionista, com a densidade da matéria diferente de zero e que explicava o desvio para o vermelho, reunindo assim, as vantagens dos modelos de Einstein e de de Sitter. Neste modelo, o universo inicia a sua expansão a partir de uma singularidade atė atingir uma fáse quase estática (com propriedades semelhantes às do universo de Einstein), e então prossegue em expansão, se aproximando do modelo de de Sitter. No

\footnotetext{
De Sitter foi o primeito prever o desvio para o vermelho (rutatift do esperto da luz emitida por objetos astronômicos gue ge afastam devido à expansäo do miverso [3]
} 
entanto, por causa da maior simplicidade do modelo de Friedmann, e pela ausência de fatos observacionais que a justificassem, foi-se perdendo o interesse pela constante cosmológica. De fato, a agitada história da constante cosmológica foi durante setenta anos a história das oscilações de preferência entre essas duas tendências, digamos, estéticas: a de manter, por completeza, o termo cosmológico nas equaçōes da TRG, já que os dados observacionais não descartam essa possibilidade, e a de eliminá-lo, por simplicidade, se esses mesmos dados não o justificam.

Nas décadas de 30 e 40 houve um renascimento do interesse pelo termo cosmológico, quando ficou claro que as medidas disponíveis do parâmetro de Hubble ( $H_{0} \sim$ $550 \mathrm{~km} \cdot \mathrm{seg}^{-1} \cdot \mathrm{Mpc}^{-1}$ ) davam para o universo uma idade de apenas 2 bilhões de anos [8]. Isto é menos que a metade da estimativa de idade da Terra e, pior, as estimativas das idades das estrelas eram de 10-20 bilhōes de anos. O modelo de Lemaitre consegue acomodar este valor de $H_{0}$ com idades mais aceitáveis porque a duração da fase quase estática pode ser fixada tão longa quanto seja necessário, escolhendo-se convenientemente o valor de $\Lambda$.

Do lado teórico, essas incertezas nas observaçōes deram espaço à grande controvérsia entre partidários dos modelos expansionistas tipo Friedmann, com origem singular e idade do universo finita (ou Big Bang, como foi chamado por G. Gamow) e defensores do modelo de estado estacionário. Esta linha propunha um universo em expansão, como requerido qualitativamente pelas observações de desvio para o vermelho, mas sem origem e com criaçāo contínua de matéria, para compensar a diluiçāo, mantendo assim a densidade de energia constante. Entretanto, mesmo esparsos e pouco confiáveis, os dados observacionais traziam problemas para ambos os modelos. Se por um lado as medidas de $H_{0}$ pareciam incompatíveis com modelos com origem singular, a cosmologia de estado estacionário tinha dificuldades para explicar as abundâncias de Hélio nas estrelas [9]. Na década de 50, com as observaçōes do recém contruído telescópio do Monte Palomar, foi verificado que as estimativas de $H_{0}$ estavam superestimadas em quase uma ordem de grandeza, eliminando o embaraço da idade do universo para os defensores do modelo de Friedmann. É claro, isto 
de modo algum resolveu a controvérsia.

Uma resoluçấo para o impasse começou a ser delineada com os estudos das consequências da termodinâmica en cosmologia, iniciados por Gamow e colaboradores [10]. Ao tentarem explicar uma origem cosmológica para o Hélio observado nas estrelas, Gamow et a. supuseram um universo primordial extremamente quente e denso de modo que este pudesse ser considerado um corpo negro em equilibrio, com temperatura suficiente para provocar a fusão dos elementos leves de acordo com a física mulear conhecida na êpoca. Esta nova abordagem termodinâmica levou ao estabelecimento de mats duas consequêtncias observáveis (e efetivamente observadas) do Big Bang que sustentam a visão atual do universo: a radiação cósmica de fundo com temperatura de $3 \mathrm{~K}$ e a nucleossíntese primordial com cálealo das abundàncias dos elementos leves observadas em estrelas (principalmente as mais antigas). $O$ crédito, porém, não foi para Gamow, russo, vivendo nos Estados Unidos exatamente na época do macartismo mais exagerado [9]. Foi apenas na década de 60 que esta linha termodinâmica foi adotada por Dicke, Peebles e colaboradores, que chegaram a conclusōes semelhantes às do grupo de Gamow e estavam até preparando um experimento para medir a radiação de fundo quando esta foi observada acidentaimente por A. A. Penzias e R. W. Wilson, em 1965 [11]. Restou a Dicke et al. dar a interpretação teórica destas medidas [12]. Diferentemente do que aconteceu com o grupo de Gamow, este resultado foi rapidamente aceito $e_{1}$ poucos anos depois, cálculos (numéricos) mais precisos das abundâncias dos elementos leves foram realizados [13], confirmando ainda mais o Big Bang como á única descrigâa aceitável do universo. Em menos de dez anos após a descoberta da radiçãa cósmica de fundo, este modelo já era chamado de "modelo padräo" da cosmologia, expressão importada da física de partículas e popularizada por $S$. Weinberg no seu livro-texto sobre gravitação e cosmologia [B].

Paralolamente às disputas sobre quais modelos descreverian o uniwerwo, uma outra vertente foi-se consolidando: o estudo da evolução de perturbaç̧̋es de densidade submetidas à instabilidade gravitacional até a formaça das galáxias e estruturas em larga escala no 
universo atual. Este tema foi praticamente dominante em cosmologia ao longo da década de 70, juntamente com o estudo da era da recombinaçäo (periodo durante o qual a radiação de fundo perdeu 0 acoplamento térmico com os núcleos de Hidrogênio, permitindo a formaţão de átomos). Esta é urna das áreas de pesquisa maais ativas e desenvolvidas (principalmente do ponto de vista observacional) da cosmologia atual, mas na época ainda näo haviam propostas consistentes para a origem das perturbaçöes de densidade, algo dificil de justificar num universo cuja homogêneidade é dada como condiçẵo inicial.

Durante os anos $80_{4}$ a cosmologia foi praticamente dominada por aplicaçotes da física de partículas a teorias de campo no domínio cosmológico. O maior resultado deste período foi a inflação, com suas muitas versōes, que resolveu alguns dos problemas do modelo padrão. Dentre eles o mais importante, o da origern das flutuaçöes de densidade a partir das quais teriam se formado as galáxias. A inflação gera naturalmente, através de flutuaçốes quânticas do campo escalar que a dirige, o espectro de perturbaçóes de densidade que servem de sementes para as estruturas observadas. Tambérn nessa década o estudo da formação de estruturas em larga escala foi refinado, com a inclusäo de defeitos topológicos (surgidos das transiçōes de fase sofridas pelos campos quänticos ao longo da expansāo e resfriamento do universo) e a introduçâto de modelos com matéria escura nāo bariônica. Outros resultados importantes do periodo săo os modelos de bariogênese e o uso da cosmologia como "laboratório" de teorias de altas energias, limitando parămetros livres da física de partículas tais como a massa e o número de tipos de neutritos, por exemplo. Um bom resumo do que foi feito nessa interface entre cosmologia e teoria de campos e/ou física de partículas pode ser encontrado na Ref. [14].

Mesmo com todo o interesse levantado pelas aplicaçóes cosmológicas das teorias de campos, os anos 90 revelaram-se muito mais excitantes. Esta tem sido uma década de experimentos e observaçốes cruciais que têm ajudado a resolver várias das dúvidas e pendências que persistiam desde os primórdios da cosmologia. Entre a imensa quantidade de resultados observacionais destacam-se: as missões para determinaçän da distribuiçăo tridimensional 
das estruturas cosmológicas, as medidas das inomogeneidades na radiaçäo de fundo (previstas no contexto do modelo padräo) [19], as medidas da distribuição de velocidades peculares (movimentos locais, superpostos à expansäo de Hubble) e, nos últimos dois anos, as medidas de luminosidade de supernovas do tipo Ia [15] (as quais, a propósito, reabilitaram mais uma vez o termo cosmológico). Estes resultados, bem como uma pequena revisão dos modelos inflacionários serâno melhor distutidos adiante.

Dit a lenda que um físico famoso se queixava que a astrofísica estava sempre em dúvida, mas nunca em erro. Ao longo desta última década este ponto de vista teria que ser rem visado, pois os novos projetos observacionats trouxeram uma nova e excitante exa para a cosmologia. Nầ é muito otimismo supor que no futuro próximo teorias e modelos poderão ser falseados aos blocos, para cada novo satélite de observaçăo que seja posto em órbita. Provavelmente o espaço para a especulaçäo pura ficará mais reduzido, mas poderả haver tambérn a necessidade de refinamentos de velhos modelos e da proposição de novas alter. nativas.

\subsection{O modelo cosmológico padrão}

Os modelos apresentados e/ ou propostos no ambito desta tese estão baseados na hipotese do Princípio Cosmológico ${ }^{2}$ e, na maioria dos casos, nas equaçöes de Binstein para o campo gravitacional, ou TRG. No Capítulo 3 , entretanto, seräo aplicadas extensóes da TRG e isto será explicitado no momento oportuno.

A consequência fundamental do Principio Cosmológico é que a geometria do espaço-

\footnotetext{
${ }^{2}$ A afirmaģăo de que o univarso ê homogêneo em larga escala năo é trivial do do ponto de vista observam cional Até recentemente, a ínica evidênèa direta em tavor do Princípio Cosmológico era a ísotropia da

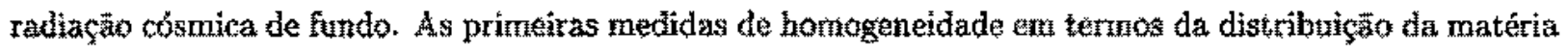
ทisivel foram anunciadas apenas tom 1092, quando for indicada a ausência de estruturas em escalas roaiores do que $100 \mathrm{Mpe}$, cerca de $2 \%$ do universo observável. Uma discussăo detalhada de medidas deste tipo, berti

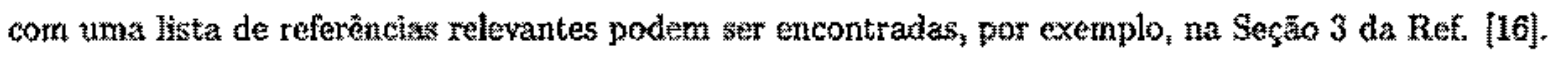


tumpo tem seçōes espaciais homogêneas e isotrópicas e pode ser descrita pelo elemento de linha de Friedmann-Robertson-Walker (FRW)

$$
d s^{2}=g_{p u} d x^{\mu} d x^{4}=d t^{2}-a^{2}(t)\left(\frac{d r^{2}}{1-k r^{2}}+r^{2} d \theta^{2}+r^{2} \sin ^{2} \theta d \phi^{2}\right)
$$

onde $g_{t a}$ é o tensor metrico, a(t) e fator de escala cósmico, uma funçäo a ser determinada pelas equações do campo fravitacional, e a constante k 6 o parametro de curvatura da seç艹 espacial. Com uma escolha apropriada de coordenadas, este parámetro pode zer normalizamdo para os valores $0, \pm 1$, denotando espacos planos, com curvatura positiva (fechados) ou negativa (abertos), respectivamente. A universos cuja geometria é descrita por (1.1) esta associado um referencial privilegiado, no qual os observadores têrn coordenadas $(r, \theta, \phi)$ fixas, ou seja, a velocidade peculiar dos elementos de volume do fluido é nula (coordenadas comóveis). Além disso, todas as grandezas só podem tepender ta coordenada ta que mede o tempo propión dos observadores comóveis.

A dinâmica dos modelos cosmológicos, descrita pela evolução temporal do fator de escala $a(t)$, é dependente das propriedades do fluido que preenche o universo e da teoria de gravitação empregada. No caso da TRG, o acoplamento entre a geometria do modelo a distribuição de massa-energia do fluido cósmico é fixado pelas equaçōes de campo de Einstein (escritas aqui com o termo cosmológico $A$ )

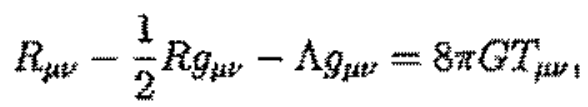

sendo $R_{\mu}$ o tensor de Ricci, $R$ o escalar de curvatura e $T_{\mu, t}$ o tensor de energia-momento de todos os campos presentes, tais como matéria, radiaçäo etc. As equaçôes de Einstein podem também ser obtidass mininimizando a açäo [8]

$$
\frac{\delta S}{\delta g_{\sharp t *}}=0
$$

com $S$ sendo a soma da açẩo de Enstein-Hilbert e a acho dos campos de matéria:

$$
S=S_{E H}+S_{m}=-\frac{1}{16 \pi G} \int d^{i} x \sqrt{-g}(R+2 A)+\int d^{4} x \sqrt{-g} \mathcal{L}_{m}
$$


e $g$ sendo o determinante do tensor métrico $g_{\mu w}$. Uma discussäo mais detalhada do uso de métodos variacionais para obter equaçôes no contexto de métricas do tipo FRW pode ser encontradă no Apêndice A.

Observe que a conservação isolada do tensor de energia-momento da matéria $\left(T^{\mu \nu}{ }_{j *}=0\right)$ e o fato do tensor de Einstein

$$
G_{\text {qut }} \equiv R_{i \nu}-\frac{1}{2} R g_{\mu t}
$$

ter também divergência nula, devido às identidades de Bianchi [8], implicam que $A_{i k}=0$, ou seja, que $\Lambda$ é constante no espaço-tempo. Algumas vezes é mais conveniente passar $\Lambda g_{\mu \nu}$ para o lado direito e reescrever (1.2) sob a forma:

$$
R_{\mu \nu}-\frac{1}{2} g_{\mu \nu}=8 \pi G \tilde{T}_{\mu \mu \nu}
$$

sendo $\tilde{T}_{p}$ o tensor de energia-momento efetivo

$$
\vec{T}_{\mu \nu}=T_{\mu \nu}+\frac{A}{8 \pi G} g_{\mu \nu}
$$

No caso de universos homogêneos e isotrópicos, a fonte de curvatura total $\left(\breve{T}_{\mu \nu}\right)$ é descrita por um tensor de energia-momento de fluido perfeito:

$$
\vec{T}_{z a v}=(\vec{p}+\vec{p}) u_{p} z_{t s}-\tilde{p} g_{p u s}
$$

$\operatorname{com}$

$$
\hat{\rho}=\rho+\frac{\Lambda}{8 \pi G} \quad \text { (e) } \quad \tilde{\mathrm{p}}=\mathrm{p}-\frac{\Lambda}{8 \pi \mathrm{G}^{2}}
$$

sendo $\rho$ e $p$, respectivamente, a densidade e a pressäo da componente material e $u^{\mu}=(1,0,0,0)$, pois o fluido está em repouso com relaçăo às coordenadas comóveis (1.1).

As equaçöes que determinam a evoluçăo do fator de escala e das demais grandezas físicas são obtidas das componentes independentes das equações de Einstein. Taís equaçôes, para a métrica (1.1) e o tensor de energita-momento (1.8), podem ser escritas como [8]:

$$
3 \frac{\dot{a}^{2}}{a^{2}}+3 \frac{k}{a^{2}}=8 \pi G \dot{p}
$$




$$
2 \frac{\ddot{a}}{a}+\frac{\dot{a}^{2}}{a^{2}}+\frac{\vec{k}}{a^{2}}=-8 \pi G \vec{p}
$$

Combinando-se as Eqs. (1.10) e (1.11) obtém-se

$$
\ddot{a}=-\frac{4 \pi G}{3}(\tilde{\rho}+3 \tilde{p}) a
$$

Esta é a equa̧̧ăo fundamental para se entender qualitativamente a existência de singularidan des em modelos com a métrica de FRW. Se $\Lambda$ for constante e $(\tilde{\rho}+3 \bar{p})$ tiver sido não negativo num instante $t_{p}$ qualquer, (1.12) implica que $\ddot{a} \leq 0$ para qualquer $t \leq t_{p}$. Como $a>0$ hoje, a curva $a\left(t<t_{p}\right) \times t$ tem que ser côncava para baixo, consequentemente, $a=0 \mathrm{em}$ algum iustante finito no passado. É claro, ä poderia ser positivo se $\Lambda$ fosse tal que $\tilde{p}<-\frac{1}{3} \tilde{p}$. Neste caso, o wniverso teria colapsado de um tamanho infinito até atingir um raio finito $\mathrm{em}$ algum instante do passado. Contudo, a partir desse momento haveria uma evoluçăo para uma fase de expausüo que seria assintoticamente dominada pelo termo cosmologico antes da nucleossintese, o que descarta esta possibilidade de modelo näo-singular.

A Eq. (1.12) tambêm permite uma discussão qualitativa da idade do universo. No caso de modelos singulares, sera deftnida como idade o tempo decorrido desde a singularidade $(t=0)$ até hoje $\left(t=t_{0}\right)$. Tomando 0 caso limite $a=0$, entāo $a(t)=A t$, onde $A$ ét uma constante. Denominando $a\left(t_{0}\right) \equiv a_{9}$, então $A=a_{0} / t_{0}=\dot{a}_{0}$, de modo que $t_{0}=a_{0} / \dot{a}_{0} \equiv H_{0}^{-1}$ (tempo de Hubble). Se $\ddot{a}<0$, a curva a(t) tem concavidade para baixo, o que significa que $t_{0}<H_{0}^{-1}$. Conclui-se portanto que modelos com singularidade fornecem idades cujo limite superior é $H_{0}^{-1}$.

Diferenciando a $\mathrm{Eq}$ (1.10) com respeito ao tempo e substituindo o resultado na Eq. (1.12), obtem-se a seguinte expressào para a conservação da energia:

$$
\frac{d}{d a}\left(\rho a^{3}\right)=-3 p a^{2}
$$

Esta equaçäo pode ser reescrita na forma da segunda lei da Termodinămica:

$$
d(\rho V)+p d V=T d S=0
$$


onde $V \propto a^{3}$ e $S$ é a entropia por volume comóvel. Esta expressäo mostra que a expansão (ou contraçăo) do luido ocorre adiabaticamente ern modelos tipo FRW.

Considere-se, como é comum en cosmologia, que o ludido cósmico é descrito por uma equaçäo de estado do tipo lei garma

$$
p=(\gamma-1) \rho
$$

com $\gamma$ constante. Esta equaçẩo de sstado caracteriza qual é a componente do fuido que determina a dinămica do universo. Se o universo é dominado por matéria näo relativística (poeira) $\gamma=1$ e se a radiação for a componente dominante $\gamma=4 / 3$. Usando as Eqs. (1.13) e (1.15), pode-se determinar a lei de escala para a densidade de energia da componente dominante do fluido cósmico (lembrando que $\Lambda$ é constante):

$$
p=p_{0}\left(\frac{a}{a_{0}}\right)^{-3 n}
$$

com $p_{0}$ sendo a densidade de energia do fluido hoje. Assim, para determinar o comportamento temporal de $\rho$, é suficiente determinar o fator de escala $a(t)$.

Usando a lei gama e combinando as Eqs. (1.10) e (1.11), encontra-se a equação que governa a dinâmica do fator de escala:

$$
a \ddot{a}+\frac{3 \gamma-2}{2} \dot{a}^{2}+\frac{3 \gamma-2}{2} k-\frac{\gamma \hat{A}}{2} a^{2}=0
$$

cuja integral primeira é

$$
\dot{a}^{2}=A a^{-(3 \gamma-2)}-k+\frac{\Lambda}{3} a^{2}
$$

e A e uma constante de integraçăo.

Uma soluçäo particular das equaçöes acima que e importante para contextualizar os temas desta tese é o modelo de de Sitter, obtido fazendo-se $p=p=k=0$ nas equaçồ acima. Neste caso, a Eq. (1.10) fornece a seguinte solução [2]:

$$
a=a_{*} e^{H\left(t-t_{*}\right)}
$$


onde $H=\sqrt{\Lambda / 3}$. Este é o modelo com expansão exponencial mais comumente associado ao cenário inflacionatrio. Os detalhes sobre como a evolução de campos escalares pode levar a este regime seräo apresentados na Seçấo 2.3.

\subsection{Situação observacional}

Os resultados favoráveis ao modelo padräo Fazendo $\Lambda=p=0$ nás equaçồ de Einstein, obtérn-se o chanado modelo padräo da cosmologia, ${ }^{3}$ cujas soluçóes para $k \pm 1$ foram encontradas por Friedmann e para $k=0$, por Einstein e de Sitter. A sen fayor existem algumas evidências observacionais que se isoladamente năo seriam suficientes para confirmá-lo, quando reunidas, säo explicadas só por ele.

A primeira evidência corroborando o modelo foram as observaçóes de Hubble, de acordo com as quais a velocidade de recessāo $v$ das galáxias é proporcional à distância $r$ que nos separa delas (lei de Hubble):

$$
v=H_{0} T
$$

O modelo tambén admite que a matéria está imersa em um banho tểrmico (radiação de fundo) que vem esfriando ao longo da expansāo a partir de urn estado primordial com temperatura e densidade infinitas ( $H o t$ Big Bang). Esta expansão ocorre en equilibrio térmico a partir de temperaturas da ordem de $10^{16} \mathrm{GeV}$ [14] (equilibrio aqui é definido como a situaça na qual a escala de tempo dos processos físicos te muito menor do que o tempo de Hubble). A lei de temperatura para a radiação b dada por [8]

$$
T(t)=T_{0} \frac{a_{0}}{a(t)}
$$

e $T_{0}$ e $a_{0}$ săo, respectivamente, a temperatura de corpo negro da radiação e o valor do fator de escala hoje. Para temperaturas suficientemente altas, os fótons da radiação de fundo tinham energia acima da necessária para ionizar a matéria. Contudo, a partir de $T \sim 1 \mathrm{eV}$

\footnotetext{
${ }^{3}$ Embora esta definiçăo esteja ficando um tanto ultrapassada. A tẹndência mais recente é consídérar $\Lambda \neq 0$.
} 
a ioniząão ja não ef eficiente e a matéria tornou-se subitamente transparente para esses fótons. Esste período é chamado de era da recombinação. Desde então a radiaçấo de fundo vem esfriando e mantendo um espectro térmico. A observaçăo na década de sessenta [11] de uma radiação de fundo isotrópica com espectro de corpo negro e temperatura $T_{0} \sim 3 \mathrm{~K}$ (microondas) foi determinante para a aceitação do modelo padrăo.

En um universo primordialmente denso e quente, as abundảncias relativas dos elementos quimicos mais leves säo fixadas já nos primeiros minutos a partir da singularidade inicial. As medidas das abundâncias dos elementos ${ }^{4} \mathrm{He},{ }^{2} \mathrm{H},{ }^{3} \mathrm{He}$ e ${ }^{7}$ Li conoordam com as previsöes baseadas no modelo padräo [14]. Além disso, a produçăo cosmologica do "He é quantitativamente ralacionada com o número de tipos de neutrinos $N_{\nu}$. $O$ limite superior calculado com base nos dados observacionais sobre este elemento $(N, 3,3)$ exta de acordo com os valores obtidos posteriormente por aceleradores de partículas $\left(N_{k}=2,98 \pm 0,06\right)$ $[17]$

Alguns consideram que uma quarta evidência em favor do modelo padrão é a concordância entre os vărios métodos de determinação da idade do universo. $O$ conceito de idade do universo, inferida dos tempos de vida dos objetos nele contidos, só tem sentido em modelos com uma fase primordial densa e quente, mesmo que estes não apresentem singularidade. Em tais casos, a idade seria o tempo decorrido entre hoje e apoca na qual o universo se tornou suffientemente frio para que se pudessem format as estruturas das quais medimos o tempo de vida. Neste sentido, fato das medidas do partmetro de Hubble $H_{0}, 0$ calculo do tempo de resfriamento das anăs brancas, a datafäo das extrelas mais antigas dos aglomerados globulares e dos elementos radioativos tornecerem, todas, tempos da ordem de $10^{10}$ anos, pode ser considerado como um forte argumento em tavor de uma origem mais ou menos simultânea para esses objetos. 


\section{Situaçăo observacional recente}

Supernovas A medida que novas tecnologias säo incorporadas ao aparato observacional da astrofisica, objetos menos brilhantes são observados e as suas distâncias estimadas com maior precisảo. Naturalmentê, as observaçoes mais relevantes para a cosmologia säo as de objetos distantes, e os últimos anos têm sido reveladores nesta área. Por um lado, há a corroboraçäo dos resultados clássicos que confirmara o modelo padrẩo e sugerem um uniwerso que realmente expandiu a partir de um estágio inicial denso e quente, com um período de nucleossíntese nos seuts primeiros minutos, com crescimento de estruturas por colapso gravitacional da matéria em torno de pequenas inomogeneidades iniciais [18].

Por outro lado, a evoluçấo futura do universo vem sendo revista. Usualmente, pensavase que o conteudo do universo era basicamente matéria e radiaçäo, as formas de energia mais facilmente detectáveis e que tendem a desacelerar o universo. A grande dúvida era se havia ou não matéria suficiente a ponto de haver um recolapso futuro do universo. As evidências, contudo, săo crescentes de que o universo está acelerando a sua taxa de expransäo. Como para objetos próximos vale a lei de Hubble Eq. (1.20), que envolve apenas a $(t)$ e $a(t)$, tais medidas de aceleração têm que ser feitas com objetos a grandes distâncias.

A maior dificuldade para medir distâneias muito grandes é saber qual a luminosidade absoluta dos objetos que se quer medir. Uma grande parte do esforço dos astrofísicos observacionais é despendido na ídentificação e estudo de objetos que possam ser usados como reterências de luminosidade de modo $\mathrm{a}$, quando um deles for observado, ter a sua distância deduzida da sua magnitute aparente. No caso das đistầncias cosmológicas, este problema é ainda maior. Nesta escala de distâncias, praticamente não há objetos que possam ser individualmente observados (como estrelas, por exemplo, que têm suas luminosidades bem estudadas).

Uma exceçä̀ to caso das supernovas, que, por um breve perído, podem ter uma luminosidade comparâvel à de uma galảxia. Sabendo-se propriedades gerais da dinâmica da explosão, e sendo tais propriedades as mesmas para supernovas de uma mesma classe, 
obtém-se uma vela-padräo confiável para medidas de longa distância. Esta homogeneidade de propriedades ocorre para as supernovas do tipo la, se for usada uma engenhosa técnica que correlaciona o pico de luminosidade da supernova com o tempo decorrido para ela atingir este pico. O que se mede então com precisão não é diretamente a luminosidade, mas este tempo. Usando esta técnica para determinar distâncias de galáxias onde ocorreram SNIa, dois grupos conseguiram inferir uma aceleração para o universo [15], o que e incompativel com o modelo padräo contendo apenas poeira ou matéria escura fria. Estes resultados indicam que deve haver uma forma de energia corn efeito repulsivo na dinâmica das equaçōes de movimento cosmológicas $(p<-\rho / 3)$ na Eq. (1.12). O candidato natural para preencher a vaga aberta no conteúdo do universo é a constante cosmológica, pois os dados observacionais são consistentes com um valor para $\Lambda$ cuja densidade de energia é responsável por cerca de $70 \%$ da massa do universo.

Idade Os limites inferiores mais estringentes para a idade do universo to vêm de estudos de populaçōes de estrelas de aglomerados globulares. Consideradas como problemáticas para o modelo padräo por serem incompatíveis com um universo dominado apenas por matéria (o problema da idade), essas medidas foram reavaliadas depois que a análise de dados do satélite astrométrico Hipparcos indicaram que as distảncias para os aglomerados que eram usualmente consideradas até 1997 estavam sistematicamente subestimadas. Isto significa que as estrelas observadas eram mais brilhantes do que se acreditava e, portanto, mais jovens. As estimativas de $t_{0}$ ainda näo têm um valor consensual, mas a reuniăo de vărias delas fornece um número em torno de 13 bilhōes de anos [20], abaixo dos resultados de há poucos anos atras. Este valor de idade implica que $H_{0} t_{0} \sim 1$, o que ainda é incompatível com um universo dominado inteiramente por matéria (o problema esta menor, mas persiste). Este é mais um argumento indireto em favor de uma componente com pressão negativa no universo. 
Expansão do universo Após anos de disputa acirrada, aparentemente o parâmetro de Hubble está "convergindo" para algo em torno de $65 \mathrm{~km} \cdot \mathrm{seg}^{-1} \cdot \mathrm{Mpc}^{-1}$, com a precisão melhorando de aproximadamente $50 \%$ para $15 \%$ graças às medidas de Cefeidas feitas pelo telescópio espacial Hubble. A composição com os resultados da idade sugerem que, apesar de ter sido mitigado, o problema da idade persiste, pelo menos para o caso de um universo dominado por poeira.

Parâmetro de densidade Fazendo $\Lambda=k=0$ na Eq. (1.10), podemos definir a densidade crítica $\left(\rho_{c}\right)$, como sendo a densidade de um universo plano:

$$
\rho_{c} \equiv \frac{3 H^{2}}{8 \pi G}
$$

Definindo $\Omega_{x}$ como sendo a fração do componente $x$ com relação à densidade crítica, tem-se que no caso da matéria $\Omega_{m} \sim 0,3$. Como os resultados da nucleossíntese indicam um valor bem abaixo deste para a densidade de número de bárions no universo, conclui-se $\Omega_{m}$ é formado por praticamente apenas matéria escura nāo bariônica.

O valor acima foi obtido a partir de diversas técnicas independentes (curvas de luminosidade de supernovas, análise do espectro da radiação de fundo para grandes valores do número de onda, medidas de velocidades peculiares de galáxias, e outros) [20]. A conclusão que se chega é que, para modelos planos, $\Lambda \sim 0,7$. Apesar de serem ainda resultados muito recentes, é estimulante que técnicas diferentes estejam dando valores similares.

Vale ressaltar porém que estes resultados nāo sāo unânimes. Uma outra técnica, a estatística de lentes gravitacionais, muito sensivel ao tamanho de um possível termo cosmológico, desfavorece valores muito altos de $\Lambda$ [20]. Entretanto, pode-se dizer aqui que os dados observacionais mais recentes e confiáveis convergem para um universo plano com $70 \%$ do seu conteúdo energético sob uma forma de energia que tem pressão negativa, como, por exemplo, é o caso da uma constante cosmológica. É também possivel que $\Lambda$ varie com o tempo, como será considerado no Cap. 4. 


\subsection{Problemas do modelo padrão}

Apesar dos sucessos citados acima, principalmente as previsóes da nucleossíntese cosmológica e a descoberta da radiação cósmica de fundo, o modelo padrão apresenta algumas consequências incômodas. Em primeiro lugar, todas as variantes do modelo padrão apresentam singularidade quando $t \rightarrow 0$ (ver Eq. (1.12)), ou seja, grandezas tais como temperatura e densidade divergem próximo ao instante inicial. Acontece que, para tempos da ordem do tempo de Planck $\left(t_{p i} \sim 10^{-43} \mathrm{seg}\right)$, não se pode mais garantir que uma teoria de gravitaçāo näo quântica, como a TRG, possa ser empregada. Conclui-se, então, que o modelo padräo näo pode ser usado para estudar a física dos estados mais primitivos do universo.

O limite da velocidade de propagação das interaçōes (velocidade da luz) nos define uma distầncia alérn da qual duas partículas nâo podem ter contato causal. Esta é a chamada distância de horizonte $d_{k}$. No modelo padrão, quando $t \rightarrow 0, d_{t k}$ tende a zero mais rapida mente do que o fator de escala [8]. Uma implicação disso é que um ponto dentro do rosso horizonte atualmente observatvel, eventualmente esteve fora dele, se tomarmos instantes suficientemente recuados no tempo. Em particular, se o fator de escala evoluiu segundo equaços do tipo FRW, estima-se que a parte do universo presentemente observável era composta por aproximadamente $10^{5}$ regiobes causalmente desconexas na era da recombinaçâo [14]. Nâo seria de se esperar, portanto, que estas regiōes estivessem à mesma temperatura naquela época. No entanto, as medidas mostram que a radiaçâo de fundo tem inomogeneidades menores do que uma parte en $10^{5}$ na temperatura [19]. Isto significa que apesar de não haver contato térmico entre essas regiōes, elas parecern ter se expandido a partir de um estado de equilibrio. No contexto do modelo padrão nāo é possível explicar esta uniformidade da radiaçấo de fundo, ela é simplesmente tornada como uma condição inicial.

Um terceiro problema está relacionado ao quão próximo o universo está de ser geometricamente plano. Se $k \neq 0$, podemos reeserever a Eq. (1.10) na forma

$$
\frac{\left|\rho-p_{c}\right|}{\rho_{c}}=\frac{1}{\dot{a}^{2}}
$$


que é uma medida da proximidade entre $\rho$ e $\rho_{c}$. Esta é uma grandeza que diverge rapidamente com o tempo. Por exemplo, na era da radiaçầ $(\gamma=4 / 3 \mathrm{em}(1.18)), \hat{a}^{-2}=A t$ $\left(A=\right.$ cte). Medidas do valor de $p$ hoje $\left(\rho / \rho_{c} \sim 1\right)$ nos däo que $A \sim \hbar_{0}^{-1}$. Portanto, na era de Planck $\left(t_{p l}\right)$

$$
\frac{\left|p-p_{s}\right|}{p_{\mathrm{t}}} \sim \frac{t_{p^{t}}}{t_{0}} \sim 10^{-6 t} .
$$

Isto indica que a mínima futuação de densidade nesta época teria inviabilizado a existência do nosso universo. Se a quantidade acima fosse da ordem de 1 (em unidades naturais), ou o universo teria recolapsado imediatamente apos o $t_{p l}(\mathrm{se} k=1$ ), ou a radiaçăo de fundo teria alcançado os $3 \mathrm{~K}$ em $10^{-11} \mathrm{seg}$ [14]. Também aqui nẫo existe uma explícação de porque as condiçāes iniciais biveram que ser tẫo restritivas [21].

De acordo com as teorias de grande unificaçă transiçós de fase ocorridas nos estágios iniciais de desenvolvimento do universo produziram diversos tipos de particulas sufiente. mente estáveis para contribuirem formidavelmente na densidade de energía presentemente observada. Tomemos, por exemplo, os monopolos magnéticos (com aproximadamente $10^{10}$ vezes a massa do próton). Sem algum mecanismo complementar ao modelo padrão que "dilua" a densidade de monopolos a longo da expansũo, teríaruos que $\rho_{0} \sim 10^{15} \rho_{\mathrm{c}}$. Com tal densidade, essível mostrar que o universo teria recolapsado em, no máximo, 30.000 anos depois do Big Bang $\lfloor 14\rfloor$.

Para explicar a formaç⿰彳 das extruturas que observamos hoje, galáxias, aglomerados etc.) é mecessánio que sejam dadas as pequenas flutuacoes primordiais $(\delta \rho / p)$ que as originaram. A amplitude dessas tutuacôes é fortemente limitada pelas medidas da anisotropia da radiação de fundo $\left(\delta \rho / \rho \lesssim 10^{-4}\right)$ na era da recombinação [14]. Existe uma gama de espectros de flutuaçoes, as sementes primordiais das perturbaçöes de densidade que sầ compatíveis com essas medidas e que resultam nas estruturas observadas, mas o modelo padrão não fornece um mecanismo que os justifique. Neste caso, todo o espectro de fiutuaçós teria que ser dado como condição ínicial.

Um último problema para o modelo padrāo é o problema da constante cosmológica. A 
cada transiçầo de fase que tenha supostamente ocorrido durante a evolução do universo està associada uma bem definida variaçâo da densidade de energia do vấcuo $\Delta \rho_{\text {vac }}$. A densidade de energia $\rho_{\text {vac }}$ é proporcional ao termo cosmológico $\Lambda$ [22],

$$
\rho_{\mathrm{vac}}=\frac{\Lambda}{8 \pi G^{2}}
$$

que pode ser incluído nas equaçōes de Einstein e o seu valor estimado a partir de observaçố astronômicas. O problema da constante cosmológica consiste na discrepância de pelo menos 40 ordens de magnitude entre os limites superiores obtidos observacionalmente para $\rho_{\text {vac }}(\sim$ $\left.10^{-47} \mathrm{GeV}^{4}\right)$ e as menores estimativas teóricas obtidas das teorias de campo $\left(\sim 10^{-4} \mathrm{GeV}^{4}\right.$ para a transição quark-hádron da cromodinâmica quântica). Esta diferença pode chegar a 120 ordens de grandeza, se a densidade de energia de Planck (um limite natural em gravitaçäo) for usada como valor para $p_{\text {vat }}$ [23].

Com exceçâo do problema da singularidade, todas as questöes levantadas aqui poderiam em princípio ser "resolvidas" por um conjunto adequado de condiçöes íniciais. Entretanto, esta solução pode ser considerada insatisfatória, pois espera-se que as leis físicas sejam capazes de explicar as características do mundo de um modo objetivo, e parece um tanto antropocêntrico supor que universo teve condições iniciais täo finamente ajustadas. Neste sentido, justifica-se uma busca por novas teorias que resolvam os problemas levantados. Em particular, alguns deles podem ser resolvidos se o universo primordial tiver passado por uma fase de expansão aproximadarnente exponencial, a chamada fase inflacionária, que será discutida no próximo capitulo. 


\section{Capítulo 2}

\section{Campos escalares e inflação}

\subsection{Introdução}

Desde o advento dos modelos inflacionários, campos escalares (aqui denotados genericamente pela letra grega $\phi$ ) vêm sendo sugeridos para assumir importantes papéis em diferentes períodos da história cósmica. Alguns exemplos conhecidos são: i) o inflaton, associado à inflação [21, 24]; ii) o áxion, um dos candidatos a matéria escura [14]; iii) o dilaton, que está presente na ação de baixas energias das teorias de cordas e pode ser usado para resolver os mesmos problemas da inflação, incluindo o da singularidade (ver Cap. 3 e Refs. [25]) e iv) como condensados de Bose-Einstein, com possíveis consequências cosmológicas no universo primitivo $[26,27]$. Mais recentemente, inspirados por dados observacionais e especulaçōes teóricas anteriores, alguns autores têm também sugerido campos escalares (também chamados de "quintessência") como sendo a tão buscada matéria escura não bariônica (ver Seção 1.4 e [28]). Esses campos podem ter consequências importantes para a formação de estruturas em larga escala, bem como ser responsáveis pela fase de expansão acelerada do universo [29], recentemente indicada pelas observações das curvas de luminosidade de supernovas do tipo Ia (ver Cap. 1 e [15]).

Neste capítulo serão apresentadas as equações de movimento do campo escalar em um espaço-tempo homogêneo e isotrópico e algumas das suas principais consequências serão 
estudadas. Apesar das várias possibilitades de aplicaçäo de eampos escalares em cosmologia, o foco das atençōes aqui sera dirigito tos modelos inflacionatrios e as suas soluçōes para os problemas clässicos do modelo padräo que foram apresentados no capítulo anterior e podem ser resolvidos neste contexto. Contudo, e importante ressaltar que tanto no caso da inflação como no da quintesşência (citada acima), näo hă justificativa fundamental para a existência do campo escalar que năo a de resolver os problemas para as quais eles sāo propostos. Além disso, apesar de haverem modelos mais elaborados, que consideram acoplamentos nâo mínimos entre $\phi$ e a curvatura, ou usam campos complexos, só sènăo considerados aqui os casos com acoplamento mínimo do campo escalar real. Neste caso, a densidade lagrangeana é

$$
c_{\phi}=\frac{1}{2} \partial^{H} \phi \partial_{\mu} \phi-V(\phi)
$$

com $V(\phi)$ sendo um potencial genérico. Do teorema de Noether, o tensor de energiamomento de $\phi$ é dado por

$$
T_{\phi}^{\mu \nu}=\partial^{\mu} \phi \partial^{\mu} \phi-g^{\mu \prime \prime} L_{\phi}
$$

do qual pode-se extrair a densidade de energia e pressão

$$
p_{\phi}=\frac{1}{2} \phi^{2}-V(\phi)-\frac{1}{6}(\nabla \phi)^{2}
$$

e

$$
\rho_{\phi}=\frac{1}{2} \phi^{2}+V(\phi)+\frac{1}{2}(\nabla \phi)^{2} .
$$

Dada a ação:

$$
S=-\frac{1}{16 \pi G} \int d x \sqrt{-g}\left\{R-\frac{1}{2}(\nabla \phi)^{2}+V(\phi)+\mathcal{L}_{m}\right\}
$$

onde $\mathcal{L}_{m}$ representa a lagrangeana dos outros campos, obtém-se a equação de movimento para o campo escalar, seja com a variaçăo de $S$ com relação a $\phi$, seja da conservação do tensor $\left.T_{\phi}^{4 t}\right)$

$$
\ddot{\phi}+3 H \dot{\phi}+\frac{d \psi}{d \phi}=0
$$


Da conservação da energia para os outros campos, aqui tratados cono um fuido perfeito com equação de estado do tipo $p=(\gamma-1) \rho$ obtém-se

$$
\dot{\rho}+3 \gamma H \rho=0,
$$

onde foi suposto que ofluido perfeito e o campo escalar têm leis de conservação de energia independentes, hipótese que será relaxada no Cap. 5. A equação de Friedmann para o sistema formado pelo campo escalar e o fluido perfeito é

$$
H^{2}=\frac{8 \pi G}{3}\left(\rho+\rho_{\phi}\right)+\frac{k}{a^{2}} .
$$

Note-se que mesmo dando um valor específico para $\gamma(4 / 3$ na era da radiaçăo e 1 na era da matéria) o sistema de equaçôes (2.6)-(2.8) näo pode ser resolvido sem alguma hipótese extra sobre o campo escalar. Isto ocorre porque os termos cinético e de potencial de $\phi$ säo em principio independentes, admitindo infinitas combinaçöes de valores. No âmbito dos cenários inflacionários, as hipóteses extras são as condiçöes de rolamento lento do campo, como será mostrado. Antes de tratar do cenário inflacionário, porém, é conveniente falar das motivaçōes que levaram a essas propostas. Para tanto é necessária uma breve exposição sobre transiç̃es de fase.

\subsection{Transições de fase}

Os mecanismos de quebra espontầnea de simetria que motivaram os primeiros cenários inflacionários podem ser ilustrados pelos exemplos que seguem (ver discussão sobre 0 assunto no Cap. 7 da Ref. [14]). Antes, porém, uma advertência. Os modelos apresentados nesta seçäo não são de modo algum realistas e cumprem apenas a função didática de expor os principais conceitos envolvidos nas transigões de fase cosmologicas. Modelos rigorosos, haseado na técnica do potencial efetivo para calcular correçốs têrmicas e quânticas poden ser encontrados, por exemplo, na Ref. [31]. Seja um potencial

$$
V(\phi)=-M^{2} \phi^{2}+\lambda \phi^{4} .
$$


Onde $M$ representa o termo de massa do campo e tem dimensões de energia e $\lambda$ é a constante de acoplamento que define a intensidade do termo de auto-interação do campo. Ao nivel de árvore (campo clássico a temperatura zero) o potencial acima é suficiente para determinar a dinâmica do campo escalar, dadas as condições iniciais. Suponha-se que $\phi$ esteja em equilíbrio térmico com outros campos, que no caso do universo primitivo seriam coletivamente representados por um gás ultra-relativístico a temperatura $T$ em equilíbrio térmico e químico. Neste caso, flutuaçōes térmicas têm que ser consideradas e este efeito pode ser levado em conta adicionando-se um termo de interaçāo $\mathcal{L}_{\text {int }}(\phi, \psi)$ à lagrangeana (2.1), onde $\psi$ corresponde a um banho térmico que induz correçōes do tipo

$$
\mathcal{L}_{\text {int }}=a T^{2} \phi^{2}
$$

com $a$ sendo uma constante da ordem da unidade que pode ser calculada em uma análise mais detalhada (ver a Ref. [31]) para incluir termos de ordern superior em loops. Este termo de interação entra na lagrangeana como uma correção ao termo de massa, o que permite definir uma massa efetiva $M_{\mathrm{ef}}^{2}=M^{2}-a T^{2}$ e uma temperatura crítica $T_{c}=M / \sqrt{a}$. O potencial efetivo que inclui este novo termo de massa representa a energia livre de Helmholtz, em analogia com os sistemas considerados na física da matéria consensada. A temperaturas mais altas do que $T_{c}$ o potencial assume uma forma parabólica e terá um mínimo em $\phi=0 .^{1}$ Abaixo da temperatura crítica o estado fundamental será localizado em $\phi= \pm M_{\mathrm{ef}} / \sqrt{2 \lambda}$. Neste caso, a simetria $\phi \rightarrow-\phi$ presente na lagrangeana năo é mais mantida no estado de vácuo e é dita espontaneamente quebrada (ou fica "escondida", como sugerido por Coleman). Além disso, o sistema só pode ocupar um dos estados de mínimo para o qual a passagem é contínua e a transição de fase ocorrida neste exemplo é o protótipo do que se chama de transiçāo de segunda ordem.

No que seria o protótipo de uma transição de fase de primeira ordem, considera-se o potencial

$$
V(\phi)=a T^{2} \phi^{2}-b \phi^{3}+\lambda \phi^{4}
$$

${ }^{1} \mathrm{O}$ sistema permanece no mínimo devido à interaçāo com o banho térmico. 
Este potencial exibe duas temperaturas criticas $T_{1}$ e $T_{2}$. Para temperaturas muito altas o termo em $\phi^{2}$ domina e o potencial tem um mínimo global em $\phi=0$. Para $T_{2}<T<T$ um ponto de minimo local se desenvolve para $\phi \neq 0$ (considerando apentas valores positivos de ๑). Quando $T=T_{2}$ há dois minimos degenerados separados por uma barreira de poteneial, um en $\phi=0$ e outro em $\phi \neq 0$. Para $T<T_{2}$ o mínimo em $\phi \neq 0$ passa a ser global lo "vacuo verdadeiro") e o ponto $\phi=0$ passa a ser um mínimo local (o "falso vácuo"), ainda com a barreira de potencial que o separa do minimo global. No caso clássico, o sistema fica preso no falso vácuo, mas se a barreira for suficientemente pequena, cnventualmente ocorre tunelamento e o sistema se estabiliza no vácuo verdadeiro. O nome da transição se justifica pela descontinuidade (devida ao tunelamento) da passagem do sistema de um vácuo para o outro. É claro, este näo é um modelo realista, pois a intenção aqui é meramente didática. Modelos que levam em conta correçöes quânticas e térmicas de modo autoconsistente săo discutidos em detalhes na Ref. [3I].

O que é mais importante para a cosmologia na discussão acima é que a diferença de energia entre os estados de vácuo pode ser calculada. Tipicamente, na transição de segunda ordem tem-se que:

$$
\Delta V=V_{s}-V_{f}=\frac{M^{4}}{2 \lambda}
$$

com $V_{s}$ sendo a densidade de energia do vácuo da fase simétrica e $V_{f}$ a densidade de energia final do vácuo. Supondo a transiçāo da teoria de grande unificaçăo, $M \sim 10^{15} \mathrm{GeV}[14]$. Neste caso, é razoável supor $V_{f}=0$, pois o valor da constante cosmológica efetiva medido hoje é dezenas de ordens de magnitude menor do que $V_{i}$. Como no equilíbrio o campo escalar permanece no estado de vácuo, na fase simétrica a equação de estado do campo

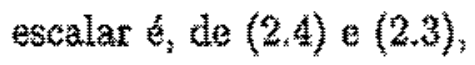

$$
p_{\phi}=-p_{\phi}
$$

e $V_{i}$ tem um valor constante. A radiaçầ, por sua vez, vem sendo diluida, devido à expansão. Se por qualquer razão a transiçãa nã̃o ocorrer imediatamente enquanto $\rho \sim V_{i}$, o vácuo passa a dominar a dinâmica, o universo entra em uma fase de Sitter e ocorre inflaçăo. 


\subsection{Inflação}

A solução da equação de movimento para $\phi$ proposta pela inflaçầ não poderia ser mais simples. É suposto que ocorreu uma fase com o domínio do termo de potencial nas equaçốt de movimento cosmológicas, de modo que a equação de Friedmann se reduz a

$$
3 H^{2} \simeq 8 \pi G V(\phi)
$$

A soluçăo da equação acima é um universo do tipo de Sitter, com $a(t) \propto \exp \sqrt{8 \pi G V(\phi) / 3}$. Mas só isso não é suficiente. É preciso assegurar que a dominaçăo do potencial seja duradoura. Para garantir que a inflaçăo persista pelo tempo $\Delta t_{t}$ suficiente para resolver os problemas do modelo padrāo, uma segunda condição é imposta, a de que o termo cinético de permaneça pequeno corn relação ao potencial ao lorgo deste intervalo. Esta segunda condiçä̉o é implementada supondo que o termo de derivada segunda de $\phi$ na equaçâa (2.5) desprezivel com relação aos demais. Neste caso,

$$
3 H \dot{\phi}+V^{\prime} \simeq 0
$$

Dividindo-se (2.15) por (2.14) e elevando o resultado ao quadrado encontra-se que

$$
\frac{1}{48 \pi G}\left(\frac{V^{t}}{V}\right)^{2} \simeq \frac{8 \pi G \dot{\phi}^{2} / 2}{3 H^{2}} \simeq \frac{\dot{\phi}^{2} / 2}{V(\phi)}<1
$$

de acordo com a Eq. (2.14). Além disso, diferenciando-se at Eq. (2.15), dividindo-se a equaçä̀ resultante por $9 H^{2}$, e notando que

$$
\hat{H}=-4 \pi G \dot{\phi}^{2}
$$

encontra-se que

$$
\frac{1}{24 \pi O} \frac{\left|V^{H}\right|}{V} \simeq \frac{\dot{H}}{3 H^{2}}+\frac{\ddot{\phi}}{3 H \phi} \ll 1
$$

onde as Eqs. (2.14) e $(2,15)$ foram usadas para que a desigualdade fosse encontrada. 0 significado geométrico das relaçöes $(2.16)$ e (2.18) é simples: para que haja inflação tanto a inclinaçâa quanto a curvatura do potencial têm que ser muito pequenas durante este 
periodo. Como a equaçäo de movimento do campo escalar é a mesma equação de uma partícula descendo uma ladeira com atrito (com coeficiente $3 H$ ), as condicotes acima foram chamadas de "condiçōes de rolamento lento." (ORL).

A duraçăo do periodo inflactonatio segue diretarnente das CLR. Sejam a a as valores do fator de escala no inicio e no finul da inflaça, respectivamente. A raza contre estes dois valores do fator de escala $a_{/} / a_{i}=\operatorname{axp} \Delta \mathbf{z}_{\mathbf{y}}$ fornece uma medida do número $N$ de potências do número e (ou e-folds) decorridas eutre $a_{i}$ e $a_{f}$ :

$$
N=\ln \frac{a_{f}}{a_{i}}=\int_{t_{i}}^{t_{f}} \not H d t \simeq-8 \pi G \int_{\phi_{i}}^{\phi_{f}} \frac{V}{V^{\prime}} d \phi
$$

onde foi usado que $d t=d \phi / \phi$ e sinal pressupöe que $\phi_{f}<\phi_{i}$. Notemse que, dado um potencial $V$ e as CRL, a quantidade de infląăo pode ser determinada sem haver a necessidade de se resolver as equaçôes de movimento. Para resolver o problema de horizonte a necessário

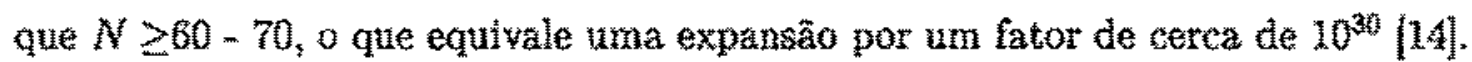

O final da inflação Como após a inflaçấo a densidade de energia da radiação é exponencialmente suprimida, é necessărio que algum processo reestabeleça o universo FRW atualmente observado. Qualquer versäo de inflaçäo tem que conter, portanto, esta fase de reaquecimento após a do rolamento lento. Os primeiros modelos de reaquecimento, assumem ane o inflaton oscila rapidamente (com relacäo a escala de tempo de Hubble $H^{-1}$ ) em torno do fundo do pogo potencial e purte da sua energia feconvertida em radiaçă, pois

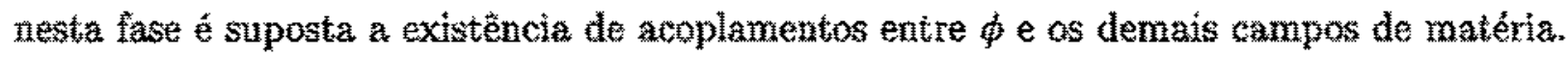
Os tratamentos tradicionats (como o exposto nas Ref. [14, 33], por extmplo) adicionavam à equaçăo de movimento de $\phi$ um termo fenomenológico de decaimento do campo ascalar do tipo $\Gamma \dot{\phi}$ para efetivar o reaquecimento. Este termo era justificado no contexto de teoria de perturbaçâo, mas mostrou-se ineficiente para prover uma temperatura suficientemente alta no final do processo de reaquecimento. Por vărios anos este ficou como um problema em aberto para cosmologia infacionaria.

Fata perspectiva desanimadora mudou apos a descoberta de que o processo de criação 
de partículas poderia se dar por amplificação paramétrica, com uma transferência muito mais eficiente de energia das oscilaçôes caerentes do campo escalar para os produtos do decaimento $[34,35]$. Neste caso, a análise tradicional pode ter importância nầ mais na fase de criação de matéria, atualmente chamada de pré-aquecimento (ou preheating), mas sim na fase de termalização dos produtos do decaimento do inflaton.

\subsection{Soluções para os problemas do modelo padrão}

A expansão do universo ao longo da fase de rolamento lento resolve vários dos problemas do modelo padrão listados no capítulo anterior. No caso do problema de horizonte, por exemplo, tem-se que a homogeneidade observada hoje seria apenas uma consequência da expansão adiabática de uma região primordialmente em equilíbrio térmico que abrangeria o horizonte na época do início da inflação, ampliada a ponto de englobar toda a distância de horizonte atualmente observada [14].

Pelo mesmo motivo, os "fósseis" indesejáveis, previstos pelas teorias de grande unificaçäo näo deveriam ser detectados hoje, pois teriam sido diluídos exponencialmente durante a fase de Sitter. Claro, é necessário supor que a temperatura de reaquecimento seja mais baixa do que a temperatura crítica da transição de fase, de outro modo o universo ingressaria novamente numa fase siméttrica e configurações estáveis do vácuo desta fase poderiam sobreviver após a nova transiçäo.

A expansâo exponencial também faz com que qualquer curvatura preexistente se torne desprezível ao final do processo inflacionário. Isso pode ser verificado através da Eq. (1.10), onde $H^{2}$ e $\hat{p}$ sầo constantes, enquanto o termo de curvatura decresce exponencialmente. Assim, um resultado quantitativo essencial da inflação é símplesmente que $\left|p-\rho_{c}\right| / \rho_{c} \sim 10^{-4}[14]$. De fato, o universo ser espacialmente plano pode ser considerada uma das principais consequêneias testáveis dos modelos inflacionắrios. Como foi visto no Cap. 1, os resultados observacionais favorecem um universo plano, corroborando táts modelos. 
Na inflacäo, flutuaçöes quânticas do campo escalar, naturalmente fornecidas durante a fase de rolamento lento sã̃o ampliadas, resultando en um espectro de perturbações de densidade. Tais perturbaç̧̋es seriam as sementes primordiais que posteriormente gerariam (por colapso gravitacional) as estruturas em larga escala observadas hoje. Além disso, o espectro (em número de onda) de Alutuaç̄es de densiddade provoca flutuações na radiação cósnica de fundo que puderan ser observadas. As análises dos dados colkidos pelo satélite COBE (Cosmic Background Explorer) [19] e de outros experimentos sugerem que as anisotropias observadas na radiação de fundo sāo compativeis com o espectro de flutuaçöes de densidade previsto pelos modelos infiacionários. Assim, a inflaçăo provế tanto um mecanismo causal para a formação de estruturas quanto um espectro mensurável de flutuaçōes de temperatura da radiação de fundo. Este é o resultado mais robusto da inflaçāo, mas ainda näo é definitivo. Novos satélites, com lançamentos programados para os próximos anos, deverão definir se a inflação persiste ou näo como paradigma na cosmologia.

\subsection{Alguns tipos de inflação}

Um roteiro típico de modelo inflacionêrio com transição de fase deve conter esta época na qual: a transição ainda näo se completou, $V_{i}$ donnina e a radiação é exponencialmente dilứca. No caso do modelo inflacionário oniginal, de Guth [21], $\phi$ está inicialmente preso em um estario metaestável na origem (falso vácuo) e sofre uma transição de fase de primeira ordem. Nas regiöes onde ocorre este tunelamento há nucleaçäo de bolhas de vácuo verdadeiro. Como nessas regiōes o potencial é (quase) nulo, a expansăo dessas bolhas não é exponencial, mas do tipo potência. Já à regiöes que não sofreram transiçäo ainda expandem inflacionariamente, de modo que as bolhas de vácuo verdadeiro näo percolam e a intlação não tem fim.

Este problema motivou a proposiçăg de variantes de inflaçào nas quais o potencial é mais plano na origem, a transigato e de segunda ordem e pode proceder suavemente as 
regiồes de vácuo verdadeiro são maiores comparadas com as bolhas da inflaçäo de Guth ${ }^{2}$ Esta versão foi chamada de nova inflação [24]. Entretanto, também a nova inflação tem problemas sérios. Um deles é que o potencial deve ser plano demais perto da origem para que possa haver inflação suficiente e para evitar flutuaçōes excessivas do campo quântico. Tais fiutuaçôes tem efeitos observacionais e foram severamente limitadas pelas observaçöes de flutuaçồes de temperatura da radiaçato cósmica de fundo. Estas duas caracteristicas săo proporcionais aos tarmos de acoplamento da lagrangeana, e conduzem a constantes de acoplamento que são tăo pequenas são consideradas pouco naturais no contexto de teoria de carnpos [31].

Um problema correlato da nova inflaçấo é que, para estar em equilíbrio termodinâmico com os demais campos no início da inflação, $\phi$ tem que ter um acoplamento forte com os mesmos. Isto ocorre porque para haver equilibrio, o tempo de colisão entre as partículas tem que ser menor do que o tempo de vida do universo $\left(t_{i} \sim H_{i}^{-1} \sim 10^{-3 y}\right.$ seg no inticio da inflação) e as seçôes choque das reaçōes entre os campos (funçôes das constantes de acoplamento) têm que ser altas. Exceto em casos muito particulares [31], tais acoplamentos violam as condiçöes impostas pelas CRL, pois a expansâo adiabática da radiaçäo supôe acoplamentos fracos. Isto é decepcionante, pois o cenário infacionário, concebido para resolver problemas de ajuste fino das condiçöes iniciais trouxe outras complicaçöes do mesmo tipo das que se propunha a resolver, pelo menos nas suas versöes mais bem fundamentadas em fisica de partículas.

Para os inflacionistas mais resolutos, entretanto, as soluçōes apontadas eram boas demais para a idéia ser abandonada: a inflaçăo tornou-se então um "paradigma em busca de um modelo" [14]. Como o mecanismo é dinamicamente consistente com a dominação do termo de potencial de qualquer campo escalar, buscaram-se modelos que apenas assumem a existência de um campo, o inflaton, que apresenta a dinânica desejada, independentemente de motivaçăa fundamental.

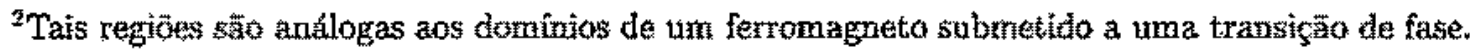


Um exemplo deste tipo é a inflaçâo caótica [30]. Neste modelo não há sequer transição de fase. O universo já parte de um estado dominado pela energia do vácuo com $\phi$ deslocado do mínimo do potencial, mas "descendo a ladeira" lentamente ebedecendo as CRL. Por ser tâo simples, este é o cenário com menos restrições fenomenolögicas dentre as variantes inflacionárias e é o que tem a simpatia de boa parte dos que trabalham atualmente com este assunto. Mas a sua grande vantagem tern também o grande inconveniente de nāo haver justificativa fundamental para que se considere um universo dominado por um inflaton como condição inicial.

Há muitos mais modelos inflacionáríos do que os citados aqui, com potenciais polinomiais, exponenciais, com mais de um campo escalar etc. Há também casos de modelos baseados em modificaçôes na relatividade geral, tais como teorias escalares-tensoriais (principalmente a de Brans-Dicke), ou teorias com termos de ordem superior nas derivadas do tensor métrico (um de tais casos será discutido no Cap. 3). Entretanto, năo é propósito desta tese exaurir a discussão sobre as variantes inflacionárias. Uma lista recente de modelos pode ser encontrada na Ref. [32].

\subsection{Problemas da inflação}

Dos problemas listados no Capítulo 1, a inflação não tem nada a dizer sobre o problema da singularidade nem sobre o problema da constante cosmológica, más talvez o maior problema da inflaçăo seja o de justificar a existẹncia do inflaton. Inicialmente este campo era bem motivado por ser associado a quebras espontåneas de simetria no contexto da velha e nova inflaçôes, algo mais ou menos de acordo com as crenças atuais no modelo padrăo da física de partículas, Com o descarte desses tnodelos por causa dos seus problemas com a fenomenologia das suas consequências cosmológicas $[14,31]$ esta motivaçăo de "primeiros principios" fol um tanto perdida. Mesmo o cenário mais livre de problemas, a inflaçäo cática, baseada em um campo escalar randomicamente distribuido no volume do universo, mas que não é parte de qualquer teoria unificada, parece ser mais uma construçăo fenomenológica com 
o propósito único de implementar uma dinâmica para o universo do que um modelo bem motivado por alguma teoria fundamental.

Um cámpo escalar que preenche este requisito é o dilaton. Este campo surge inevitavelmente na ação de baixas energias da teoria de supercordas, talvez a mais promissora candidata a teoria consistente de gravitaçăo quântica [40]. Uma cosmologia motivada pelo dilaton mais especificamente voltada para o problema da singularidade sera discutida no próximo capítulo. 


\section{Capítulo 3}

\section{Cosmologia dilatônica não-singular}

\subsection{Introdução}

A singularidade inicial é um dos maiores problemas dos modelos cosmológicos propostos atualmente. No modelo padräo, a existência da singularidade inicial é consequência inevităvel dos teoremas de Penrose-Hawking [36, 37]. Apesar de modelos inflacionários dirigidos por campos escalares tais como a inflação caótica [30] resolverem muitos dos problemas da cosmologia convencional, as singularidades iniciuts ainda säo genéricas no contexto inflacionấrio. Geralmente espera-se que alguma teoria mais fumdamental, válida para a escala de energia de Planck, como a teoria de cordas, possa sugerir alguma resolução para este problema. $^{1}$

Numa tentativa de abordar o potencial da teoria de cordas para resolver o problema da singularidade cosmológica, Gasperini e Veneziano iniciaram um programa de pesquisa conhecido como cosmologia do pré big bang [25], baseada na açäo efetiva resultante da teoria de cordas. Em ordem maís baixa, esta é a açầ da gravitação com $Q$ dilaton, o campo escalar

\footnotetext{
1 Formalmente, existe maik de una teoria de cordas (cinco, na verdade), mas os ultimos desenvolvimentos na área sugeren que todas as teorias de cordas são diferentes aspectos de uma mesma teoria (ver, por

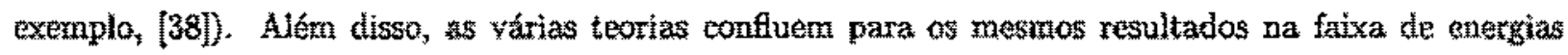
considerada aqui [38], o que explica o uso do singular.
} 
que surge inevilavelmente nas faixas de "baixas" energlas da teoria de cordas

$$
S=-\frac{1}{16 \pi G} \int d^{4}+\sqrt{-g}\left\{R-\frac{1}{2} \partial^{\mu} \omega \partial_{\mu} t+\cdots\right\}
$$

com $\phi$ sendo o dilaton, campo que é associado aos acoplamentos gravitacionais, como na teoria de Brans-Dicke. Ao nivel de árvore, ou seja, em mais baixa ordem na constante de acoplamento das cordas fundamentais e nas derivadas do tensor métrico, esta ação é conformalmente invariante para os movimentos das cordas em espaços curvos. Note que ao impor víneulos sobre pröprio espaç-tempo esta simetria conforme cstabelece uma das grandes diferenças tentre as cordas fundamentais e as particulas pontutuis, que näo impōem vínculos sobre o espaço onde se movem. Alêm disso, note-se que a açüo acima esta escrita no referencial de Einstein ${ }^{2}$ (mais natural para discutir soluçōes do tipo FRW) e foi assumida a compactificação de todas as demais 1 - 3 dimensões espaciais normalmente presentes na ação efetiva de batxa energia da teoria de cordas. Uma discussa com uma dedução mais detalhada da Eq. (3.1) está fora dos propósitos desta tese, que estuda apenas as consequências dinâmicas dos campos escalares, mas pode ser encontrada nas Refs. [40, 41]. Neste capítulo, baseado na Ref. [42], será feita uma exposição basseada apenas nesta açäo de mais baixa ordem, que é a que tem maior interesse cosmológico atualmente, em particular por causa do pré big bang (PBB).

As equaçoes de campo do PBB exibem uma nova simetria dual para o fator de escala a(t). No referencial de Einstein, esta simetria mapeia uma cosmologia FWW arn expansäo em um universo em contrata com a dinamica dominada pelo dilaton. Isto sugere que é possivel encontrur uma cosmologia nâomsingular na qual o universo vem dessa fase em contração, passa por um mínimo no fator de escala e entäo emerge em um universo tipo FRW expansionista ${ }^{3}$ A esperança deste programa (o PBB ainda não chega a ser um modelo

\footnotetext{
${ }^{2} \mathrm{Em}$ comparaçäo ao referencial das cordas, ou de Brans-Dicke, qute e o referencial mais fundamental para a teoria de cordas. A passagem do referencial de Einstein, com métrica gat para o das cordas, com métrica $\ddot{g}_{p v}$ se dá pela transformaçâo conforme $g_{j z}=e^{\dot{\phi}} \tilde{g}_{j s y}$.

3 Un bom artigo de revisäo sobre o $\mathrm{B}$ BB é a Ref. [41], e uma lista exaustiva atualizada de réererências sobre o assunto pode sar encontrada ro enderecco http:/ wrww, to.infn.it/ gasperin/.
} 


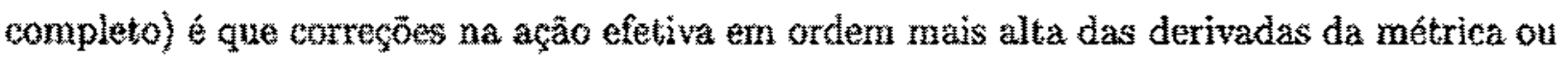
em loops da constante de acoplamento das cordas (relacionada à constante gravitacional $Q_{,}$no caso de trêts dimensöes espaciats) garantam uma passagem contínua entre o ramo em contraçă o ramo ERW. A motivaçäo para esta esperança reside na simetria dual do fator de escala e no fato que a teoria de cordas tem um comprimento minimo fundamental a extensão da própria corda que serve de limite inferior para todas as escalas de comprimento da fisica $[45]$.

Infelizmente, foi mostrado que esses dois ramos da cosmologia do PBB näo podem ser conectados suavemente usando-se apenas equaçōes obtidas da ação ao nível de árvore $[46,47,48]$. A fase em contração dominada pelo dilaton apresenta uma singularidade futura e a fase em expansäo tem uma singularidade passada. Efeitos de um loop em cosmologia de cordas podem, am princtpio, regular a singularidade [49] e fazer uma conexão suave entre os dois ramos, pelo menos na presenga de curyatura espacial $(k=1)$. Outras propostas para regular as singularidades do PBB podem sem encontradas na lista de referências de [42], mas convếm notar que maioria dessas abordugens são perturbativas, e as suas consequênelas só sảo relevantes em regimes para os quals o tratamento auto-consistente da teoria deveria usar métodos não perturbativos $[43,44]$.

\subsection{Modelos não-singulares}

Uma forma natural para resolvar o problema da singularidade da TRG é considerar uma teoria efetiva que contenha termos em derivadas superiores do tensor metrico adicionados ao escalar de Ricci $R$ na açäo de Einstein.Hilbert. Esta abordagem é bem motivada, pois espera-se que qualquer açẩo efetiva para a gravitação clássica assim obtida, seja da teoria de cordas ou da gravitaçäo quântica, conterá esses termos em derivadas mais altas. No caso da teoria de cordas, como já foi dito, as simetrias duais sugerem que as quantidades físicas permaneçam finitas ao longo de toda a história do universo [45]. Assim, é razoável considerar teorias gravitacionais baseadas em açōes com termos de derivadas mais altas 
quando se investiga as propriedades do espaço-tempo a grandes curvaturas. Um exemplo desta linha de pesquisa é o modelo não-singular de Starobinski [50] que foi precursor dos modelos inflacionários.

As várias extensỗes possiveis da relatividade geral clássica têm a intençấo de ser uma teoria de gravitaçâo totalmente năo-singular e conseqüentemente fornecer uma cosmologia livre de grandezas divergentes. Entretanto, esta promessa ainda está para ser cumprida em uma teoria efetiva de gravitaçäo que seja rigorosamente derivada de um modelo fisicamente bem motivado para a escala de Planck. Aqui será tentada uma abordagem diferente da usual. O que se quer é derivar uma gravitação de ordem mais alta que possa produzir uma cosmologia que retenha as caracteristicas qualitativas de uma evoluçăo näo-singular, como a pretendida pelo cenário do PBB.

Uma forma de construir explicitameste uma ação gravitacional efetiva que garanta que os invariantes físicos serão sempre finitos é dada nas Reffs. $[43,44]$. A açäo resultante inclui uma combinação particular de invariantes quadráticos do tensor de Riemann, além da ação usual de Einstein-Hilbert. Esse termo é tal que, em grandes curvaturas, força todas as soluções das equaçốes de movimento a tenderem ao espaço-tempo de de Sitter, tornando-as assim năo-singulares. O modelo obtido desta forma é portanto uma teoria de gravitação particular baseada em termos com derivadas de ordem superior, como pretendido.

Como jả foi mencionado, uma dificuldade adicional da abordagem perturbativa para o problema da singularidade cosmológica é que espera-se que a expansäo perturbativa deixe de ser válida em escalas de energia menores do que as necessárias para "suavizar" a singularidade. As Refs. $[43,44]$ tambérn tratam este problema, garantindo que haja um valor máximo de curvatura permitido em um modelo cosmológíco dado usando uma téenica similar a aplicada para eliminar as singularidades. Com isto, foi possível evitar a inclusão de correçôes qquânticas e a teoria clássica de ordem superior obtída é auto-consistente. Neste capítulo, contudo, a atenção será voltada apenas para o problema da singularidade. Não foi imposto qualquer limite sobre a curvatura além daquele associado à remoçăo da sin- 
gularidade e que garante que, para qualquer soluçāo obtida, a curvatura terá um limite superior.

A abordagem mais simples para achar uma cosmologia não-singular é adicionar um invariante $I_{2}$ à ação com a propriedade de que $I_{2}=0$ é verdade se e somente se o espaçotempo é de Sitter. Inserindo-se $I_{2}$ na ação gravitacional via um multiplicador de Lagrange $\psi$ com um potencial escolhido para assegurar que este invariante se anule a grandes curvaturas, permite-se impor que todas as soluçōes tendam à de de Sitter nestes regimes de curvatura. Para espaços-tempos homogêneos e isotrópicos, uma escolha de $I_{2}$ que satisfaz esta condição é (ver também o Apêndice A)

$$
I_{2}=\sqrt{4 R_{\mu \nu} R^{\mu \nu}-R^{2}}
$$

Na sua forma mais simples, a ação resultante é

$$
S\left(g_{\mu \nu}, \psi\right)=\int d^{4} x \sqrt{-g}\left(R+\psi I_{2}+V(\psi)\right)
$$

onde $V(\psi)$ é uma função a ser escolhida de modo à ação ter a TRG como o limite para pequenas curvaturas (quando $\psi \rightarrow 0$ ). Note-se que o campo multiplicador de Lagrange nảo tem significado físico independente. Em si mesmo, ele não representa nem uma simetria particular, nem algum campo de matéria. O seu papel na ação é representar o vínculo físico (neste caso o limite superior sobre o invariante $I_{2}$ ) que está sendo imposto sobre o sistema. Para $|\psi| \rightarrow \infty$ a equação de vínculo força $I_{2} \rightarrow 0 .{ }^{4}$

No caso tratado aqui, com resultados da Ref. [42], sāo investigadas as consequências da adição dos mesmos termos de ordem superior das derivadas à açāo da cosmologia do PBB. É examinado se tais termos podem eliminar as singularidades e produzir uma passagem suave entre as fases de contração e expansão do universo do PBB. O principal resultado obtido é que é possível achar um potencial $V(\psi)$ para os multiplicadores de Lagrange que assegura que todas as soluçōes cosmológicas desta ação extendida para a gravitação dilatônica sāo não-singulares. É também mostrado que existe uma classe de soluções corrspondentes a

\footnotetext{
${ }^{4}$ Uma descriçāo talvez mais didática deste método pode ser encontrada no Apêndice B
} 
um universo em contração que são suavemente conectadas a uma fase ERW expansionista. Majs ainda, isto ocorre mesmo oom a ausência de curvatura espacial. Este modelo, portanto, constitui uma implementaça bem sucedida do programa do PBB.

\subsection{Ação e equações de movimento}

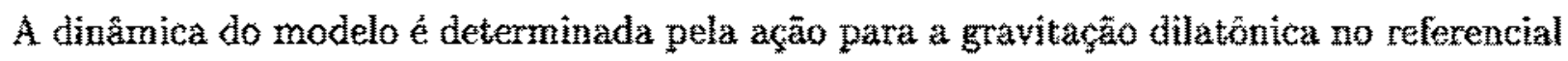
de Einstein, Eq. (3.1), à qual é somado um termo de derivadas de ordem superior dado por $I_{2}$ analogamente ao que fo feito sem o dilaton nas Refs. $[43,44]$

$$
S=-\frac{1}{16 \pi G} \int d^{4} x \sqrt{-g}\left\{R-\frac{1}{2} \partial^{4} \partial_{\mu} \phi+c \psi e^{2 t} L_{2}+V(\psi)\right\}
$$

Por completeza, um acoplamento geral entre o invariante $T_{2}$ e dilatori será considerado. 0 acoplamento minimo corresponde a fazer a constante $\gamma$ igual a zero. A constante $c$ serve para redimensionar o campo multiplicador de Lagrange $\psi$ e será escolhida de modo a simplificar as equaçōes de movimento.

Restringindo o modelo a mẹtricas homogêneas e isotrópicas (1.1) as equaçöes de movimento de (3.4) serão

$$
\begin{aligned}
& \ddot{\phi}+3 H \dot{\phi}+\gamma c \psi \dot{e} \gamma \dot{1} \sqrt{12}\left(\frac{k}{a^{2}}-\dot{H}\right)=0, \\
& \dot{H}=\frac{k}{a^{2}}-\frac{z^{-7 \phi}}{d x} \frac{\partial V}{\partial \psi} \\
& 6 \frac{k}{a^{2}}+6 H^{2}-\frac{d^{2}}{2}-V(w)=
\end{aligned}
$$

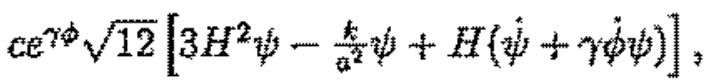

com os pontos denotando derivadas com respeito ao tempo $t$, como usual.

Busca-se aqui näo necessariamente um modelo final (algo que tote certamente näo e). mas sim verificar a passibilidade de realizaga de uma cosmologia inspirada pelo dilaton com as caracteristicas desejaveis no ambito do PBB fum universo que "quica em torno de um minimo do fator de escalal. Assim, como passo inicial sutu mats conveniente tratar de universos espacialmente planos, e serấ considerado que o parànetro de curvatura é nulo 
$(k=0)$. Tambẻm com o propósito de simplificar as equą̧öes será considerado o acoplamento mínimo entre $\phi$ e $I_{2}$, o que fixa $\gamma=0$. E para simplificar a notaçäo escolhe-se $c \sqrt{12}=1$. As equações de movimento resultantes serão

$$
\begin{aligned}
& \dot{\psi}=-3 H \psi+6 H-\frac{1}{H}\left[\frac{1}{2} \chi^{2}+V(\psi)\right] \\
& \dot{H}=-V^{z}(\omega) \\
& \dot{\chi}=-3 H \chi
\end{aligned}
$$

$\operatorname{com} \chi=\dot{\phi}$ e a linha (i) significando derivadas com respeito a $\psi$.

Agora é necessário estabelecer as vínculos físicos que devera ser impostos sobre o potencial $V(\psi)$ para que as condiçoes desejadas sejam satisieitas. Para pequenas curvaturas, os termos na ação (3.4) que dependen de $\psi$ têm que ser despreziveis quando comparados ans termos usuais da gravitaçẫo dilatônica. Isto é assegurado se

$$
V(\psi) \sim \psi^{2} \quad|\psi| \rightarrow 0
$$

pois a região de pequenos valores de $|\psi|$ corresponderi ao domínio de baixas curvaturas [44]. Para implementar a hipótese limitadora de curvatura, o invariante $I_{2}$ deve tender a zero de modo à métrica $g_{k \nu}$ tender à de de Sitter no limite de grandes curvaturas. A variaçăo da ação com respeito a $\psi$ fornece a equação de vínculo (segunda equação de (3.6)). É desta equação que o limite sobre grandes curvaturas deve ser imposto. No espaço-tempo de de Sitter, $\dot{H}=0$, de modo que a equação de vinculo impöe que

$$
V(\phi) \rightarrow \text { const }|\psi| \rightarrow \infty
$$

As condiçôes (3.7) e (3.8) são as mesmas empregadas nas Refs. $[43,44]$, mas não são suficientes para limitar o potencial como pretendido aqui. Para obter uma soluçã̃o que rexpanda após uma contraçăo (com um valor mínimo para o fator de escala $\left.a(t)=a_{b}\right)$ é necessário impor um terceiro critério: as equaçōes devem permitir uma configuraçäo com $H\left(a_{b}\right)=0$ e $\psi \neq 0$. Da equação de movimento para $\psi$ en $(3.6)$ segue que $V(\phi)$ tern que se tornar negativo para grandes curvaturas (e valores suficientemente altos de $|\psi|$, supondo 
que ele seja positivo para $|\hat{\psi}|$ pequeno. De outro modo, a primeira equação de (3.6) poderia exibir uma divergência em torno de $a_{b}$. Seja $\psi_{b}$ o zero não trivial de $V(\psi)$ :

$$
V\left(\psi_{k}\right)=0 .
$$

Na ausencia do dilaton, $\psi_{b}$ corresponderá ao valor de $\psi$ no mínimo de $a(t)$ (quando o universo ixticia a expansão). Irucluindo o campo $\phi$ na ação, o valor de $|\psi|$ neste mínimo dependerá de $\chi$ e será maior do que $\left|\psi_{b}\right|$.

Um potencial simples que satisfaz a condiçöes $(3.7),(3.8)$ e (3.9) \&

$$
V(\psi)=\frac{\psi^{2}-a \psi^{4}}{1+b \psi^{4}}
$$

onde os coeficientes $a$ e $b$ são números positivos, em princípio arbitrários, que serão definidos aqui como sendo

$$
a=\frac{1}{16} \text { e } b=\frac{1}{32}
$$

apenas para tornar a discussẫo abaixo mais clara. Note que o potencial usado nas Refs. $[43,44]$, um pouco mais simples, nẩo satisfaz a condição (3.9).

\subsection{Diagramas de fase das soluções sem o dilaton}

As condiços (3.7) - (3.9) sobre o potencial $V(\varphi)$ da seçăo anterior săo necessárias, mas não suficientes para obter uma cosmologia näo-singular. Tais condiçoses garantem que todas as

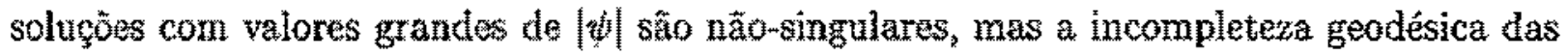
soluçôes que se mantenham sempre dentro de uma faixa de valores baixos de $|\vec{\psi}|$ ainda é possivel e tem que ser estudada. Nesta seçäo será determinado o espaço de fase, o plano $(\psi, H)$ do modelo sem o dilaton. Serâa usados métodos analíticos e numéricos para estudar as trajetórias das soluções de (3.6) no plano de fase e entāo seră mostrado explicitamente a ausência de singularidades. Isto significa que a açấo (3.4) representa mais um exemplo de gravitação de ordem superior completarnentente não-singular. Além disso, diferentemente 
do modelo das Refs. $[43,44]$, pode-se mostrar que este caso, mesmo sem dilaton, admite soluçôs que passam suavemente de uma fase em contraçäo para uma fase em expansâo.

Há vários pontos especiais e curvas no plano de fase $(\psi, H)$. Primeiro, o ponto $(\omega, H)=$ $(0,0)$ corresponde ao espago-tempo de Minkowsk: O potencial $V($ w) se anula neste ponto, mas tamberm se arula nos pontos

$$
w_{b}= \pm 4
$$

Como discutido anteriormente, os pontos $\left(\psi_{0}, 0\right)$ correspondem aos pontos de retorno das trajetorias cosmológicas.

A derivada de $V(p)$, e portanto $\dot{H}$, anula-se para os valores

$$
\psi_{d}= \pm 2
$$

As linhas do plano de fase $\left(\psi_{d,} H\right)$ são portanto linhas ao longo das quais $H=0$.

Para mostrar que o ponto $(\psi, H)=(4,0)$ é mesmo um pouto de retorno, pode-se expandir a equação de movimento de $\psi$ em torno de $H=0$, o que implica (ver (3.0))

$$
H \dot{\psi}=-\dot{V}
$$

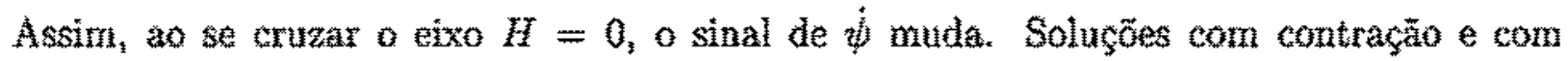

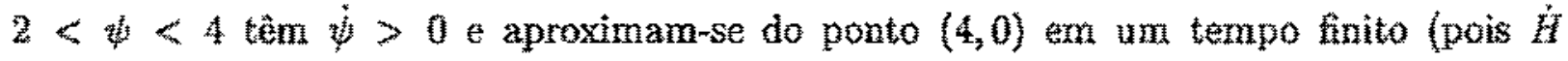
e positivo nāo tande a zero) e emergem com $H>0$ como trajatonias expunsionistas enquanto a curvatura diminuí (pois $\dot{\psi}<<0$ ). As trajetónias no plano de fase sấc simétricas em tormo do eixo $H=0$

Agora, expandindo as equações em torno da origem do plano de fase, obtểm-se que

$$
\frac{d \psi}{d H} \simeq \frac{1}{2 H}\left(\psi-\frac{6 H^{2}}{\psi}\right)
$$

da qual pode-se ver que existem linhas críticas localizadas em

$$
\psi_{c}(H)= \pm \sqrt{6} H
$$

Tornando-se appenas as soluçöes em contraçăo, a equaçäo de movimento para

$$
\dot{H} \simeq-2 \text { w. }
$$




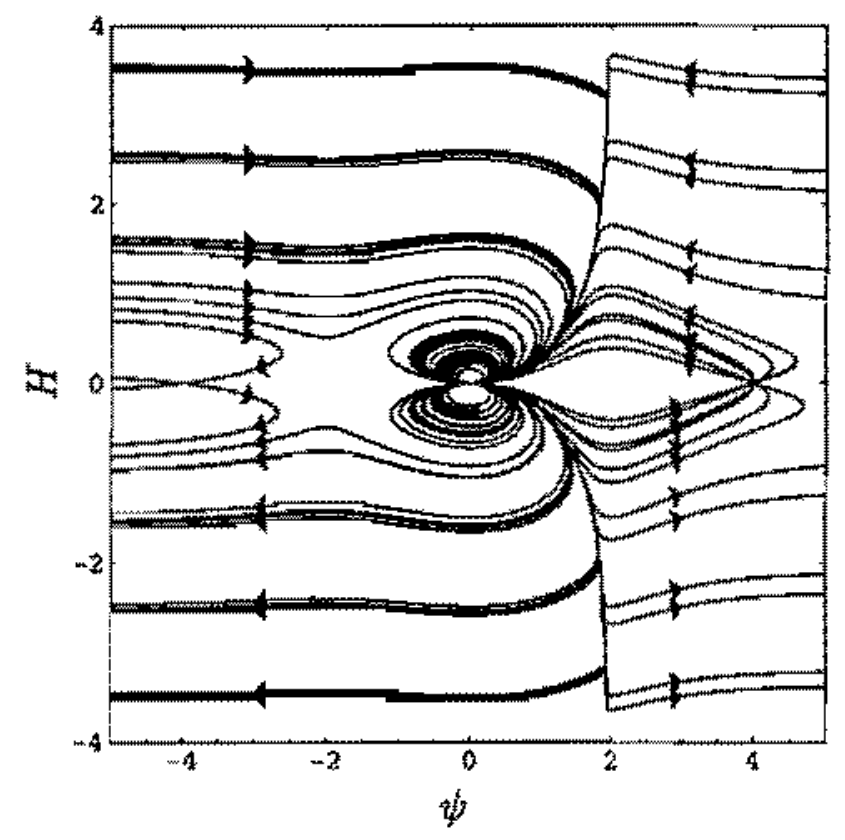

Figura 3.1: Diagrama de fase para as soluçōes das equaçöes de movimento, com a energía cinético do dilaton $(\chi)$ nula. O parâmetro de Hubble $H$ é representado no eixo vertical, enquanto $\psi$ corresponde ao eixo horizontal.

Consequentemente, trajetórias que se localizam acina da linha crítica têm $\dot{H}<0$ e (da Eq. (3.14)) $\dot{\psi}>0$. Estas trajetórias então apontam na direção da linha $\psi=2$ na qual $\not{H}$ inverte o sinal. Desde que aão cruzem a linha crítica, as soluçóes que se iniciam nesta região do plano de fase sầ portanto candidatas a universos espacialmente planos com a característica pretendida, com contração e expansäo sucessivas (normalmente modelos com este comportamento têm $k=1$ nas equações de movimento).

Soluçỏes abaixo da linha crítica têm $\dot{\psi}<0$, portanto não exibirão o retorno à expansão. Note-se que a linha crítica em si não é uma trajetória da dinâmica do modelo. De fato, sobre a linha critica, as trajetớria apontam na direção vertical, pois $d \psi / d H=0$. Há uma linha separatriz entre as trajetórias do plano de fase que se inicia próximo à origem tende a $\psi=2$ (e são portanto candidatas a universos com retorno) e aquelas trajetórias que cruzam a linha crítica $\psi_{c}(H)$ se encurvam, ou seja, tornam-se soluçöes corn $\dot{\psi}<0$. Para deterninar a localização da linha separatriz, é suficiente resolver as equaçöes (3.6) em torno da origem 
do plano de fase parà $|H| \ll \psi$, que é o caso no qual a equação variational com respeito a $\psi$ em (3.6) torna-se

$$
H \dot{\psi} \simeq-\dot{\psi}^{2},
$$

e que deve ser resolvida juntamente com (3.16). Após a diferenciação de (3.16) com respeito ao tempo e substituindo (3.17) para eliminar

$$
H \ddot{H}-\frac{1}{2} \dot{H}^{2}=0,
$$

a qual tem soluçă

$$
H(t)=-m t^{3},
$$

sendo $m$ uma constante que rotula as diferentes trajetơitas. A segunda soluçäo de $(3.18)$ t $H(t)=$ const e é, portanto, sem interesse. Da Eq. (3.16) segue que para a soluçắo acima.

$$
\psi(t)=m t
$$

As equaçöes (3.19) e (3.20) fornecern as soluções para as equaçöes dinêmicas em torno da origem do espaço de fase, desde que $|H| \ll \psi$. Para se ter uma idéia de onde se localiza a linha separatriz, pode-se impor que a trajetória fique acima da linha crítica em $\psi=2$. Esta condiçäo implica que

$$
|H|=\frac{1}{m} \psi^{2}, .
$$

com $m \geq 4 \sqrt{2}$. Fazendo-se $m=4 \sqrt{2}$ em (3.21) pode-se obter uma primeira estimativa de localização da linha separatriz. Uma vez que o conjunto de trajetórias próximas à origen é rotulado pelo parâmetro $m$, segue de (3.21) que o conjunto de universos com contraçẵo precendendo expansäo e partindo das proximidades do espaç̧o-tempo de Minkowski têm medida finita. Quando $\psi= \pm 2, \dot{H}$ inverte o sinal. Soluçōes em contração que começan de pontos próximos à origen no plano de fase chegam ao valor mäximo de $|h|$ em $\psi=2.0$ que acontece posteriormente com tais trajetórias depende do valor de $|H|$ para $\psi=2$. Se

$$
|H(\psi=2)| \ll 1,
$$


então (3.13) fornece uma boa aproximação para a dinâmica na região $2<\psi<4$, e conluise então que as trajetórias "quicam". Usando $|H|=\psi^{2} / m$ (ver (3.21)), a condição (3.22) torna-se

$$
m \gg 4
$$

a qual é consistente com a condiçāo anterior (3.21) para as trajetória com contração seguida de expansão.

Trajetórias com $|H(\psi=2)| \gg 1$ também atingem o seu valor mảximo de $|H|$ ern $\psi=2$, mas elas não "quicam" porque a equaçăo de movimento para $\psi$ pode agora ser aproximada por

$$
\dot{\psi} \simeq-3 H
$$

o que implica que $\psi$ mantém-se crescendo indefinidamente. Em combinação com a equação para $H$ en (3.6), a qual resulta em

$$
\dot{H} \simeq 0
$$

para $|\psi| \gg 4$, vê-se que as soluçōes tendem a ser do tipo de Sitter em contração. Soluções abaixo da linha crítica têrn $\dot{\psi}<0$ e não exibem a mudança de sinal em $H$. Para valores de $\psi$ que tendam $a \psi=2$, as duas linhas críticas divergem para $|H| \rightarrow \infty$. Isto pode ser visto a partir da tquaçäo para $\psi$ em (3.6). Para valores grandes de $|H|$, o lado direito desta equação é dominado pelos primeiros dois termos. Na ausência do terceiro termo, a soluçăo de $\dot{\psi}=0$ que determina a linha crítica seria $\psi=2.0$ terceiro termo, entretanto, provoca uma correçäo pequena, mas de sinal positivo, para o primeiro termo (no quadrante inferior direito do plano de fase) desviando assim a linha crítica ligeiramente para a esquerda de $\psi=2$, satisfazendo

$$
-3 H \psi+6 H-\frac{1}{H} V=0 .
$$

Para provar que todas as soluções das equações (3.6) são não-singulares, é necessário mostrar que as soluçöes tendem assintoticamente ou para a origem (espaço-ternpo de Minkowki), ou para o espaço-tempo de de Sitter (as regiōes com $|\psi| \rightarrow \infty$ ). Soluções 
para as quais $|H| \rightarrow \infty$ para $|\psi|$ finito têm que ser excluídas. As regiöes a to longo das linhas criticas săo as únicas que podem corresponder a trajetớrias singulares. Contudo, dif́eren-

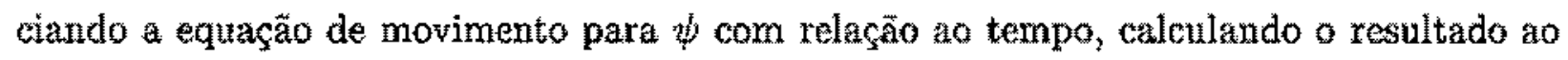
longo da linha crítica e fazendo uso de (3.26), encontra-se

$$
\ddot{\psi}=-V^{2} \frac{2 V}{H^{2}}<0
$$

Portanto, a linha crítica nào é um atrator, mas ao contrảo, as trajetơtias tendem a divergir da linha väo assintóticamente para regiâo de Sitter.

As equaços de movimento $(3,6)$ tambem foram resolvidas numericamente. $O$ diagrama de fase resultante é mostrado na Figura 3.1. A ausência de solucốes singulares ç manifesta. Nas regioes assintóticas $|\psi| \psi \mid \gg$, todas as soluçoses tendem ao espaco de de Sitter. As línhas críticas são vistas como soluçōes em contraçäo sendo repelidas na direçắo das regiồes de Sitter assintóticas. A classe mais interessante de soluçoes e a que exibe o retorno do universo à expansão. Como foi dito, este tipo de soluçóes forma um conjunto de medida fuita que partem das proximidades da origem do plano de fase. Háa também soluçōes que "oscilam" em torno do espaço-ternpo de Minkowski. Essas soluçôes serăo melhor discutidas na próxima seção, uma vez que se espera que elas sajam fortemente perturbadas pela presença de matéria, em particular o dilaton.

\subsection{Efeitos do dilaton}

Na presenga do dilaton, o espaço de fase torna-se tridimensional $(\psi(t), H(t), \chi(t))$, e portanto mais dificimente discubido com argumentos analiticos, Para comeģar, convém notar que no referencial de Einstein o dilaton corresponde a um campo escalar sem massa com equaŗão de estado

$$
p_{1}=\rho_{0}
$$

onde $p_{\text {p }}$ e denotam pressäo e densidade de energta respectivamente. Isto significa que

$$
\rho_{\phi}(t) \propto a(t)^{-m}
$$



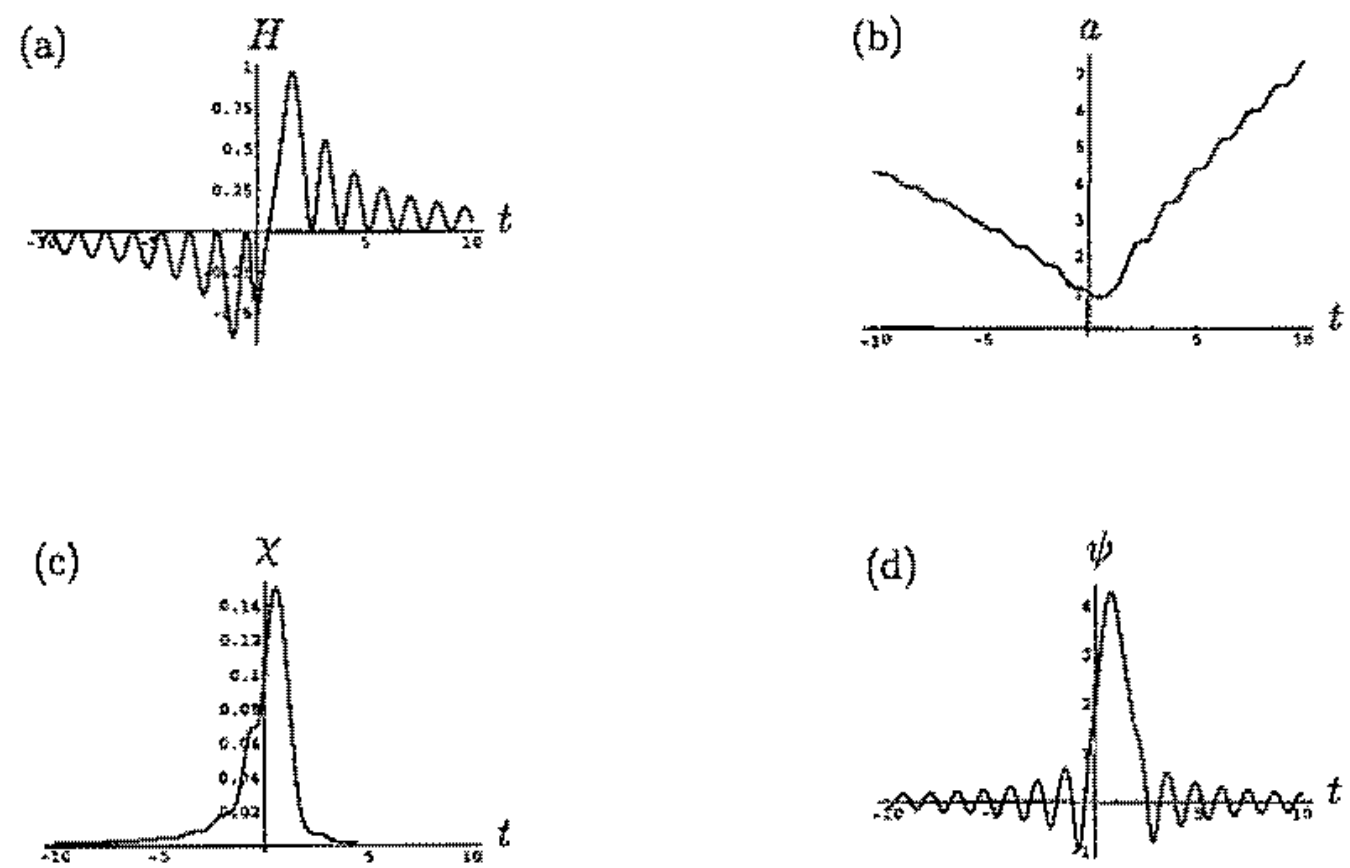

Figura 3.2: Uma solução expecifica com contração seguida de expansẫo com uma contributçăo näo trivial do dilaton é representada graficamente. a) mostra a evolução de $\not H$ como função do tempo, b) indica a de $a(t)$, c) a de $\chi(t)$ e d) a de $\psi(t)$. 
Assim, como no caso estudado em [44], o dilaton não introduzirá singularidades no sigtema. De fato, da equação de movimento para $H$ (ver (3.6)) segue que, na região com grandes valores de $|H|$, a presença de $\chi$ não mudará as trajetórias do plano de fase projetado no plano $(\psi, H)$ (uma propriedade chamada de "liberdade assintótica" em [44]). Porém, a presença de $\chi$ acelerará muito a evolução temporal de $\psi$ na trajetória $(\psi, H)$ que for dada. No caso das soluçōes do tipo de Sitter contraindo isto pode ser visto mais claramente, pois neste caso ocorre um crescimento exponencial de $\chi$ (ver a equação de movimento para $\chi$ em (3.6)). Neste caso, demonstra-se que o termo $\chi^{2}$ domina a evoluçäo de $\psi$ se este assumir grandes valores em módulo.

0 efeito de $\chi$ sobre as trajetorias projetadas no plano $(\psi, H)$ tambérn podern ser estudados. O papel das linhas $\psi= \pm 2$ permanece inalterado: elas corresponden aos máximos de $|H|$ para uma dada trajetória. Conludo, a condiçăo para haver mudança de sinal de $H$ muda. Em vez de $V\left(\psi_{0}\right)=0$, agora segue de (3.6) que a condição torna-se

$$
\frac{1}{2} x^{2}+V\left(\psi_{b}\right)=0 .
$$

Assim, $\left|\psi_{b}\right|$ é deslocado para um valor maior e dependente do dilaton. Note que para valores muito altos de $|\chi|$ para os quais a equação acima não tem soluçào, não haverá passagem de contraţăo para expansão.

A presença de $\chi$ tambérn muda as linhas críticas. Para un valor fixo de $\psi_{3}$ a condição $\psi=0$ que determina a linha crítica ocorre para um valor maior de $|H|$ do que no caso sem $\chi$. como pode ser visto a partir da equação de movimento de $\psi(3.6)$. Alếm disso, para um par $(\psi, H)$ inicial fixo, o valor de $\psi \hat{\psi}$ para soluçōes em contração é maior com $\chi \neq 0$ do que $\operatorname{com} \chi=0$. Assim, conclui-se que a adição de um pequeno valor para $\chi$ aumenta a faixa de condiçöes iniciais no plano $(\psi, H)$ que contraem e expandem. E mais, quanto maior o valor de $\chi$, maior será o efeito (pelo menos enquanto (3.30) ainda tiver uma soluçào).

Um aspecto interessante do caso com o dilaton é que soluçôes cora colapso na presença de um $|\chi|$ pequeno evoluem genericamente para uma fase expansionista do universo. Considere-se condiçôes iniciais com um $\chi$ pequeno mas positivo, as quais localizem-se abaixo 
da linha separatriz no plano $(\psi, h)$ e que inicialmente "oscilarn" em torno do espaço-tempo de Minkowskl. Como, de (3.6),

$$
H=-V
$$

e uma vez que $\dot{\psi}\rangle 0$ para estas trajetórías, elas näo "quicam" em torno de $H=0$ mas sim iniciam um novo ciclo cora $H<0$. Como $H \leq 0$ em todos as tempos, $\chi(t)$ cresce até atingir um valor suficentemente alto de modo que a trajetoria cruza a "separatriz" no plano $(\psi, H)$ e evolui atê $\psi=2$, para uma passagem bem sucedida para a fase FRW. Um exemplo de trajetória deste tipo é mostrado na Figura 3.2.

Agora está claro que é possivel construir condiçâes iniciais nas quais o universo esta inicialmente contraindo dominado pelo dilaton e evolui para uma fase FRW. Por exemplo, pode-se assumir condições iniciais para $(\psi, H, \chi)$ como sendo aquelas dá solução (na Figum ra 3.2) que corresponde ao final do ciclo precedente à entrada na fase FRW. Este modelo consiste entāo numa implementação bem sucedida do tipo de evoluçäo postulada pela cosmologia do PBB. Note que após a entrada na fase FRW, o dilaton tende a uma constante e torna-se rapidarnente irrelevante para a evolução desta fase. Este aspecto diferencia este modelo de outras abordagens que tentam prover uma passagem contínua entre as duas fases no contexto do PBB. Nos demais casos, o dilaton continua a crescer ao longo da expansão, e a teoria assintótica resultante não é a TRG, com $Q$ constante, como necessário.

\subsection{Conclusão}

Foi mostrado neste capitulo que a técnica de limitaçẫo de curvatura via multiplicadores de Lagrange das Refs. $[43,44]$ pode ser aplicada am uma cosmologia dilatönica para produzir soluçōes com continuidade entre uma fase de contraçäo e outra em expansão. Em particular isto permitiu implementar um modelo que satisfaz com sucesso a evolução qualitativa pretendida pelo programa do PBB.

O estudo das trajetórias no espaço de fase mostrou analitica e numericamente que todas 


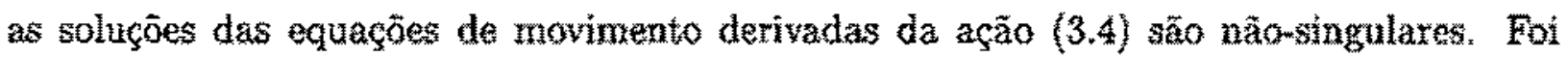
justificada uma classe de trajetórias que se iniciam de pontos próximos à origem do espaço de fase e que apresentam o comportamento desejavel de mudança de sinal do parä́netro de Hubble com e sem o dilaton. E interessante que a inclusão do dilaton aumenta a fração do espaço de fase para as quais as soluçōes exibem este comportamento. Mas também ẻ relevante que a exclusão do dilaton ainda permita a obtenção de tais soluçôs, mostrando que este modelo é uma outra proposta de cosmologia com termos de ordem superior nas derivadas da métrica que exibe comportamento não-singular. Este tipo de abordagen pode indicar caminhos na busca de novos temos na açäo efetiva das cordas fundamentais que se

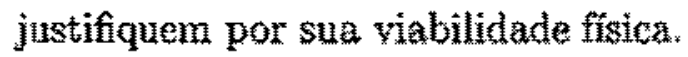

Convém ressaltax que este trabalho näo discute o problena de fixar o valor do dilaton para tempos muito grandes nem responde às recentes objeçöes levantadas contra o cenărio do PBB [51]. Uma objeçäo natural mais dirigida a este trabalho é que os termos extraxs na ação são postos à mäo em vez de serem derivados de uma teoria fundamental. Há, contudo, algumas justificativas para seguir esta abordagem. Primeiro, é geralmente esperado que os invariantes fisicos tenham que ser limitados em teoria de cordas [45]. Isto significa que, para grandes curvaturas, tal comportamento deveria se refletir na açäo efetiva para a gravidade, e a açẵo proposta aqui e uma maneira simples de se obter quantidades limitadas, Segundo, termos de derivadas de ordem superior surgem mevitavelmente em toortas tefivas de gravitagäo, taif como as resultantes de teoria de cordas, te outras abordagents de gravitaçāo quântica ou da quantizaçäo de campos de matéria em espaços curvos. Apesar de não ser diretamente derivada da teoria de cordas, a açăo considerada aqui demonstra que um conjunto especifico de correcöes de curvatura mais alta pode tanto assegurar que todos os invariantes físicos permaneçam finitos quanto produzir um universo consistente com a simetria dual do fator de escala, pois apresenta uma fase de expansăo após uma contraçăo.

Por fim, vale notar que, apesar deste trabalho ter se limitado a estudar soluçôs no referencial de Eunstein, a sua extensão pare o referencial das cordas foi proposta recentemente 
por Easson e Brandenberger [52] com resultados similares aos dados aqui e usando o mesmo potencial (3.9). O fato do mesmo vínculo fornecer resultados similares em referenciais diferentes pode ser uma indicaçäo da robustez da técnica emprégada aqui. 


\section{Capítulo 4}

\section{Cosmologias com decaimento do}

\section{vácuo}

\subsection{Termo cosmológico variável}

Modelos fenomenológicos com $\Lambda$ variável se propöem a explicar senäo o porquê da constante cosmológica ser tão pequena, pelo menos como ela chegou a este valor. Nessas propostas o termo cosmológico é suposto uma função definida do tempo, sendo entāo suas consequências investigadas. Como em qualquer abordagem deste tipo, năo he preocupaçăo em extrair uma teoria a partír de primeiros principios, mas tầo somente reproduzir a evoluçâo do universo levando em conta a variação temporal do termo cosmológico. Note-se que a divergência nula do tensor de Einstein (ver Eq. (1.5)) e a variação temporal do termo cosmológico implicam uma troca de energia entre o vácuo e a matéria, ou seja, de (1.7):

$$
u_{\mu} T^{z a t}{ }_{i z}=-\frac{u^{\mu} \Lambda_{j i}}{8 \pi G}
$$

Nos modelos que consideraremos nesta tese, esta troea de energia se dé através de criação de matểia. Entretanto, convém notar que existem hoje vários modelos com variação temporal da "constante cosmologica" que na verdade se tratam de campos escalares (as vezes chamados de "quintessência") e que näo envolvem esta tranferência de energia entre 
os campos. ${ }^{1}$ Uma compilaçâo impressionante das dezenas de modelos com decaimento de $A$ propostos pode ser encontrada no artigo de revisão de Overduin e Cocperstock [53]. Abaixo serão descritos alguns modelos mais diretamente relacionados aos resultados apresentados neste capítulo.

Praticamente precursores da aborgem de modelos fenomenológicos com decaimento do vácuo, Özer e Taha [54] apresentaram um modelo no qual säo propostas as seguintes hipóteses: 1) em algum estágio primordial da sua evoluçãa, o universo expandiu produzindo entropia (ao contrărio do modelo padräo, adiabático) devido à variação de $A$ e ii) a densidade de energia do fluido que preenche o universo (matéria e/ou radiaçäo), t sempre igual à densidade critica $\rho_{c}=3 H^{2} / 8 \pi G$. Com estas suposiçöes, podese encontrar a lei especifica de variação do termo cosmológico como função do fator de escala:

$$
\Lambda(a)=\frac{3}{a^{2}}
$$

Este modelo descreve um universo com origem não-singular e sem os problemas de condiçōes iníciais do modelo padrão. Neste caso, o problema da constante cosmológica se reduz a encontrar uma teoria que imponha que $\rho=\rho_{c}$, já que o valor de $\Lambda\left(a_{0}\right)$ obtido por Özer e Taha e bem menor do que os limites observacionais. A dificuldade de se justificar esta restrição sobre p foi considerada a principal objeçäo a este modelo [55].

Admitindo a hipotese de um termo cosmológico variâvel, mas em um desenvolvimento independente do de Ozer e Taha, Freese et al. [56] fizeram urna análise detalkada de uma classe de modelos caracterizada pelo parâmetro

$$
x=\frac{\rho_{y}}{p_{r}+p_{g}}
$$

onde $\rho_{y}$ é a densidade de energia do vácuo e $\rho_{r}$ é a densidade de energia da radiaçăo. Como restriçăo sobre o modelo, Freese et al assumiram a existência de um estágio inflacionário primordial, de modo que o universo apresenta seções espaciais planas $(k=0)$. Além disso,

${ }^{1}$ Modelos com campos escalares acoplados serão considerados no próxino capítulo. 
foram usadas as hipóteses de que o vácuo decai apenas em radiação ${ }^{2}$ e que, para valores suficientemente altos do tempo cosmológico $t, \rho_{v}$ e $\rho_{r}$ são näo nulos e decaem à mesma taxa, de modo que o parâmetro tende a um valor constante. Pode-se mostrar que neste $\mathrm{CasO}_{\text {, }}$

$$
\Lambda=3 x H^{2}
$$

Buscando impor limites sobre $x$, foram avaliadas as consequências do decaimento do vácuo sobre as abundâncias dos elementos leves produzidos na mucleossintese primordial, bem como possiveis distorçôes no espectro da radiaçăo cósmica de fundo (no caso de se admitir que a radiaçấo produzida pelo decaimento do vácuo näo tenha espectro planckiano). A conclusão do trabalho é que o modelo só é consistente com os limites observacionais se o universo nāo for dominado por $\rho_{y}$ para tempos $t>1$ seg. Isto porque, dada a compatibilidade entre as previsões do modelo padrão e os resultados observacionais das abundâncias dos elementos leves, $x \leq 0,1$. Considerando-se que o espectro da radiação produzida pelo decaimento do vácuo é não planckiano, obtém-se limites ainda mais restritivos $\left(x \lesssim 10^{-4}\right)$. Mais recentemente, Birkel e Sarkar [57] reestudaram os limites sobre $x$ extraidos de observaçöes de abundâncias dos elementos leves e chegaram a um limite um pouco menos restritivo (a $\leq 0,13)$. Quanto ao limite obtido das distorçôes da radiação de fundo, Lima [58] fez uma análise termodinâmica do decaimento do vácuo e mostron que se a entropia específica da radiaçäo for constante ao longo do decaimento, o espectro planckiano é mantido sem distorçôes. Esta condição equivale, na maioria dos casos, à condição de termalização entre o banho térmico e os produtos do decaimento.

Uma outra possibilidade de lei fenomenológica foi sugerida por Gasperini [50]. Esta proposta é baseada em um trabalho de Gibbons e Hawking [60] onde é dada uma ligação

\footnotetext{
"Freese at al argurnentam que, caso o vácuo decaia em bárions na era da matéria o vale a lei de conservação do nútmero bariônico, tais partículas deveriam ser produzidos em pares bárions-antibárions, de modo que os limites observacionais sobre o fuxo isotrópico de ralos-y praticamente descartariam esta

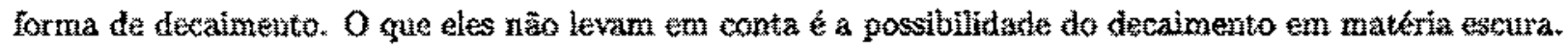


entre a constante cosmologica e a temperatura do vâcuo no espaço-tempo de de Sitter:

$$
T_{y}^{*}=\left(\frac{A}{12 \pi^{2}}\right)^{\frac{1}{2}}
$$

sendo $T_{v}$ a temperatura da radiacăo termica isotrópica detectada por observadores geodésicos neste espaço-tempo. Gasperini estende este resultado, supondo que de va valdo para qualquer instante $t$ em modelos do tipo FRW com termo cosmolótico e propäe que $T_{v}$, ou equivalentemente $A$ (via $(4.4)$ ), decaem como funções do fator de escala. Neste caso, supondo que o vácuo acopla apenas com a radiaçāo, pode-se obter a seguinte leỉ fenomenológica (compatível com a condiçăo $x=$ const. $\mathrm{em}(4.3)$ ):

$$
A=\frac{12 \pi^{2} b^{2}}{a^{2 n}}
$$

onde $b$ e $n$ săo parâmetros a serem determinados. Adotando os limites obtidos por Freese

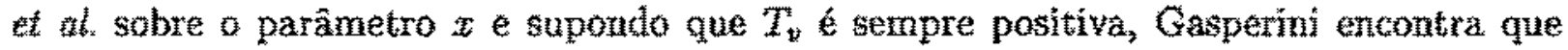
$9 / 5<n<2$ e que $\Lambda_{0} \leqslant 10^{-127} \mathrm{~m}_{\mathrm{p}, \mathrm{l}}^{2}$ bem dentro dos limites observacionais.

Abandonando a restrição $\rho=p_{c}$ usada por Ozer e Taha, Chen e Wa [61] apresentaram ưn modelo no qual é também proposta uma dependência de $\Lambda$ com $\alpha^{-2}$, obtida a partír de argumentos dimensionais compatíveis com a cosmologia quâtica. De acordo com Chen 0 Wu, esta teoria sugere escrever o termo cosmologico como proporcional a densidade de Planck $\rho_{\text {pl. }}$. Além disso, é comum admitir en cosmologia quẫntica [61] que a evoluçäo do termo cosmológico é mais convenientemente descrita pelo fator de escala n, no lugar da idate do universo. Supondo que näo há mus parâmetros relevantes, Chen e Wu propōem que o thrstutz mais natural é que o vácuo decai de acordo com uma lei de potência do fator de escala:

$$
\Lambda(a) \propto \rho_{\mathrm{pl}}\left(\frac{r_{\mathrm{pl}}}{a}\right)^{n}
$$

onde $\tau_{p}$ é o comprimento de Planck. A escolha $n=2$ é justificada pelo fato de qualquer outro valor de $n$ na equaçâ acima levar ao aparecimento de uma potêtrcia positiva ou negativa de $\mathrm{n}$ em e, portanto, nas equaçö (clássicas) da relatividade geral, Em outras

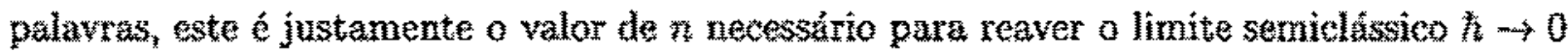


nas equaçōes de Einstein. Com $n=2$, a Eq. (4.6) pode ser reescrita em uma forma similar à de Özer e Taha

$$
\Lambda(a)=\frac{\gamma}{a^{2}}
$$

onde $\gamma$ é um número da ordem da unidade que, em principio, pode ser estimado a partir de dados observacionatis. Este argumento é sirnilar a empregado em mecânica quâtica elementar paza estimar o estado fundamental de enargia do átomo de Hidrogênio Ev [61]. Por razōes dimensionais, podemse escrever $E_{0}$ como o produto entre a massa de repouso do elétron $m_{e} c^{2}$ e uma potência da constante adimensional de estrutura fina $\alpha_{e}=e^{2} / \hbar c$. Lembrando que este é um sistema não relativístico, a velocidade da luz não deveria aparecer explicitamente na expressäo para $E_{0}$. Isto requer que seja usada uma potência $n=2$ de $\alpha_{2}$ de modo que $E_{0} \propto m_{e} e^{4} / h^{2}$, como calculado usando a metânica quântica.

Supondo que o vácuo decai na componente dominante do fuido que presnche o universo nas aras da radiaçăo e da matéria, Chen e Wu apontam como resultado favoravel ao sen modelo (além de reformular o problema da constante cosmológica) o fato dele aliviar os problemas da idade e do parâmetro de densidade, consequências do cenário inflacionário (ver Cap. 1). Além disso, a lei (4.7) prevê uma taxa de criação de matéria comparável à do modelo de estado estacionário [g], o que forneceria um teste experimental para o modelo. ${ }^{3}$ Como o modelo de Chen a Wu admite soluçôes singulares e năo-singulares, Abdel-Ranman [55] apresentou um modelo no qual é empregada a mesma lei (4.7), mantendo a produçă丶 de entropia, mas com a restrição de que que não haja singularidade inicial. Com isto, pôde se obter um modelo que retém as vantagens do de Özer e Taha sem a necessidade de impor que $p=p_{\mathrm{s}}$

\footnotetext{
\$Naturalmente, Chen e Whi ascumezn que o vacuo năo decal em pares batron-antibárion, evitando assim we limites iropostos pelas medidas da radiaçãa $\gamma$ isotropica.
} 


\subsection{Um caso geral}

Uma extensăa dos argumentos dimensionais de Chen e Wu foi sugerida por Carvalho et al. [62] e uma lei mais geral para o decaimento de $A$ foi obtida. Por completeza, nesta seção esta proposta será apresentada como caso particular do modelo da Ref [63]. Assumindo que o termo cosmológico deva depender de una escala de tempo cosmológica, pode-se escrever

$$
A \propto \frac{1}{r_{\mathrm{pl}}^{2}}\left(\frac{t_{\mathrm{pl}}}{t_{f t}}\right)^{\mathrm{m}}
$$

onde $t_{H} \approx H^{-1}$ é o tempo de Hubble. Seguindo em parte Chen e Wu, e supondo $A$ não dependa explicitamente de $\hbar$, encontra-se também neste caso que $m=2$. Mas para reter o caso de Gasperini como limitê, será usada uma potência genérica de $a(t)$. Com isto em mente, considera-se um termo cosmológico que varia da forma

$$
A=3 \beta x^{2}+\frac{3 a}{a^{2}}
$$

$\operatorname{com} \alpha, \beta$ en sendo números adimensionais da ordem da unidade (com apenas $c=1$ ) e 0 fator 3 tendo sido inclúdo por conveniêncía matemática.

Considerando o elemento de linha de FRW (ver Eq. 1.1) e a lei gama (1.15) como equaçäo de estado para o fluido cósmico: tem-se que a equação de movimento para o fator de escala é dada por

$$
a \ddot{a}+\Delta_{1} \dot{a}^{2}+\Delta b-\frac{3 \alpha \gamma a^{2-n}}{2}=0
$$

A integral primeira de (4.10) é uma das seguintes expressōes:

$$
\begin{array}{cc}
\dot{a}^{2}=A a^{-2 \Delta_{1}}-\frac{3 \alpha \gamma a^{2 n n}}{n-2-2 \Delta_{1}}-\frac{\Delta k}{\Delta_{1}} ; \quad\left(\Delta_{1} \neq 0, \frac{n-2}{2}\right) \\
a^{2}=A-\frac{3 \alpha \gamma a^{2-n}}{n-2}-2 \Delta k \ln a ; \quad\left(\Delta_{1}=0, \Delta_{1} \neq \frac{n-2}{2}\right) \\
a^{2}=A a^{-2 \Delta_{1}}+\frac{3 \alpha \gamma}{a^{2 \Delta_{1}}} \ln a-\frac{\Delta k}{\Delta_{1}} ; & \left(\Delta_{1}=\frac{n-2}{2} \neq 0\right) \\
\dot{a}^{2}=A+(3 \alpha \gamma-2 \Delta k) \ln a ; & \left(\Delta_{1}=\frac{n-2}{2}=0\right)
\end{array}
$$

com $\Delta_{1}=\frac{3 \gamma(1-\beta)-2}{2}, \Delta=\frac{3 \gamma-2}{2}$, e $A$ sendo uma constante dependente de $\gamma$. 
Por simplicidade, nảo serão considerados os casos particulares $\Delta_{1}=0, \frac{n-2}{2}$. Das equacoes acima pode-se obter $\rho$ e $p_{n}$, as densidades de energia da matéria e vácuo, re spechivamente

$$
\begin{gathered}
\frac{8 \pi G \rho}{3}=(1-\beta) A a^{-3 \Delta_{1}-2}+\frac{n}{2 \Delta_{1}+2-n} \frac{\alpha}{a^{n}}-\frac{\beta}{\Delta_{1}} \frac{k}{a^{2}} \\
\frac{8 \pi G \rho_{2}}{3}=\beta A a^{-2 \Delta_{1}-2}+\frac{3 \gamma-n}{2 \Delta_{1}+2-n a^{n}}-\frac{\beta \Delta k}{\Delta_{1} a^{2}} .
\end{gathered}
$$

Naturalmente, as equações acima reproduzem os modelos considerados anteriormente: o modelo padrä̊ $(\alpha=\beta=0)$, modelos com constante cosmológica $(\beta=n=0)$, Orzer e Taha $(\beta=0, \alpha=k=1$ e $n=2)$, Freese el al. $(\alpha=k=0)$ e $\left.\beta=\rho_{y} / \rho+\rho_{y}\right)$, Gasperini

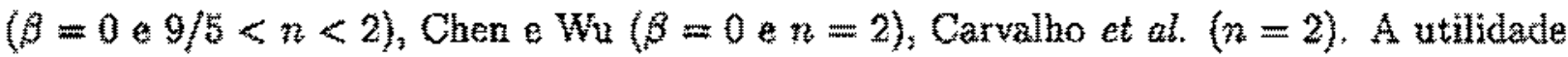
de se usar este conjunto mais complexo de equaçoes é que características genéricas dos modelos particulares ficam mais explicitas neste formato. Por exemplo, soluços singulares e nä0-singulares estảo presentes no conjunto de equagöes, dependendo do sinal de A. Notese também que modelos planos e abertos que recolapsam sảo sempre possiveis. $O$ exemplo mais simples é obtido fazendo $k=0, A>0$ e $\alpha<0$. Para $n=2$, o parâmetro $\alpha$ atua como um parâmetro de curvatura com o sinal invertido [62]. Por esta razão, para valores positivos de $\alpha_{\text {, }}$ encontram-se modelos fechados $(k=1)$ nos quais o universo segue em expansäo eterma altarando o seu destino com relação aos modelos do hipo Fredmann. Soluçöes para o caso plano outros casos particulares foram obtidas na Ref. [63] em termos de hipergeombtricag e uma analise mais detalhada do modelos pode ser encontrada lá. No que segue, serả discutido apenas o caso relativamente mais simples, $\operatorname{com} n=2$, da Ref. [62] que generaliza todos os outros modelos expostos anteriormente, exceto o de Gasperini.

Em geral, as características físicas do modelo $\operatorname{com} n=2$ são fortemente dependentes dos valores dos parâmetros e dos sinais das constantes de integração. Como no modelo de Chen e Wu, a assume o papel de um parametro de curvatura com sinal invertido. Contudo, devido axistência do termo $\beta$, sugem algumas modificaçoes importantea com relaçăo a aquele modelo: i) se 3 for suficientemente grande, contributiçäo da densidade de anergia da 
radiaça para a curvatura näo pode ser desprexata no universo primordial, como feito por

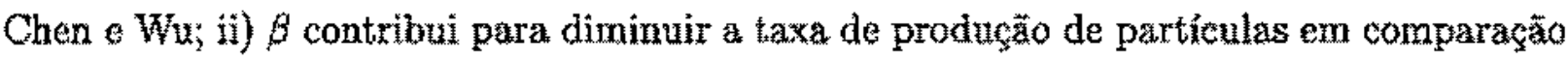
ao resultado obtido na Ref. [61] e para ammentar a idade do universo $t_{0}$ com relaçă aos resultados do modelo padräo. Para considerar apenas um exemplo particular, se $k=3 \alpha$ e admitindo um modelo singular $(A>0, \gamma=1)$, ancontra-se que [62]

$$
t_{0}=\frac{2}{3(1-\beta)} H_{0}^{-1}
$$

que fornece idades compatíveis com os limites observacionais (caso $\beta$ assuma valores suficientemente altos).

Com relaçâo ao modelo de Freese et al., a principal modificaçắo introduzida pelo parâmetro $\alpha$ diz respeito šs prediçöes da nucleossintese. No caso do modelo de Carvat Iho et al, o parâmetro $x$ é pode ser escrito como (para $k=0$ )

$$
w=\beta+\frac{\alpha}{a^{2} H^{2}}
$$

que explicitamente dependente do tempo. Note-se que apenas se $|\alpha| / a^{2} H^{2}<\beta$ ra época da nucleossintese é que o limite $\beta \leq 0,1$ obtido por Freese et al. é valldo. Concluisse, portanto, que o parâmetro $\alpha$ pode ter um papel importante na nucleossintese cosmológicaly podendo inclusive permitir valores de p maiores do que 0,1 (particularmente se $\alpha<0$ ), o que poderia poderia eventualmente resolver os problemas de idade e do parametro de densidade $[62]$.

As relaçổes cinemáticas de distância devem ser confrontadas com os dados observacionais de modo a serem impostos limites sobre os parâmetros livres do modelo. A informaçấo sobre escalas de distâncias cosmologicas é obtida através da observạăo do desvio para o vermelho da luz emitida pelas tontes distantes. Para calcular tais desvios de trequencia, considera-se um observador na origem $r=0$ do sistema de coordenadas (apenas uma convenção, quando Se trata de um universo homogêneo e isotrópico) a imagina-se uma onda elotromagéticat propagandomse ao longo da direçấo $-r, \operatorname{com} \theta$ e $\phi$ constantes. A ecuação de movimento de 
urna dada frente de onda é, de acordo com o elemento de linha de FRW (ver Eq. (1.1) $)^{4}$;

$$
0=d s^{2}=d t^{2}-a^{2}(t) \frac{d r^{2}}{1-k r^{2}}
$$

Portanto, se a onda foi enitida por uma fonte localizada nas coordenadas $\left(t_{1}, r_{1}, \theta_{1}, \phi_{1}\right)$, ela alcançarâ o observador em um instante $t_{2} \mathrm{e}$ a coordenada radial comóvel da fonte luminosa serà dada por

$$
\int_{0}^{r_{1}} \frac{d r}{\sqrt{1-k T}}=\int_{t_{1}}^{t_{2}} \frac{d t}{a(t)}=\int_{a_{1}}^{a_{2}} \frac{d a}{a \dot{a}}
$$

onde $a_{i} \equiv a\left(t_{i}\right)$. A relação distância-luminosidade $\times$ desvio para o vermelho $\left(d_{L}\right)$ é definida como $[8]$

$$
d_{L}=a_{2} T_{1}(1+z)
$$

Sabendo que o desvio para o vermelho $z$ é definido por $\left(a_{2} / a_{1}\right)=1+z$, pode-se obter (para os modelos planos considerados aqui)

$$
d_{L}=H_{0}^{-1}(1+z) \int_{(1+z)^{-1}}^{1} \frac{d x}{x[f(x)]^{\frac{2}{2}}}
$$

onde $f(x)$ b dada por

$$
\begin{array}{r}
f(x)=1-\frac{2 \varphi_{0}}{1-3 \beta}+\frac{2 \varphi_{0}}{(1-3 \beta) x^{1-3 \beta}}+\left(1-\frac{2 q_{0}}{1-3 \beta}\right) \times \\
{\left[\frac{(n-2)\left(1-\frac{1}{x^{1-3 \beta}}\right)-(1-3 \beta)\left(1-\frac{1}{x^{n-2}}\right)}{3-3 \beta-n}\right] .}
\end{array}
$$

Como a distuância de diâmetro angular $d_{A}$ satisfaz a relação $d_{A}=d_{L}(1+z)^{-z}$, as expressões usıais sẫo explicitamente modificadas pela presença dos parâmetros $\beta$ e n e implicitamente pelo parámetro $\alpha, O$ exemplo mais simples é estabelecido comn $=2$. Neste caso, fazendo sucessivamente as substituiçöes de variáveis

$$
x^{1-3 \beta}=u^{2}
$$

e

$$
\frac{2 q_{0}}{1-3 \beta} u^{2}=\left(\frac{2 q_{0}}{1-3 \beta}-1\right) w^{2}
$$

4 Seguindo o procedinento usual de cálculo de distanciak, tal como pode ser encontrado na Ref. [8] 
encontron-se

$$
d_{L}=\frac{\left.2 H_{0}-1+z\right)}{1-3 \beta}\left(\frac{2 g_{0}}{1-3 \beta}-1\right)^{-\frac{1}{2}}\left(\sin ^{-1} \alpha_{1}-\sin ^{-1} \alpha_{2}\right)
$$

neste caso particular, válida para qualquer valor de $k$ e onde

$$
\alpha_{1}=\left[\frac{1}{(1+z)^{1-3 \beta}}\left(1-\frac{1-3 \beta}{2 q_{0}}\right)\right]^{\frac{1}{2}}, \quad \alpha_{2}=\left(1-\frac{1-3 \beta}{2 q_{0}}\right)^{\frac{1}{2}}
$$

Uma analise mais abrangente das consequências dinamicas deste modelo pode ser encontrada nas Refs. $[63,64]$.

Um comentário final que poderia ser feito sobre os modelos fenomenológicos discutidos nesta seção é que todos eles carecem de uma descrição contínua unindo o período inflacionário e o atual estágio da evolução do universo. Uma possivel solução para esta característica insatisfatória serä proposta na próxima seçäo.

\subsection{Modelo deflacionário não-singular}

Nesta seção será apresentada uma proposta de dependência temporal de A que parece ser melhor notivada do que as anteriores, por tratar diretamente do problema da singularidade inidial e conectá-lo ao problema da constante cosmológica de uma forma explicita.

Em geral, a forma funcional de $A(t)$ é escolhida extrapolando os valores do termo cosmologico a partir do limite superior $\Lambda_{0}$ observado atualmente. Contudo, uma vat que este valor é remanescente de um desejável estaxgio inflacionário primordial, uma leí fenomenológica para o decaimento de $\Lambda$ deveria descrever toda a história cósmica, incluindo açuele estágio (com $A$ aproximadamente constante). Neste caso, para rnodelos näo-singulares, um limite superior absoluto para $A(t)$ seria estabelecido em um instante finito no passado. Em princtioio, sua magnitude poderta ser dada por uma teoria ntais fundamental que descrevesse o feromenos gravitacionats na era de Planck.

No que segue, a dependência natural no parâmetro de Hubble $\Lambda \propto H^{2}$ apresentada uas seçöes anteriores é estendida e mostra-se como tais leis levan a um modelo cosmológico con- 
sistente dirigido pelo decaimento da densidade de energia do vácuo. O cenário inflacionário primordial será gerado pela seguinte lei fenomenológica [65]:

$$
\Lambda(H)=3 \beta H^{2}+\frac{3(1-\beta) H^{n+2}}{H_{I}^{n}},
$$

onde $H_{I}^{-1}$ é uma escala arbitrária de tempo (quando teria ocorrido a fase inflacionária), $\beta$ é um parâmetro adimensional da ordem da unidade, o fator 3 foi introduzido apenas por conveniência matemática e o $n$ por generalidade. Observe que se $H=H_{I},(4.25)$ implica que $\Lambda=3 H_{I}^{2}$, como requerido para haver inflação, e para grandes tempos cosmológicos $\Lambda \sim 3 \beta H^{2}$, como esperado. Em relação aos modelos fenomenológicos apresentados anteriormente, esta proposta tem a grande vantagem de fornecer naturalmente a dinâmica de todas as fases que supostamente ocorreram durante a evolução do universo, incluindo uma origem não-singular e explicitando a passagem da fase inflacionária para a era da radiação.

No caso de um espaço-tempo descrito pelo elemento de linha de FRW (ver Eq. (1.1)) e no caso plano $(k=0)$, as equações de campo de Einstein para a componente material mais o termo $\Lambda$ podem ser escritas na forma (Eqs. (1.10) e (1.11)):

$$
\begin{gathered}
8 \pi G \rho+\Lambda=3 H^{2}, \\
8 \pi G p-\Lambda=-2 \frac{\ddot{a}}{a}-H^{2},
\end{gathered}
$$

sendo $\rho$ e $p$ a densidade de energia e pressão do meio material. Considerando a lei gama como equação de estado $p=(\gamma-1) \rho$ e o termo $\Lambda$ dado por (4.25), obtém-se de (4.26) e (4.27) a seguinte equação diferencial que governa a evoluçāo do fator de escala:

$$
\frac{\ddot{a}}{a}+\frac{3 \gamma(1-\beta)-2}{2} H^{2}-\frac{3 \gamma(1-\beta)}{2} \frac{H^{n+2}}{H_{I}^{n}}=0 .
$$

A equação acima pode ser reescrita na forma

$$
\dot{H}+\frac{3 \gamma(1-\beta)}{2} H^{2}\left[1-\left(\frac{H}{H_{I}}\right)^{n}\right]=0,
$$

cuja solução é dada por

$$
H=\frac{H_{I}}{\left(1+C a^{n \frac{3 \gamma(1-\beta)}{2}}\right)^{\frac{1}{n}}},
$$


onde $C$ é uma constante de integração dependente de $\%$ Observe que $H=H_{Y}$ e uma soluçẫo particular da Eq. (4.29), a qual descreve o espaço-tempo de de Sitter. Esta soluça Anstavel com respeito ao valor crítico $C=0$ e, como dito anteriormente, ela fornece 0 mator valor possivel para o termo cosmológico varível, $a_{*} A_{l}=3 h_{1}$

De $(4.25)$ e (4.26), obtém-se a seguinte densidade de matérla-nergla

$$
8 \pi G p=3(1-p) H^{2}\left[1-\left(\frac{H}{H_{\eta}}\right)^{n}\right]
$$

de modo gue se $H \rightarrow H_{I}, \hat{p} \rightarrow 0$ e o vácuo decai de uma instabilitade da configuragăo de Sitter inicial, gerando toda a matéria e energia do universo observivel. Neste modelo näo existe estágio pré-infacionário, que aparece em algumas variantes de intaçäo apresentadas na literatura [14, 21]. A evolução do universo dada pela Eq. (4.30) se inicia sem singularidade a partir de uma fase de Sitter $a \cdots e^{H t}$ para $C a^{3 \gamma(1-3) / 2} \ll 1$, evolui continuamente para uma fase quase-FRW, $a \sim t^{2 / 3 \gamma(1-B)}$, para $C a^{3 \gamma(1-B) / 2} \gg 1$. Tal comportamento pode ser descrito exatamente se integrarmos (4.30) para o caso $n=1$ [66]:

$$
H_{I} t=\ln \left(\frac{a}{a_{*}}\right)+\frac{2 C}{3 \gamma(1-\beta)} a^{\frac{3 \gamma(1-\beta)}{2}}
$$

onde $a_{*}$ é um valor arbitrário do fator de escala, o qual pode ser fixado para definir o comeco da fase quase FRW (ver a próxirna seção).

Para $\beta=0$, uma solução deste tipo fol obtida por Murphy [67] como um exemplo de cosmologia com viscosidade volumar. Barrow [68] remterpretou o modelo de Murphy como uma descrição macroscópica para a produçấo de particulas vcorrendo no final do novo cenário inflacionário [69]. Posteriormente, esta soluçäo fol obtida em um caso mais geral $(B=0, n$ qualquer) para deserever o espaço tempo dirigido pela produção quântica de condas fundamentais [70]. Mais recentemente, Lima and Gemano [71] mostraram que a soluçẩo com $n=1$ também aparece no contexto de modelos cosmologicos com criaçäo irreversivel de matéria, como formulado por Prigogine et al. [72]. Porta, como sera mostrado a seguir, a presença do parâmetro $p$ nas Eqs. (4.30)-(4.32) muda as previátos usuais do modelo padrão de FRW para a presente fase dominada pela materia. Este fato será útil 
para conciliar os dados atualmente disponiveis com o estágio ínflacionário inicial do modelo. Os resultados com $\beta \neq 0$ en $=1$ da Ref. [66] foram estendidos por Lima e Trodden [73] para incluir os casos aberto e fechado.

\subsection{Consequências observacionais}

De modo a limitar os parâmetros do modelo proposto na última seçâa, algumas das suas implicações para o estágio atual de evolução do universo seräo analisadas. Primeiro serão definidas as quaritidades observacionais usuais, ou seja: $\Omega_{m}=8 \pi \mathrm{C}_{0} / 3 K_{0}^{2}$ (parâmetro de densidade), $q_{0}=-\left[a \ddot{a} / \dot{a}^{2}\right]_{t_{0}}$ (parâmetro de desaceleraçăo) e $H_{0}=[\ddot{a} / a]_{t_{0}}$ (parâmetro de Hubble\}. Convém relembrar que o cenário inflacionắrio não aconoda $\Omega_{m} \neq 1, q_{0} \neq \frac{1}{2} \mathrm{e}$ idades maiores do que $H_{0}^{-1}$, porque para modelos FRW com curvatura nula, $\Omega_{n_{n}}=2 \rho_{0}=1$ e $t_{0}=\frac{2}{3} H_{0}^{-1}$ (ver Cap. 1). Agora, inserindo as quantidades definidas acima nas equacooes (4.25), (4.26) e (4.28), encontram-se as seguintes expressōes para a fase dominada por vácuo-matéria (FVM);

$$
\begin{gathered}
\frac{\Lambda_{0}}{3 H_{0}^{2}}=\Omega_{\Lambda_{0}}=\beta+(1-\beta)\left(\frac{H_{0}}{H_{I}}\right)^{n}, \\
\Omega_{m}=1-\beta-(1-\beta)\left(\frac{H_{0}}{H_{l}}\right)^{n}, \\
\varsigma_{0}=\frac{1-3 \beta}{2}-\frac{3(1-\beta)}{2}\left(\frac{H_{0}}{H_{1}}\right)^{n},
\end{gathered}
$$

Nas relaçốes acima, os últimos termos do lado direito podem ser sempre desprezados. Por exemplo, na descriçấo inflacionária usual $H_{I}^{-1} \sim 10^{-35} \mathrm{seg}$ e como $H_{0}^{-1} \sim 10^{17} \mathrm{seg}$, temse que $H_{0} / H_{t} \sim 10^{-52}$. Esta quantidade pode ser ainda menor se a inflação tiver acontecido no tempo de Planck, para o qual obtém-se $H_{0} / H_{1} \sim 10^{-50}$. Assiri, para todos os propósitos práticos: $\Lambda_{\mathfrak{0}}=3 \beta H_{0}^{2}, \Omega_{m}=1-\beta$ e $q_{0}=(1-3 \beta) / 2$. No limite $\beta \rightarrow 0$, as conhecidas expressões do modelo FRW plano são recuperadas. 
Um teste adicional de consistência para o modelo é obtido dos limites observacionais do parâmetro de idade $H_{0} t_{0}$. O parârnetro de idade computado do modelo $\mathrm{FRW}$ plano $\left(H_{0} t_{0}=\right.$ $2 / 3)$, tende a ser menor do que a laixa de valores obtidas das observaçóes $0,0 \leq H_{0} t_{0} \leq 1,4$. Alérn disso, como indicado por Jordan e Olson [74], um termo $\Lambda$ dependente do tempo é usualmente menos efetivo para acomodar o parămetro de idade observado do que uma densidade de energia do vácuo constante. Contudo, fatável que linitando o $\beta$ usando as medidas do parâmetro de idade citadas acima, 0 modelo prevê valores razoáveis para $\Omega_{n}$, $\Lambda_{0}$ e qo. Para mostrar isto, calcularn-se primeiro as constantes $C$ e $a_{*}$ que aparecern nas Eqqs. $(4.30)$ e $(4.32)$, em termos de $H_{7}, H_{0}$ e $t_{0}$. De (4.30) encontrarse

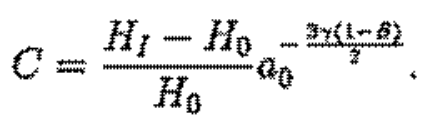

Se $H_{I} \gg H_{0},(4.30)$ pode ser reescrita como

$$
H=\frac{H_{f}}{1+\frac{H_{x}}{H_{0}}\left(\frac{a}{\alpha_{0}}\right)^{\frac{3 n_{n}\left(1-B_{i}\right.}{3}}} .
$$

Lembrando que o regime de Sitter $\left(a \sim a_{*} e^{H F}\right)$ ocorre para $a \ll a_{*}$, é razoável definir o início do estágio quase-FRW para $a=a_{*}$ onde $a_{*} \sim a_{0}\left(H_{0} / H_{l}\right)^{2 / 3 \gamma(1-\beta)}$. Para $a>a_{*} 0$ modelo entra em um regime quase-FRW. De fato, uma fase dominada por vácuo-radiação (FVR) $\operatorname{com} \gamma=\frac{6}{3}$. Eventualmente o modelo evolui para a FVM $(\gamma=1)$, pelo mesmo tipo de transiçẫo que ocorre no universo FRW. Esta última transiçẫo nāo envolve a escala arbitrária de tempo $H_{I}^{-1}$, já que ela é efetivamente desprezível em (4.37).

Agora, considerando que para $a_{\approx} a_{*}$ o fator de escala satisfaz

$$
a \sim a_{0}\left(\frac{3 \gamma(1-\beta)}{2} H_{0} t\right)^{\frac{3}{37(1=\beta)},}
$$

entäo o intervalo de tempo decorrido durante a fase quase-FRW $\left(\Delta t=t_{0}\right)$ é dado por $t_{0} \sim 2 H_{0}^{-1} / 3 \gamma(1-\beta)$. Consequentemente, o parâmetro de idade é fortemente dependente

\footnotetext{
${ }^{5}$ Un valor mais preciso de $a_{n}$ pode ser derivado se considerando exn $(4,37)$ que $\left(H_{1} / H_{0}\right)\left(a / a_{0}\right)^{3 \gamma(1-a) / 2}$

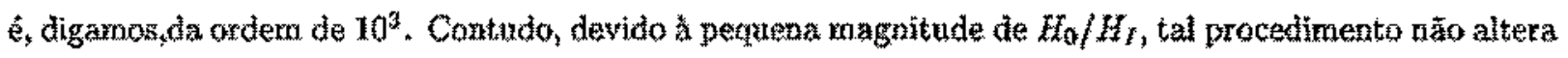
apreciavelmente as estimativas de $a_{*}$.
} 
de $\beta$. É claro que os valores de $\beta$ devem ser fixados levando em conta näo apenas os parầmetros observacionais disponiveis, mas também o valor de $a_{*}$ o qual depende da escala de tempo $H_{I}^{-1}$.

Um vínculo natural aparece aqui. Se $H_{I}^{-1}$ é da ordem ou maior do que o tempo de Planck, a. tem que ser maior do que o comprimento de Planck de modo a caracterizar o regime quase-FRW clássico. Uma escolha adequada de valores de $\beta$ e $1 / 3 \leq p \leq 1 / 2$. Neste caso, tomando $\gamma=1$, obtém-se $1 \leq H_{0} t_{0} \leq 1,33$, justamente dentro dos limites observacionais mencionados. Além disso, para valores de $\beta$ dentro de val intervalo, os valores de $\Lambda_{0}$, qo e $\Omega_{m}$ säo respectivamente restritos ans intervalos: $H_{0}^{2} \leq \Lambda_{0} \leq 1,5 H_{0}^{2}$; $-0,25 \leq q_{0} \leq 0$ e $0,5 \leq \Omega_{m} \leq 0,67$. Pode-se notar que $\Lambda_{0}$ é da mesma ordem do limite superior presentemente aceito $\left(\sim 3 H_{0}^{2}\right)$, enquanto que os valores de $q_{0}$ sảo ligeiramente menores ou iguais a zero. Neste ponto convém ressaltar que valores negativos de $q_{0}$ são favorecidos pelas observaçōes das explosões de supernovas (ver Cap. 1 e [15]). Na verdade eles näo podem ser evitados quando se tenta resolver o problema do parâmetro de densidade usando apenas um termo $\Lambda$. Pode-se mostrar que, independentemente da lei sspecífica de decaimento de $\Lambda$, modelos homogêneos e isotrópicos com curvatura nula implicam que

$$
\Omega_{m}=\frac{2}{3}+\frac{2}{3} g
$$

de modo que $\Omega_{m} \leq 2 / 3$ somente se qo $\leq 0$. Alén disso, para todos os valores de $\beta$, se $H_{l}^{-1} \sim 10^{-43} \mathrm{seg}$, encontra-se que $a_{*} \sim a_{0} 10^{-30 / 1-\beta}$. Portanto, se $\beta$ esta no intervalo $[1 / 3,2 / 3]$, o valor $a_{0} \sim 10^{28} \mathrm{~cm}$ implica que $10^{-32} \mathrm{~cm} \leq a_{*} \leq 10^{-17} \mathrm{~cm}$. Note que o modelo entra no regime quase-FRW depois da era de Planck, como esperado.

\subsection{Discussão}

O principal propósito dos modelos cosmológicos com decaimento do vácuo é determinar como a densidade de energia que dirigiu a inflaçäo esté relacionada com o pequeno valor apresentado atualmente por $A$. A dependência de $A$ em $H$ proposta neste capítulo [66] foi 
a primeira a preencher tal condição. Foi obtido um universo defacionário, cono Barrow [68] denonimou o modelo de Murphy [67]. No entanto, ao invés do mecanismo clássico de viscosidade volumar, o modelo é caracterizado por uma densidade de energía do vácuo que decai corn o tempo. Diferindo do modelo de Murphy, que tem uma densidade de energia finita $\rho$ durante a fase de Sitter, este modelo começa com $\rho=0 \mathrm{e} A=3 H_{I}^{2}$, seu valor máximo (ver Eqs. $(4.25)$ e (4.31)). Subsequentemente, uma componente material, obedecendo uma equafão de estado do tipo lei gama, é gerada às expensas da densidade de energia do vácuo. Para $\gamma=4 / 3$ o modelo evolui suavernente de uma cra de Sitter, pa qual os problemas do parametro de densidade, de honizonte e de monopolos podern ser resolvidos, param um estágio quase-FRW dominado por vácuo mais radiaçäo (deflaça). Com a passagem do tempo, encuanto o valor de A decresce, a densidade de energia o da componente material cresce, atüngindo o seu valor máximo para $a \simeq a_{*}$ justamente no inicio do estagio quase-FRW. Além disso, ala decaí como $p \sim a^{-3(i-\beta)}$ para valores suficientemente altos do tempo de expansão, ou seja, quando o fator de escala varia como $a \sim t^{2 / 3(1-\beta)}$. Desta ponto de vista, toda a matéria e entropia específica da radiação observada, teria sido gerada do "nada" inicial. Alén do mais, as mudanças introduzidas pelo parâmetro $\beta$ no modelo FRW padräo estão em razodvel concordância com alguns dados cosmologicos, particularmente as atuais estimativas de $\Lambda_{0}$ e to. $O$ modelo também permite valores do parametro de densidade no intervalo $1 / 2 \leq \Omega_{m} \leq 2 / 3$ o do parâmetro de desaceleraçäo no íntervalo $-0,25 \leq 0 \leq 0$.

A escala arbitrúria $H_{1}$ não e fxada pelo modelo, permitindo assim que a configuração inicial de de situew ocorra na escala de energia de Planck ou mesmo an escalas mais baixas (em escalas mais altas, de se esperar que a TRQ perca a valudade). De fato, apesar do parâmetro de idade da fase quase-FRW ser finito, o periodo de inflactồo é infinito, já que o universo "começon" em $t=-\infty$. Desse modo, o universo seria infinitamente velho. Por outro lado, os efeitos quẩnticos no espaço-ternpo de de Sitter levam a um estado de equilíbrio geometrotermodinâmico caracterizado pela temperatura de CibbonsmHawking, $k_{B} T=\hbar\left(\Lambda / 12 \pi^{2}\right)^{1 / 2}$, onde $k_{B}$ é a constante de Boltzmann [60]. Portanto, considerando 
que o modelo inicia com $p=0$ e $=3 H_{h}$, os observadores fundamentais devem medir uma radiañăo térmisa de fundo cufa tempezatura inicial é

$$
T_{I}=\frac{\hbar H_{I}}{2 \pi k_{B}}
$$

¿qualé determinada apenas pela escala de tempo (desconhecida) da defaçäo. Em princípio, a arbitrariedade de $H_{f}$ reflete justamente a presente fal ta de conhecimento da relaçäo entre a inflaçầ o regime de gravitaçäo guantica. Por exemplo, se $H_{I}=2 \pi t^{-1}$, onde $t_{p l}=$ $\left(n G / c^{b}\right)^{1 / 2}$ a tempo de Planck, a temperatura inicial $T_{l}$ é justamente a temperatura de Planck $T_{p t}^{x}=k_{B}^{m}\left(h c^{*} / C\right)^{1 / 2}$. No presente contexto, tal resultado năo parece ser apenas uma coincidência por causa da natureza quântiò da radiaçäo de Hawking. Observe-se que, para o valor considerado de $H_{H}$ o modelo também prevê que $\Lambda_{I} / \Lambda_{0}=\left(H_{I} / H_{0}\right)^{2} \sim 10^{120}$, como teoricamente sugerido (ver Cap. 1).

O modelo deflacionário apresentado neste capitulo foi examinado por Birkel e Sarkar [57], que usaram as abundâncias de elementos leves fornecidas pela nucleossíntese primordial para restringír o valor do parâmetro $\beta$. Os autores concluem que o limite encontrado $(\beta \leq 0,13)$ é baixo demais para ajudar no problema da idade e, portanto, não teria efeito sobre o universo hoje. Entretanto, há vários pontos a considerar. Em primeiro lugar, uma análise atualizada das consequências deste parâmetro sobre a nucleossintese primordial indicou que $\beta \leq 0,16$, valor que pode ser compatibilizado com os resultados mais recentes đa idade dos aglomerados globulares [75]. Ambos os valores de $\beta$ näo säo suficientes para provocar uma aceleraça do universo, como vem sendo observado [29], e o decaimento exclusivamente em radiaça estaria descartado. Mais ainda se $\beta$ fosse maior do que $1 / 4$ com 0 decaimento do vắcuo em radiaçă a densidade de energia desta decaitia mais lentamente do que a da matérta não relativística e o universo jamais sainia da era da radiaçăo. Assim, a suposição de decaimento continuo em apenas radiaçāa jo teria problemas independentemente de nucleossintese.

Por outro lado, se fecair na componente dominante em cada fase, uma restricāo na

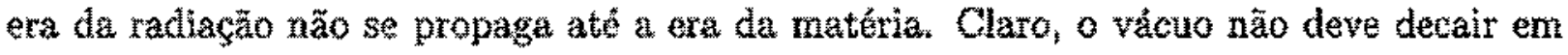


bárions, mas nada impede que o decaimento seja em materia eseura, por exemplo [7o]. Se um $A$ variá vel deste tipo for o responsável pela aceleraşăo do universo tal qual medida, então am $\beta \sim 0,7$ implica que a matéria escura não se diluiria com o volume, mas na forma $\rho \sim a^{-1}$. Unna possivel linha de continuação deste trabalho é considerar que testes cosmológicos sāo sensiveis e esta relaçăo funcional entre a densidade de energia da matéria escura e o fator de escala. 


\section{Capítulo 5}

\section{Campos escalares acoplados}

\subsection{Introdução}

Apesar do uso generalizado de campos escalares em cosmologia (ver Cap. 2), as situaçöes físicas nas quais eles são normalmente considerados tendem a ser particulares. Por exemplo, no caso da nova inflação [1.4], näo há justificativa fundamental para "desligar" todos os acoplamentos possiveis durante a fase de rolamento lento (ver Seçāo 2.3) e fazer o contrário no inicio da fase de reaquecimento. ${ }^{1}$ Isto só pode ser obtido considerando condiçöes iniciais muito especiais, o que enfraqueceu a viabilidade deste cenário. Contudo, este não é um caso isolado. Desprezar possiveis acoplamentos térmicos entre os campos escalares e os outros constituintes do universo é regra usual en quase todos os modelos com campos escalares apresentados na literatura.

Uma exceção importante é o explosivo periodo de reaquecimento necessário no final de todas as versôes de inflação isentrópica. Ao longo deste processo, o campo oscila coerentemente em torno do minimo do potencial e sua energia é transferida, totalmente ou em parte, para os demais componentes do fluido cósmico. Seja em sua versäo original [33], seja na mais moderna, baseada na ressonăncia paramétrica do campo oscilante e chamada

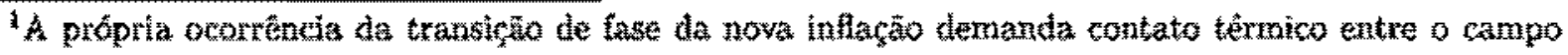

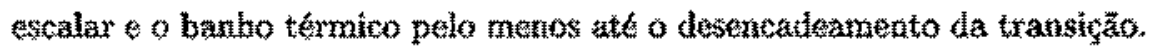


de pré-aquecirnento, ou preheating $[34,35]$, o mecanismo de reaquecimento é relativamente rápido, com virtualmente toda a entropia do universo atual tendo sido gerada desta forma.

Este não en, entretanto, o caso mais geral. Em principio, acoplamentos permanentes ou temporários entre $\phi$ e os demais campos podem também levar a processos dissipativos que produzam entropia em eras diferentes daquela do reaquecimento. Espera-se que progressos na toria de campos fora do equilibrio forneçam justificativas fundamentais necessárias para discutir dissipação em casos gerais (ver, por exemplo, [76] e referências lá citadas). Uma outra possibilidade é o "prók aquecimento instantâneo" [77]. Neste processo, o inflaton decai contimuamente em outro campo escalar às custas da sua energia potencial. Partículas deste segundo campo têm vida muito curta e rapidamente decaem em férmions, gerando entropia, podendo assim justificar modelos tipo quintessência.

Apesar de uma justificativa para efeitos dissipativos bem fundamentada em primeiros principios ainda näo ter sido obtida, tais processos não deveriam ser descartados com base apenas na facilidade dos callculos. Muito trabalho pode ser feito de modo fenomenológico aplicando-se ao problema, por exemplo, técricis de termodinâmica de não-equilíbrio, on tnesmo estudando modelos particulares com dissipaçäo. Um exemplo interessante desta última abordagem é o modelo de inflaçẫo morna (ou varm inflation), proposto por Berera [78]. Como na nova inflação, supõe-se uma transiçă de fase levando o universo para um periodo inflacionário dominado pela densidade de energia do potencial. Entretanto, um termo dissipativo fenomenológico $\Gamma \hat{\phi}^{2}$ é inserido na equaçâo de movimento do eampo escalar para representar a transferência contỉnua de energia de hi para o campo de radiação. Este contato terrmico persistente durante a infiação e tẫo finamente ajustado que o campo escalar evolui todo o tempo em um regime amortecido, gerando uma expansão isotérmica. Como consequênçia, não hâ necessidade de um mecanismo de reaquecimento subsequîtente à fase inflacionária e flutuaçōes térmicas produzem o espectro primordial de perturbações de densidade $[79,80,81]$.

A inflaçẫo morna foi originalmente formulada em bases fenornenológicas, mas algumas 
propostas com justificativas fundamentais foram apresentadas [82]. Além disso, uma analise de sistemas dinâmicos [85] mostrou que transizôs suaves de uma fase inflacionária para uma era da radiaça podem ser obtidas para muitos valores to parânetro de dissipaça $\Gamma_{\text {. }}$ mostrando assim que a inflaç̆o morna pode ser uma variante vảavel de inflaçäo. Aparentemente seu único aspecto negativo este possível ajuste fino bemodinâmico relacionado expansão isotérmica, tornada como principio em algumas versôtes de inflaçă morna mesmo levando em conta que, durante a inflaçöo, a radiaça (ver comentários nas Refs. [82]).

Neste capitulo, que é baseado na Ref, [83], procuramse relaxar esta hipófese. Entretanto, em vez de se propor mais um modelo de infiacäo morna, aqui buscam-se formas de explicitar as diferenças entre os cenários isotérmico, resumidamente apresentado abaixo, e isentrópico (ver Seçäo 2.3) em um espaço de parâmetros convenítente. Como veremos, estes modelos sāo apenas dois casos extremos de um conjunto infint to de pontos no espaço de parâmetros. Espera-se que este ponto de vista unificador possa indicar caminhos para tratamentos fenomenológicos consistentes destes modelos, em princípio baseando-os nos métodos da termodinâmica de não-equilibrio. Tarnbém discute-se como as condiçōes de rolamento lento sầ modificadas devido ao decaimento do campo escalar a apresentâ-se um modelo simples, como aplicação do que é exposto no capitulo.

\subsection{Equações básicas}

Como tem sido feito ao longo desta tese, as andises seruto limitadas a universos homogenens e isotrópicos, com geometria describa pelo elemento de linha de FRW. Além disso, apenas o caso plano $(k=0)$ será tratado, de modo que (ver Eq (1.1)):

$$
d s^{2}=d t^{2}-a^{2}(t)\left(d^{2}+r^{2} d \theta^{2}+r^{2} \sin ^{2} d d \theta^{2}\right)
$$

A fonte desse espaco-tempo é uma mistura de um campo escalar real minimamente acoplado e um fuido perfeito representando todos os outros campos, sendo que o primeiro esta 
transfexindo continuamente energia para o segundo. A densidade lagrangeana para o campo escalar é

$$
c=\frac{1}{2} \partial^{\mu} \phi \partial_{\mu} \phi-V(\phi)+\mathcal{L}_{\text {int }}
$$

com a interaçäo sendo representada pelo termo $\mathcal{L}_{\mathrm{in}} \mathrm{e} V(\phi)$ é a densidade de energia potencial do campo $\phi$. Este campo tem o tensor de energia momento dado por (ver discussão no Cap. 2)

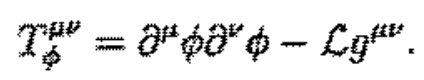

0 outro componente da mistura tem o tensor de energia momento usual do fluido perfeito (ver Eq. (1.7))

$$
T^{p \mu \nu}=(\rho+p) u^{\mu} u^{\nu}-p g^{p \nu}
$$

O tensor de energiammomento total do sistema $T_{i}^{\mu \nu}=T_{\phi}^{\mu \nu}+T^{\mu \nu}$ obedece as equaçóes de Eirstein, das quais obtém-se as equações de movimento

$$
\begin{gathered}
3 H^{2}=8 \pi G\left(\frac{\dot{\phi}^{2}}{2}+V(\phi)+\rho\right), \\
3 H^{2}+2 \ddot{H}=-8 \pi G\left(\frac{\dot{\phi}^{2}}{2}-V(\phi)+p\right),
\end{gathered}
$$

usando-se que a densidade de energia e pressão do campo escalar são, respectivamente,

$$
\begin{aligned}
& \rho_{\phi}=\frac{1}{2} \dot{\phi}^{2}+V(\phi), \\
& p_{\phi}=\frac{1}{2} \dot{\phi}^{2}-V(\phi) .
\end{aligned}
$$

Considerando que ofluido perfeito satisfaz a lei gama como equação de estado $p=(\gamma-1) \rho$, a lei de conservaçato da energia para esta mistura autogravitante pode ser escrita na forma

$$
\dot{\phi}\left(\tilde{\phi}+3 H \dot{\phi}+V^{\prime}(\phi)\right)=-\dot{p}-3 \gamma H \rho
$$

onde a linha, como antes, denota derivaçăo com respeito a $\phi$. Para desacoplar os dois lados da equaçăo acima e representar o decaimento do campo escalar em matéria usual, assume-se o termo dissipativo fenomenológico $\left(3 \Gamma \dot{\phi}^{2}\right)$, de modo que (5.9) se desmembra ras equaçôes

$$
\ddot{\phi}+3 H \dot{\phi}+V^{\prime}(\phi)=-3 \Gamma \dot{\phi}
$$


e

$$
\dot{\rho}+3 \gamma H \rho=3 \Gamma \dot{\phi}^{2},
$$

sendo o coeficiente $\Gamma$ a largura de decaimento de $\phi$ e o fator 3 incluído por conveninência matemática. Para modelos que têm um estágio inflacionário isentrópico, sabe-se que $\rho \sim 0$ no início das oscilaçōes coerentes do campo em torno do mínimo do potencial $V(\phi)$. Nesses casos, o termo $\Gamma \dot{\phi}^{2}$ não é, em geral, eficiente para descrever os primeiros estágios do processo de reaquecimento $[34,35]$ e é considerado inoperante durante a inflação exponencial. Contudo, na presença de uma componente térmica apreciável, um termo dissipativo pode ser justificado sob condições especiais durante o regime de Sitter [76]. Aplicações dessa teoria levam a complicados mas promissores modelos de inflação morna com uma quantidade anormalmente grande de campos leves acoplados ao inflaton [82], apesar de já haverem interpretações para tais modelos baseadas em teoria de cordas [84].

Neste capítulo, será aceito que este termo dissipativo representa o contato térmico entre o campo escalar e os demais em qualquer época. Também será considerado que o coeficiente de dissipação $\Gamma$ é função genérica da temperatura ou, equivalentemente, do tempo cósmico. Um exemplo de uso particular das equações acima é a versão original de inflação morna, descrita a seguir em linhas gerais.

\subsection{Inflação morna: um exemplo}

A inflação morna foi proposta originalmente por Berera e Fang [79] como um cenário isotérmico, alternativo aos modelos inflacionários isentrópicos. O modelo é baseado no conjunto de equaçōes apresentadas na seçāo anterior e tem como principais característica, além do fato de conter uma expansão exponencial isotérmica, a geração de um espectro térmico de perturbaçōes de densidade durante a fase inflacionária. De fato, esta é a principal motivação do trabalho: mostrar que a geração de tal espectro é possível numa versão matematicamente simples, na qual são admitidas algumas hipóteses simplificadoras. Isto 
pode ser contraposto a geracäo do espectro de fututucōes das inflaçōes isentrópicus, naste caso, quânticas.

modelo tem a mesma história pré-inflacionaria da nova inflaçāo, con um universo dominado por radiaçăo e uma transigâo de fase que ocorre quando $T=T_{c} \simeq M \sim V(\phi)^{1 / 4}$, (onde $M$ é a escala de energia da transição). Os dois modelos também têm em comum a existencia de uma fase de rolamento lento que faz o campo to permanecer no potencial por um intervalo de tempo $\Delta t_{I}$ suficiente para resolver os problemas do modelo padräo. A diferença reside no fato de que a temperatura da radiação nầo caí sa zero como na inflação isentrópica, pois o termo de atrito $\Gamma$ é tal que a temperatura da radiaçäo cai até um valor constate. Para ter um cenário auto-consistente, Berera e Fang tiveram que fazer algumas hipóteses: i) o campo escalar decai apenas tn matérix relativística (algo razoável quando se trata do universo primitivo), que atua como banho térmico para o campo $\phi_{;}$il)

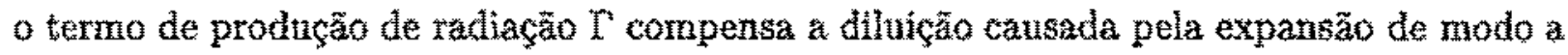
manter o banho térmico a temperatuma constante; ili) vale o equilíbrio temodina a iv) condiçōes de rolamento lento ( $\not \dot{\phi}$ é desprezivel com relaçăo aos demais termos da Eq. (5.9)), obtem-se que esta equacão e mais (5.11) simplificam-se em

$$
\dot{\phi} \simeq-\frac{V^{\prime}(\phi)}{3(h+\Gamma)}
$$

0

$$
\dot{p} \simeq 0
$$

De (5.11) com $\gamma=4 / 3$ (equação de estado da matéria relativística) e a equação acima,

$$
\rho \simeq \frac{3 \Gamma}{4 H} \phi^{2}
$$

Para haver uma fase de Sitter, o termo de potencial do campo escalar deve ser amplamente dominante sobre o termo cinético e a densidade de energia da radiaçäo, portanto, de (5.5),

$$
H^{2} \simeq \frac{8 \pi G}{3} V(\phi)
$$

Mais ainda, para caracterizar o banho térmico, Berera e Fang supōem que $\rho$ 汶 $\phi^{2}$. 
A temperatura final da componente térmica será obtida subtituindo (5.15) em (5.14):

$$
T \simeq \rho^{1 / 4} \simeq\left(m_{\mathrm{pl}} W \Gamma\right)^{1 / 4} M^{1 / 2}
$$

onde $W=\left(\dot{\phi}^{2} / 2 V(\phi)\right)$ é a razão entre os termos cinético e potencial do campo escalar e $M^{4}=T_{c}^{4} \sim V$.

Com o tipo de abordagem delineado acima, pode-se chegar a modelos que geram flutuações térmicas suficientemente intensas para servirem de sementes na geração do espectro de flutuaçōes de densidade que depois deram origem às estruturas observadas no universo (para mais detalhes, ver [79] e, com cálculos mais detalhados, [80]). Isto é relevante, pois os modelos inflacionários com espectros gerados por flutuaçōes quânticas têm sido considerados como os únicos viáveis, desde que as medidas das flutuações de temperatura da radiação cósmica de fundo aparentemente desfavoreceram os modelos baseados em defeitos topológicos.

\subsection{Inflação morna generalizada}

Algumas vezes é mais simples buscar novos modelos em uma teoria apenas com redefinições de equações, ou mesmo transformações de coordenadas. No caso das equaçōes apresentadas na Seção 5.2 isto pode ser feito com a definição dos seguintes parâmetros:

$$
x \equiv \frac{\dot{\phi}^{2}}{\dot{\phi}^{2}+\gamma \rho},
$$

e

$$
\alpha \equiv \frac{3 H \dot{\phi}^{2}}{3 H \dot{\phi}^{2}+|\dot{\rho}|} .
$$

A adoção destes parâmetros é razoável quando entendida como se segue. Para que haja expansão exponencial, $V(\phi)$ tem que ser fortemente dominante tanto na inflação morna quanto na isentrópica. O que as diferencia são os valores comparativos entre o termo cinético do campo escalar e a densidade de energia do fluido perfeito, com limites tais que uma dessas densidades de energia é muito maior do que a outra. Isto significa que é necessário 
comparar apenas a energia do termo cinético $\dot{\phi}^{2}=\rho_{\phi}+p_{\phi}$ com a quantidade envolvendo a energia da componente material em uma forma escrita convenientemente. Para a mistura, a quantidade equivalente (total) é $\rho_{t}+p_{t}=\dot{\phi}^{2}+\gamma \rho$. Desta forma, relembrando a lei de conservaçào de energia, $x$ é definido como a razão entre as duas "massas inerciais" que se "diluem" devido à expansão do universo. Entretanto, não é suficiente apenas comparar os valores de $\dot{\phi}^{2}$ e $\gamma \rho$. É também necessário quantificar como estas duas quantidades evoluem ao longo da expansão. Uma maneira de fazer isto mantendo as equações numa forma simples é introduzindo o parâmetro $\alpha$, que envolve $3 H \dot{\phi}^{2}$ e $\dot{\rho}$. A presença de $|\dot{\rho}|$ neste parâmetro justifica-se quando o cenário isotérmico da descrito acima é considerado apenas como caso limite, pois supor que a taxa de resfriamento da radiação devida à expansão exponencial é completamente compensada pela transferência de energia do campo escalar para o fluido perfeito parece ser uma situação teórica extrema. Na definição de $\alpha$ está implícito que $\dot{\rho} \leq 0$, uma vez que uma fase de reaquecimento é desnecessária na inflaçāo morna. Todavia, é importante notar que um $\dot{\rho}$ positivo é possível e já foi considerado na literatura [80].

Por serem adimensionais, estes parâmetros têm a característica conveniente de serem limitados aos intervalos $0 \leq x \leq 1$ e $0 \leq \alpha \leq 1$. Em particular, para a inflação isotérmica $[78,79]$ tem-se que $\alpha=1$ e $x \rightarrow 0$, pois $\dot{\rho}=0$ e $\gamma \rho \gg \dot{\phi}^{2}$. Para a inflação isentrópica tem-se $x=1$ e $\alpha=1$, uma vez que $\gamma \rho \ll \dot{\phi}^{2}$ e $\dot{\rho} \ll 3 H \dot{\phi}^{2}$ (a radiação torna-se exponencialmente desprezível com o tempo). De modo semelhante, modelos tipo quintessência com acoplamento térmico entre as componentes estão situados em algum valor intermediário entre 0 e $1 \operatorname{com} \alpha=x$. Quando ambos os parâmetros são nulos tem-se o modelo padrão (mais uma possivel constante cosmológica). Assim, todas as situações mais comuns, com ou sem acoplamentos térmicos, podem ser representadas em um espaço de parâmetros (ver Fig. 5.4). Além disso, como o potencial não aparece nas definiçōes dos parâmetros, convém mencionar que o espaço de parâmetros abaixo comporta tanto soluçōes inflacionárias (com o domínio do potencial na equação de Friedmann) quanto cosmologias não inflacionárias com campo escalar. 


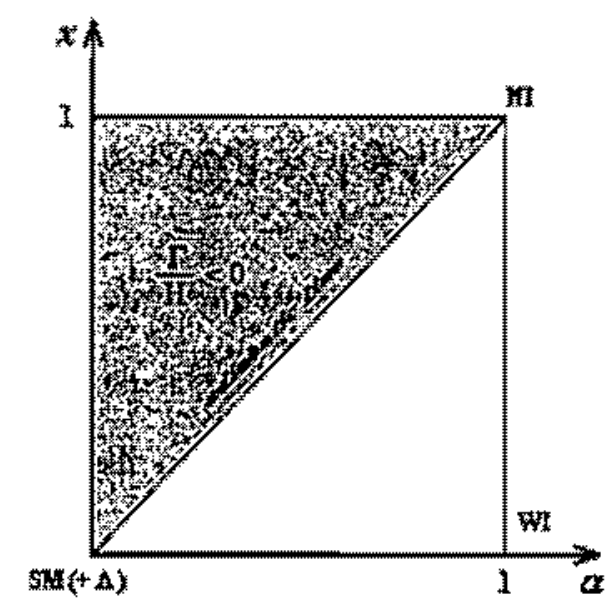

Figura 5.1: Espago de parämetros representando acoplamentos térmicos para os modelos com campo escalar mais comums ( $V(\phi)$ arbitrário). A regiâno sombreada é proibida para um universo em expansäo com decaimento do campo escalar. A linha diagonal $\Gamma=0$ inclui o modelo padrāo com uma possivel constante cosmológica $(0,0)$ e inflaçäo isentropica $(1,1)$. O ponto $(0,1)$ indica o cenário da Seçăo 5.3. A característica mais marcante da figura é a grande área disponível onde modelos diferentes poden ser representados.

\subsection{Dissipação e condições de rolamento lento}

Um ingrediente fundamental de muitas variantes inflacionárias é o período de "rolamento lento" do campo escalar, durante o qual o inflaton evolui täo lentamente que o seu termo cinético mantém-se sempre muito menor do que $V(\phi)$. Uma descrịzão desta dinâmica, para a mistura que estamos considerando, requer a introduçäo de um parâmetro que seja função da energia total da mistura. Neste caso, é conveniente usar o parämetro $\gamma_{\text {ef }}$ derivado de manipulaçoes nas Eqs. $(5.5)$ e $(5.6)$

$$
\gamma_{\alpha f}=-\frac{2 H^{4}}{3 H^{2}}=-\frac{p_{l}}{3 H p_{s}}=\frac{\phi^{2}+\gamma p}{p_{b}}
$$

As condiçô de rolamento lento são impostas para garantîn soluçỏes (aproximadamente) de Sitter por um periodo $\Delta$ it que deve ser sufcientemente longo para resolver os problemas do modelo padräo. Uma inspeçäo mas Eqs. (5.5) $(5.6)$ a (5.19) permite a verificação das 
seguintes condiçöes para se ter um universo de Sitter:

$$
3 H^{2} \gg 2|\dot{H}| \Leftrightarrow \gamma_{\mathrm{ef}} \approx 0 \Leftrightarrow V(\phi) \gg p+\frac{\phi^{2}}{2}
$$

Além disso, uma quantidade de inflaçào suficiente requer que as relaçôes acima sejam válidas ao longo do intervalo $\Delta t_{\eta}$. Isto usualmente estabelece condiç̧öes sobre a inclinação a a eurvatura de $V(\phi)$. Porérn, o acoplamento entre $\phi$ e o fluido $\gamma$ durante a infaçäo pode relaxar estas condiçôes para uma larga faixa de situaçöes intermediárias entre as situaçöes isentrópica e isotérmica. Com o termo dissipativo, tais condiçốes sâo representadas pelas relaçöes $(5.12)$ e (5.15) que, juntas, implicam os seguintes vínculos sobre a forma de $V(\phi)$ :

$$
\left(\frac{V^{\prime}(\phi)}{V(\phi)}\right)^{2} \frac{1}{16 \pi G} \approx\left(1+\frac{\Gamma}{H}\right)^{2} \frac{\dot{\phi}^{2}}{2 V(\phi)}
$$

$\varepsilon$

$$
\frac{V^{n}(\phi)}{V(\phi)} \frac{1}{24 \pi C} \approx-\left(1+\frac{\Gamma}{H}\right) \frac{\dot{\phi}^{2}+\gamma \rho}{2 V(\phi)}-\frac{1}{3 H} \frac{d}{d t}\left(\frac{\Gamma}{H}\right)
$$

E interessante notar que os resultados acima foram obtidos independentemente do sinal de $\dot{\rho}$, de modo que eles não estäo limitados à definiçâo de $\alpha$. As condiçotes de rolamento lento usuais säo reestabelecidas para $\Gamma=0$ (mistura desacoplada). Neste caso, elas implicam que a inflação só é possível para potenciais extremamente planos (ver Cap. 2), devido à áltỉna desigualdade em (5.20). Entretanto, no limite $(\Gamma \gg H)$ pode-se notar que a primeira e segunda derivadas do potencial nẫo são necessariamente pequenas de modo a garantir uma expansäo acelerada continnua. Assim, as condições de rolamento lento da inflação isentrópica podem ser subtituidas por um termo dissipativo suficientemente grande, que garanta inflaçäo sem condiçōes extremas sobre as derivadas do potencial. Neste caso, o campo năo "acelera" de tal forma que $\dot{\phi}^{2}$ torna-se comparável a $V(\phi)$ porque o "atrito" (com coeficiente $\Gamma$ ) é grande, e não porque o potencial é extremamente plano. Isto relaxa os vínculos sobre as constantes de acoplamento do termo de potencial, diminuindo assim os problemas de ajuste fro que afetaram a viabilidade de modelos como a nowa inflaçäo. 


\subsection{Um modelo simples}

O procedimento heuristico padräo para a elaboração de modelos cosmológicos com campos escalares é supor desde o principio um potencial específco $V(\phi)$, motivado ou não pela física de particulas, Este potencial ể usado para resolver a equação de movimento para $\phi(5.10)$. Caso seja necessário considerar a densidade de energia dos dernais campos (lembrando que normalmente considera-se que $\rho \rightarrow 0$ ao longo da inflaçäo), $O \notin$ assim obtido é inserido em (5.11), a qual é resolvida para $\rho$. A solução $a(t)$ pode entãa ser encontrada a partir da equação de Friedmann, caso jư năo tenha sido imposta desde o princípio por meio das condiçōes de rolamento lento. Isto é necessário porque mesmo que o acoplamento seja dado, o potencial ainda é parâmetro livre do sistema de equaçōes e diferentes potenciais resultam em diferentes modelos de inflação. Esta metodologia sera chamada aqui de abordagem dinâmica, para fixar a terminologia.

Numa abordagem alternativa, pode-se usar o espaço de parâmetros $(\alpha, x)$ como guia na busca por novos modelos. Para tanto divide-se $(5.11)$ por $3 H \phi^{2}$ e reescreve-se a equação resultante em termos de $x$ e $\alpha$ :

$$
\frac{\Gamma}{H}=\frac{1}{x}-\frac{1}{\alpha}
$$

A Eq. (5.23), útil também para discutir o espaço de parâmetros da Fig. 5.4, näo inclui o potencial, pois é representativa apenas dos possiveis acoplamentos e näo da dinâmica. Em princípio uma análise mats quantitativa esclarecerá os aspectos mais interessantes contidos no espaço de parẩnetros. Um modelo genérico (incluindo a possibilidade de decaimento de $\phi$ em qualquer era da história do universo) que se pode extrair partindo-se das Eqs. (5.17), (5.18) e (5.23) è aprezentado a seguir.

Uma vez que $x$ e $\alpha$ näo dependem de $V(\phi)$, é conveniente escrever a Eq. (5.11) na forma

$$
\hat{\rho}=-3 \gamma H \rho(1-\delta)
$$

onde foi usado que $\dot{\phi}^{2}=\frac{x \gamma \not}{(1-x)}$, , por economia de notaçăo foi introduzida a quantidade

$$
\delta=\frac{3 \Gamma \dot{\phi}^{2}}{3 \gamma H_{p}}=\frac{\alpha-x}{\alpha(1-x)}
$$


a razão entre o termo de fonte e o de diluição de $\rho$ pela expansão do universo. Uma solução simples, porém abrangente, para a equação acima é encontrada para $\alpha$ e $x$ constantes e dada por

$$
\rho(a)=\rho_{\mathrm{I}}\left(\frac{a}{a_{\mathrm{I}}}\right)^{-3 \gamma(1-\delta)},
$$

com a constante de integração $\rho_{\mathrm{I}} / a_{\mathrm{I}}^{-3 \gamma(1-\delta)}$ denotando as condições do início do estágio inflacionário. Se $\delta=1$ ou, equivalentemente, $\alpha=1$, a densidade de energia $\rho$ permanece constante $\left(\rho=\rho_{1}\right)$. Em particular, se $x \rightarrow 0$, ou seja, se $\rho \gg \dot{\phi}^{2}$, recupera-se a inflação morna isotérmica da seção anterior (ver também a Fig. 5.1). Isto mostra que modelos com valores no intervalo $0<x<1$ podem também evoluir isotermicamente durante a inflaçāo, seja exponencial, seja tipo lei de potência. A outra situação extrema ocorre se $\delta=0$, ou $\alpha=x$, com a densidade de energia variando como $\rho \sim a^{-3 \gamma}$. Este comportamento é típico de uma expansão isentrópica e na Fig. 5.4 corresponde à linha adiabática. Note-se que mesmo nessas circunstâncias nas quais os parâmetros são constantes, é de se esperar que a situação intermediária $(0<\delta<1)$, que corresponde aos modelos mais comuns de quintessência, seja fisicamente mais provável.

Dadas as condições acima, a densidade de energia do campo escalar pode ser calculada em termos do fator de escala. Primeiro, escreve-se a (5.10) como

$$
\dot{\rho}_{\phi}=-3 H \dot{\phi}^{2}\left(1+\frac{\Gamma}{H}\right)
$$

ou ainda

$$
\frac{d \rho_{\phi}}{d a}=-\frac{3 \dot{\phi}^{2}}{a}\left(\frac{\Gamma}{H}\right)
$$

Agora, uma vez que $x=$ const. e usando (5.23) e (5.26), esta equaçāo pode ser integrada:

$$
\rho_{\phi}=\rho_{\phi_{I}}+\rho_{I}\left(\delta+\frac{x}{1-x}\right)\left[\frac{\left(\frac{a}{a_{I}}\right)^{-3 \gamma(1-\delta)}-1}{1-\delta}\right],
$$

onde a constante $\rho_{\phi_{I}}$ é a densidade de energia inicial do campo escalar. Esta equaçāo pode ser escrita numa forma talvez mais esclarecedora:

$$
\rho_{\phi}=\rho_{\phi_{J}}+B\left(\rho-\rho_{I}\right)
$$


com

$$
B \equiv \frac{\dot{\rho}_{\phi}}{\dot{\rho}}=\frac{x}{(1-x)(1-\delta)}\left(1+\frac{\Gamma}{H}\right) .
$$

No limite adiabático $(\delta=0)$ as expressōes acima reduzem-se a

$$
\rho_{\phi}=\rho_{\phi_{I}}+\rho_{I} \frac{x}{1-x}\left[\left(\frac{a}{a_{I}}\right)^{-3 \gamma}-1\right] .
$$

O caso isotérmico $(\delta=1)$ é obtido com o uso da relação

$$
\lim _{q \rightarrow 1} \frac{f^{1-q}-1}{1-q}=\ln f
$$

Neste caso encontra-se que

$$
\rho_{\phi}=\rho_{\phi_{I}}-\frac{3 \gamma}{1-x} \rho_{I} \ln \left(\frac{a}{a_{\complement}}\right)
$$

Se $\delta \neq 1$, e usando (5.26) e (5.29), a densidade de energia total pode ser escrita como

$$
\rho_{t}=\rho_{\phi_{I}}-B \rho_{I}+(B+1) \rho
$$

Como $\rho_{\ell}$ tende a um valor constante quando $a \rightarrow \infty, \rho \rightarrow 0$, os dois primeiros termos da equação acima podem ser interpretados como uma constante cosmológica residual $\Lambda_{0}=$ $\frac{8 \pi G}{3}\left(\rho_{\phi_{I}}-B \rho_{I}\right) \equiv \rho_{\Lambda_{0}}$, que em algum momento da evolução do universo torna-se dominante. A soluçāo geral de (5.34) pode ser calculada analiticamente, mas nāo é realista. Mesmo fazendo a suposição mínima de que o campo escalar decai em radiação (fótons) ao longo da história do universo. Neste caso, $B=\rho_{\phi_{I}} / \rho_{I}$ vale durante toda a era da radiação, mas na era da matéria há que se modificar a equaçāo de Friedmann, seja adicionando um termo de densidade de matéria $\rho_{m}$ em (5.34), seja especificando em qual componente do fluido cósmico $\phi$ está decaindo e fazer as mudanças apropriadas em $\gamma$ e $\Gamma$. Discutir os detalhes de um modelo realista foge do escopo desta seção, onde pretende-se apenas mostrar que os parâmetros introduzidos podem ser bons pontos de partida na busca de novas soluçōes.

Os casos assintóticos, entretanto, sāo válidos e têm soluçōes simples. Substituindo (5.34) em (5.19) e usando (5.24) encontra-se que

$$
\gamma_{\mathrm{ef}}=-\frac{(1+B) \dot{\rho}}{3 H\left(\rho_{\Lambda_{0}}+(1+B) \rho\right)}=\frac{\gamma(1-\delta)}{1+\frac{\rho_{\Lambda_{0}}}{(1+B) \rho}}
$$


O caso extremo $\rho_{\Lambda_{0}}$ 沙 $\rho$ resulta em $\gamma_{\mathrm{ef}} \sim 0$ e no universo de Sitter $\left(H \simeq\right.$ const. $a \propto \mathrm{e}^{H t} \rightarrow$ $\infty$ ). Como as medidas de curvas de luminosidade das SNIa (ver Seção 1.3) indicam que, se existe constäate cosmológica, a transição para uma nova fase inflacionária está ocorrendo agora, $\operatorname{com} \rho_{A_{0}} \sim 10^{-47} \mathrm{GeV}^{4}$, este caso descreve o destino final do universo.

Mais interessante é a aproximação $\rho \gg p_{A_{0}}$. Isto implica que antes da era atual o termo cosmológico pode ser desprezado en $(5.34)$ e $B=\rho_{\phi_{1}} / p_{1}$ é uma aproximaçäo razoável no mínimo durante a era da radiação. Neste caso tem-se que

$$
\gamma_{\mathrm{ef}}=\gamma(1-\delta)
$$

e a dependência temporal do fator de escala pode ser obtida usandomse, por exemplo, estete último resultado em (5.19):

$$
a(t)=a_{I}\left(\frac{t}{t_{f}}\right)^{\frac{2}{3 \pi(i=\delta)}}
$$

Uma das formas de se encontrar o potencial como funçâo de $\phi$ para este caso é mostrada a seguir. Prímeiro explicita-se o potencial na Eq. (5.30) e obtem-se a sua dependência com respeito ao fator de escala:

$$
V(a)=\rho_{\phi}-\frac{\dot{\phi}^{2}}{2}=V_{I} \frac{\rho}{\rho_{I}}=V_{l}\left(\frac{a}{a_{I}}\right)^{-3 \gamma_{\mathrm{el}}} .
$$

Por outro lado, podemos obter $\phi(a)$ notando que, de (5.19), $\dot{\phi}^{2}=x \gamma_{e} p_{t}$ :

$$
\frac{d \phi}{d a}= \pm \sqrt{\frac{3 \pi \gamma_{\mathrm{et}}}{8 \pi G}} \frac{1}{a}
$$

Os sinais indicam que $\phi$ pode ser uma função crescente ou decrescente com o fator de escala. A soluçä̧o de (5.39) pode ser escrita na forma

$$
\left(\frac{a}{a_{I}}\right)^{-3 \gamma_{a} i}=\mathrm{e}^{-\lambda(\phi-\phi)}
$$

$\operatorname{com} \lambda= \pm \sqrt{24 \pi G_{\text {el }} / x}$. Para um universo em expansão, temos que o lado esquerdo da equaçäo acima é urna funçäo decrescente, portanto $\lambda\left(\phi-\phi_{I}\right)>0$ e o sinal de $\lambda$ serả positivo se $\phi$ for decrescente e negativo no caso contrário. Substituindo o resultado acima em (5.38), obtém-se

$$
V(\phi)=V_{J} e^{-\lambda\left(\phi-\phi_{f}\right)}
$$


onde foi assumido apenas o valor positivo de $\lambda$. Note que se $V_{I} \gg$ pr ocorre inflagazo exponencial, e se $V_{I}$ domina apenas moderadamente, o fator de escala evoluirá como na inflação do tipo potência de Lucchin e Matarrese [86], mass com uma componente térmica. Concebida originalmente como uma alternativa para a inflaçäo exponencial, a inflação de lei de potência tem sido reinterpretada como estando ocorrendo hoje. Se $0=0$, ou $\gamma=\gamma=1$, tem-se o caso mais comum de quintessência $[28]$ e se $\gamma_{y}=1-$ f tem-se o caso de quintesencia acoplada (ver tambếm [87]).

Como vimos, o modelo simples apresentado acima representativo de dois modos diferentes de se estender a inflaçäo morna original. Em um deles, mantém-se a condição isotérmica $(\alpha=\delta=1)$ para valores genéricos de $x$. Na outra abordagem, considera-se que

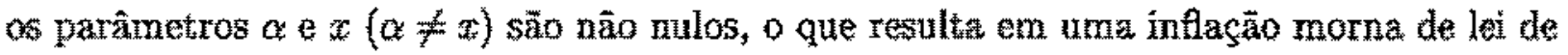
potencia. E de so esperar que em um caso mais geral, com ambos os parametros funçôs do tempo, seja possivel encontrar um modelo consistente o unificado que contenha tanto os casos extremos (infação morna jsotérmica e inflaçäo isentrópica) quanto as situaçöes intermediárias.

\subsection{Conclusão}

Eata análise baseada nos parămetros $(\alpha, x)$ pode ser útil como uma ferramenta heuristica na construça de modelos contendo campos escalares acoplados ao meio material. Em princípio, ela pode ser aplicada a modelos do tipo da infaçăo morna (envolvendo ou não transiçōes de fase) e modelos do tipo quintessência. Esta abordagem poderia ser tentada com um primeiro passo, para esclarecer as possíveís dinâmicas e estudar condiçôn termodinamicas, antes de se tentar diferentes potenciais para os campos escalares. Isto tornam se mats importante quando te considera que as condiçôs dinẩmicas, incluindo regimes inflacionários, podem ser relativamente independentes da forma do potencial devido ao termo de acoplamento, como foi visto ra Seção 5.5 . O acoplamento pode relaxar os vínculos sobre o potencial de tal forma que mesmo modelos exóticos de inflaçäo oscilante como o de 
Damour e Mukhanov [88] podem apresentar inflaçäo suficiente para resolver os problemas do modelo padrão.

Un resultado interessante da ulltima seçâto é que a dinâmica do modelo de decaimento do vácuo de Freese et al. [56] é reproduzida por uma campo escalar com potencial exponencial e acoplamento. Este pode ser um primeiro passo na busca de uma forma sistemâtica de se encontrar lagrangeanas que representern modelos com decainento do vácuo e, subsequentemente fazer a conexão entre os diversos modelos fenomenológicos discutidos no Capítulo 4 e teorias de campos.

Numa outra direçäo, um tratamento fenomenológico mais abrangente desses modelos com acoplamento deveria incluir necessariamente os métodos da termodinâmica de näoequilíbrio. Como exemplo da utilidade desta abordagem, foi mostrado recentemente [89] que a imposição de termalizaçäo entre os produtos do decaimento e o banho térmico (adotada em praticamente todas as versöes de inflaçäo morna mesmo em alguns casos do reaquecimento padräo dos modelos infacionários usuais) implica que o termo tenomenolögico de acoplamento depende explicitamente da densidade de energia do banho térmico. Na linguagem dos parâmetros introduzidos neste capitulo, isto significa que termalizaçäo impöe um valor constante para o parâmetro $x$. Este fato pode ter consequêncuas importantas sobre os modelos de inflaçäo rnorna, uma vez que os vinculos termodinâmicos säo menos dependentes de modelo do que os de teoria de carmpos [90]. 


\section{Considerações finais}

Como foi visto, campos escalares podem ser empregados em contextos e com motivaçöes diferentes para resolver diversos problemas do modelo cosmológico padrão. No caso dos modelos inflacionários, problemas clássicos da cosmologia de FRW tais como o da homogeneidade e isotropia, do horizonte e da origem das perturbaçōes de densidade são satisfatoriamente resolvidos. Entretanto, os cenários inflacionários mais bem sucedidos do ponto de vista observacional nẵo têm ligaçăo com teorias fundamentais. Versöes melhor motivadas, bașeadas en transições de fase, como a velha a nova inflaçăo, mostraram-se inviáveỉs do ponto de vista fenomenológico. Mais que isso, como as escalas de energia associadas à inflação são próximas à energia de Planck, seria também desejável que os modelos inflacionários fossem resultantes de alguma teoria de gravitação quântica que evitasse a existêncta da singularidade inicial. Por fim, há ainda o problema da constante cosmológica, que näo é considerado no âmbito da inflação. Esses assuntos deixados pendentes pelo cenário inflactonário, mais o avanço sem precedentes na cosmologia e astrofísica observacional sugerem uma busca por novas idéias. Claro, é desejável que tais idẻias sejam aplicadas sem que se percam as vantagens do tratamento com campos escalares nem o contato com a corroboraçāo experimental.

As três aplicações de campos escalares apresentadas nesta tese mostram que muito pode ser feito fora da inflação usual. As abordagens foram fenomenológicas, mas bem motivadas. No caso da cosmologia dilatônica apresentada no Cap. 3, buscou-se uma soluçảo para o problema da singularidade que fosse compativel com as teorias de cordas fundamentais 
e suas simetriass. Dos modelos com decaimento do vácuo do Cap. 4, o mais interessante parece ser o que apresenta o estágio deffacionário, por conectar o problema da singularidade com o da constante cosmológica e ainda apresentar uma passagem suave entre a dinâmica inflacionária e a fase do tipo FRW. Por fim, espaço de parâmetros proposto no Cap. 5 pode sẹr útil da busca de modelos com campos escalares com ou sem acoplamentos térmicos.

Em cada um dos casos tratados abrem-se boas perspectivas de trabalhos futuros. No caso das cosmologias dilatônicas um desenvolvimento possivel é incluír matéria na ação efetiva considerada e estudar os resultados. Numa outra linha, seria interessante explorar as possibilidades da inclusäo de um potencial para o dilaton avaliar seus efeitos tanto no referencial de Einstein quanto no Brans-Dicke, pois as dinämicas nesses referenciais säo diferentes e podem sugerir diferentes propostas fenomenológicas, motivadas seja pela cosmologia, no caso do primeiro, seja pela teoria de cordas, no segundo caso.

Uma extensão natural dos modelos deflacionários com decaimento do vácuo é obter soluçöes para o caso geral $(n \neq 1)$ e estudar os seus efeitos [65]. Cada um dos parâmetros fenomenológicos $\left(H_{T}, \beta\right.$ e $\left.n\right)$ tem consequências em regimes diferentes. $H_{I}$ conecta o modelo com a física na escala de Planck, $n$ é uma medida do quăo rápido ocorre a passagem entre a fase de Sitter $e$ a fase quase FRW (época que equivale ao reaquecimento na inflaçäo usual). Por sua vez, $\beta$ tem consequếncias observáveis desde a nucleossintese até o universo atual e todas elas podem ser estudadas para impor limites sobre este parâmetro [75].

O aparato heurístico do Cap. 5 abre perspectivas para muitas aplicaçöes. A mais imediate é fazer a analise termodinămica de modelos com campos escalares usando os mêtodos da termodinâmica de năo-equilibrio nos moldes da Ref. [58]. Uma outra possibilidade é buscar versöes com campos escalares das dinârnicas obtidas com os diversos modelos com decaimento do termo cosmológico. Por fim, o modelo simples discutido neste capítulo pode ser aprofundado e apresentado como uma outra proposta no contexto das cosmologias com quintessência [90]. 


\section{Apêndice A}

Obter as equaçöes de movimento do Capítulo 3 a partir da ação no caso de espaços curvos é normalmente uma tarefa cansativa đevido às manipulaçốs com o tensor métrico e suas derivadas. Como o caso estudado limita-se a universos homogêneos e isotrópicos, convếm simplificar os cálculos das equaçoes de movimento a partir da ação empregada. O procedimento mais direto é calcular os tensores da teoria de gravitaçăo escritos na métrica de FRW modificada:

$$
d s^{2}=n^{2}(t) d t^{2}-a^{2}(t)\left(\frac{d r^{2}}{1-k r^{2}}+r^{2} d \Omega^{2}\right)
$$

onde $d \Omega^{2}$ a a métrica do espaço tridimensional em coordenadas esféricas en $n(t)$ é uma função de lapso arbitrária que será feita igual a um nas equaçöes de movimento obtidas. A equaçấo de Friedmman e obtida diretamente da variaçâo da ação com relação à finção n(t). Nesta métrica, os invariantes usados na ação (3.4) adotam formas mais simples. $O$ determinante do tensor métrico será escrito como

$$
y=-\frac{n^{2} a^{6} r^{4} \sin ^{2}(\theta)}{1-k r^{2}}
$$

o escalar de Ricoi será

$$
R=6\left(\frac{\dot{n} H}{n^{3}}-\frac{\dot{H}}{n^{2}}-\frac{2 H^{2}}{n^{2}}-\frac{k}{a^{2}}\right),
$$

e o invariante $I_{2}$ usado no Capítulo 3

$$
I_{2}=\sqrt{4 R_{t u t} R^{\mu y}-R^{2}}=\frac{\dot{n} H}{n^{3}}-\frac{k}{a^{2}}-\frac{\dot{H}}{n^{2}},
$$


onde foi usado o pacote GRTensorll escrito para o programa de computação algébrica MapleVr3. A açäo (3.4)

$$
\left.S=-\frac{1}{16 \pi G} \int d^{4} x \sqrt{-g}\left\{R-\frac{1}{2}(\nabla \phi)^{2}+c \psi e^{* \phi}\right]_{2}+V(\psi)\right\}
$$

pode agora ser escrita em termos da métrica (A.1)

$$
\begin{array}{r}
S=-\frac{1}{16 \pi G} \int d^{4} x \frac{r^{2} \sin (\theta)}{\sqrt{1-k r^{2}}} a^{3}\left\{\frac{\dot{n} H}{n^{2}}\left(6-c \sqrt{12} \psi e^{\gamma \phi}\right)-\right. \\
n\left[\frac{k}{a^{2}}\left(c \sqrt{12} \psi e^{\gamma \phi}+6\right)+\frac{\phi^{2}}{2}+V(\psi)\right]- \\
\left.\frac{1}{n}\left[\dot{H}\left(\theta-c \sqrt{12} \psi e^{\gamma \phi}\right)+12 H^{2}\right]\right\} .
\end{array}
$$

Fazeado

$$
\frac{\delta S}{\delta \eta(t)}=0
$$

com $\eta(t)$ podendo ser $n(t), \phi(t)$ ou $\psi(t)$, obtêm-se as equaçốs de Euler-Lagrange:

$$
\frac{d}{d t}\left(\frac{\partial \mathcal{L}}{\partial \dot{\eta}}\right)-\frac{\partial \mathcal{L}}{\partial \eta}=0
$$

com a lagrangeana $\mathcal{L}$ sendo o integrando de $S$. Para $\eta(t)$ assumindo respectivamente os valores das funçöes $n(t), \phi(t)$ e $\phi(t)$, obtêm-se as equaçôes de movimento (3.5),

$$
\begin{aligned}
& \ddot{\phi}+3 H \dot{\phi}+\gamma c \psi \mathrm{e}^{\gamma \phi} \sqrt{12}\left(\frac{k}{a^{2}}-\dot{H}\right)=0, \\
& H=\frac{k}{\alpha^{2}}-\frac{e^{-r \beta}}{c \sqrt{12}} \frac{a V}{\partial t}, \\
& 6 \frac{k}{a^{2}}+6 H^{2}-\frac{d^{2}}{2}-V(\psi)= \\
& c e^{\gamma \phi} \sqrt{12}\left[3 H^{2} \psi-\frac{k}{a^{2}} \psi+H(\dot{\psi}+\gamma \dot{\phi} \psi)\right] .
\end{aligned}
$$

Note que nas equaçoes de movimento foi feito $n(t)=1$. 


\section{Apêndice B}

Neste apêndice será mostrada a técnica de multiplicadores de Lagrange aplicada no Capítulo 3 a um caso simples, com o objetivo de esclarecer como a técnica opera em linhas geraís. 0 caso estudado aqui trata da passagern da teoria newtoniana para a teoria relativística do movimento de uma partícula livre [44]. A diferença entre as duas teorias, do ponto de vista da açà̀o, reside na existência ou não de um limite superior para as possiveis velocidades da partícula. Correçando com a ação newtoniana de uma partícula livre

$$
S_{n}=\int d t \frac{\dot{x}^{2}}{2}
$$

A ação acima é somado um termo com um multiplicador de Lagrange $\psi$ acoplado a $\dot{x}^{2}$, a quantidade que se quer limitar, e que tem um potencial $V(\psi)$ a ser determinado de acordo com o vínculo físico no limite na velocidade da particula,

$$
S_{r}=\int d t\left(\frac{\dot{x}^{2}}{2}+\psi \dot{x}^{2}-V(\psi)\right)
$$

A variação da equação acima com relação a $\psi$ fornece a equação de vínculo do sistema:

$$
\tilde{x}^{2}=\frac{\partial V}{\partial y}
$$

$\dot{x}^{2}$ será limitado desde que $V(\psi)$ varie linearmente com $\psi$ para grandes valores de $|\psi|$ pois de (B.3), $\dot{x}^{2}$ tenderá a uma constante neste caso. O comportamento assintỏtico para velocidades baixas é obtido demandando que o limite newtoniano seja válido neste caso. Para isso acontecer basta que os dois últimos termos de (B.2) se cancelem. Uma forra de 
obter tais comportamentos assintóticos é impor as seguintes relaçōes:

$$
\begin{aligned}
& V(\psi) \sim \psi^{2} \text { para }|\psi| \rightarrow 0 \\
& V(\psi) \sim \psi \text { para }|\psi| \rightarrow \infty
\end{aligned}
$$

Escolhendo um potencial que interpola esses dois limites

$$
V(\psi)=\frac{2 \psi^{2}}{1+2 \psi^{2}}
$$

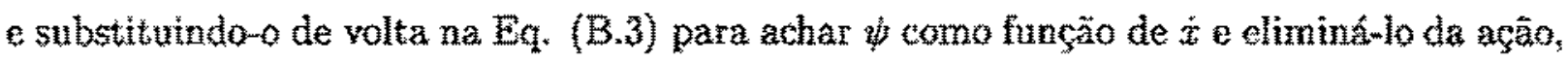
encontra-se que

$$
S_{r}=\frac{1}{2} \int d t \sqrt{1-\dot{x}^{2}}
$$

a açäo que descreve a partícula livre na relatividade especial. É claro, a açäo da relatividade especial só foi obtida mediante uma escolha extremamente particular dos coeficientes de $\psi$ na Eq. (B.5), mas em princípio coeficientes mais gerais, que ainda descreveriam uma teoria com limite de velocidade, poderiam ser experimentalmente estimados. 


\section{Bibliografia}

[1] Binstein, A. - "Consideraçōes Cosmológicas Sobre a Teoria da Relatividade Geral," em O Princípio da Relatividade, Fundaçäo Calouste Gulbenkian, Lisboa, p. 225 (1958).

[2] de Sitter, W. "On Einstein"s theory of gravitation and its astronomical consequences?" en The cosmological constants, editado por J. Bernstein e G. Feinberg, Columbia University Press, New York, p. 27 (1986).

[3] Bernstein, J.; Feinberg, G.; Eds. - The cosmological constants, Columbia University Press, New York, p. 8 (1986).

[4] Friedmarn, A. A. - "On the curvature of space," idem, p. 49; "On the possibility of a world with constant negative curvature," idem, p. 59.

[5] Slipher, V. M. - Tabela com resultados até $1922 \mathrm{em}$ Eddington, A. S. - The mathematical theory of relativity, 2nd ed., Chelsea, New York, p. 162 (1924).

[6] Hubble, E. P. - A relation between distance and radial velocity among extra-galactic nebulae," Proc. N. A. S. (U.S.A.) 15, 168 (1929).

[7] Lemaitre, G. - "A homogeneous universe of constant mass and increasing radius accounting for the radial velocity of extra-galactic nebulae," Mon. Not. R. astr. Soc. 91, 483 (1931).

[8] Weinberg, S. - Gravitation and cosmology, Wiley, New York (1972). 
[9] Jones, B. J. T. - "A brief history of Cosmology," em From quantumn fiuctuations to cosmological structures, editado por D. Valls-Gabaud, M. A. Hendry, P. Molaro e K. Chamcham, Vol. 126 das ASP Conference Series, Astronorny Society of Pacific, p. 1, 1997.

[10] Gamow, G. - "The origin of elements and the separation os galaxies" Phys. Rev. 74, 505 (1948); Alpher, R. A.; Herman, R. C. - "Rernarks on the evolution of the expanding universe," Phys, Rew 75, 1089 (1949).

[11] Penzias, A. A.; Wilson, R. W. - "A measurement of excess antenna temperature at $4080 \mathrm{Me} / \mathrm{s}, "$ Astrophys. J. 142, 419 (1965).

[12] Dicke, R. H.; Peebles, P. J. E; Roll, P. G.; Wilkinson, D. T. - "Cosmic background radiation," Astrophys. $J .142_{1} 414$ (1965).

[13] Peebles, P. J. E. - "Primordial Helium abundance and the primordial fireball," Astrophys. J. 146, 542 (1966); Wagoner, R. W.; Fowler, W. A.; Hoyle, F. - "On the synthesis of elements at very high temperatures," Astrophys. J. 148, 3 (1967).

[14] Kolb, E. W.; Turner, M. S. - The early universe, Addison-Wesley, Redwood City (1990).

[15] Perlmutter, S. al. - "Discovery of a supernova explosion at half the age of the universe and its cosmological implications," Nature 391, 51 (1998); Riess, G. et al "Observational evidence from supernovae for an accelerating universe and a cosmologleal constant," Astron J, 117, 707 (1999).

[16] Peebles, P. J. E. - Principles of physical cosmology, Princeton University Press, Prince$\operatorname{ton}(1993)$.

[17] Peebles, P. J. E.; Schramm, D. N.; Turner, E. L.; Kron, R. G. - "The Case for the Reiativistic Hot Big Bang", Nature 352, 769 (1991). 
[18] Peacock, J. A. - Cosmological physics, Cambridge University Press, Cambridge (1999).

[19] Smoot, $\mathrm{G}_{\text {. }}$ et al. " "Structure in the COBE DMR first year maps," Astrophys. J, 396, L1 (1992).

[20] Primack, J. R. - "Status of cosmology," astro-ph/9912089.

[21] Guth, A. H. - The inflationary universe: a possible solution to the horizon and flatness problems," Phys. Rev. D23, 347 (1981).

[22] Zeldovich, Ya. B. - "Cosmological constant and elementary particles", JETP Lett. 6, 316 (1967); "The cosmological constant, and the theory of elementary particles", Sov. Phys. Uspekhi 11, 381 (1968).

[23] Weinberg, S. - "The cosmological constant problem," Rev. Mod. Phys.61, 1(1989).

[24] Linde, A. D. "A new inflationary universe scenario: A possible solution of the horizon, flatness, homogeneity, isotropy and primordial monopole problems," Phys. Lett. 108B, 389 (1982); Albrecht, A.; Steinhardt, P.J. - "Cosmology for grand unified theories with radiatively induced symmetry breaking;" Phys. Reu. Lett. 48, 1220 (1982).

[25] Gasperini, M.; Veneziano, G. - "Pre big bang in string cosmology" Astropart. Phys. 1, 317 (1993); Gasperini, M. - "Inflation and initial conditions in the pre-big bang scenario," gr-qu/9902060.

[26] Parker, L; Zhang, Y. - "Relativistic condensate as a source for inflation," Phys. Rev. D47, 416 (1993); idem "Cosmological perturbations of a relativistic condensate," Phys. Rev. D51, 2709 (1995).

[27] Brandenberger, R. H.; Zhitnitsky, A. R. "Can asymptotic series resolve the problems of inflation?" Phys. Rev. D55, 4640 (1997)

[28] Peebles, P. J. E; Ratra, B. - "Cosmology with a time variable cosmological "con" stant;" Astrophys J. 325, $L 17$ (1988); Ratra, B.; Peebles, P. J. E. - "Cosmological 
consequences of a rolling homogeneous scalar field," Phys. Rev. DB7, 3406 (1988); Caldwell, R. R. Dave, R; Steinhardk, P. J. - "Cosmological imprint of an energy component with general equation-of-State," Phys. Rew Letw. 80, 1582 (1.988); Fujil, Y. Nishioka, T. "Model of a decaying cosmological constant," Phys. Rat. D42, 361 (1990); Frieman, J. A.; Waga, I. "Constraints from high redshift supernovae upon scalar field cosmologies," Phys. Rev. D57, 4642 (1998).

[20] Bahcall, N, Ostriker, J. P,; Perimutter, S; Steinhardt, P. J. - "The cosmic triangle: revealing the state of the universe," Science 284,1481 (1999).

[30] Linde, A. D. - "Chaotic inflation," Phys. Lett. B129, 177 (1983).

[31] Brandenberger, R. H. - "Inflationary universe models," Rew. Mod. Phys, 57, 1 (1985).

[32] Lyth, D. H.; Riotto, A. "Particle physics models of inflation and the cosmological density perturbation," Phys, Rept, 314, I (1999)

[33] Albrecht, A.; Steinhardt, P. J.; Turner, M. S.; Wilczek, F. - "Reheating and inflationary universe," Phys. Rev. Lett. 48, 1437 (1982); Dolgov, A. D.; Linde, A. D. - "Baryon asymmetry in inflationary universe," Phys. Lett. 116B, 329 (1982); Abbott, L. F.; Farhi, E.; Wise, M. B. - "Particle production in the new inflationary cosmology," Phys. Lett. 117B, 29 (1982).

[34] Dolgov, A. D.; Kirilova, D. P. - "Production of particles by a variable scalar field," Sov. J. Nucl. Phys. 51, 172 (1990); Traschen, J; Brandenberger, R. H. - "Particle production during out of equilibrium phase transitions," Phys. Rev. D42, 2491 (1990).

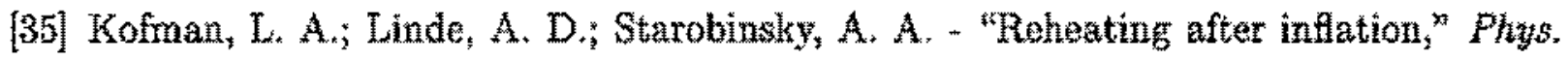
Rev. Lett. 73, 3195 (1994); idem - "Tovards the theory of reheating after infation," Phys. Rev. D56, 3258 (1997).

[36] Penrose, R. "Gravitational collapse and space-time singularities" Phys. Rev. Lett. 14, $57(1965)$. 
[37] Hawking: S. W.; Penrose, R - "The singularities of gravitational collapse and cosmology" Prot. Roy. Soc. Lond. A314, 529 (1969).

[38] Duff, M. J. - "M-Theory, (The theory formely known as strings)," hep-ph/9608117.

[39] Lidsey, J. E; Wands, D.; Copeland, E. J. - "Superstring cosmology", hep-th/9909061.

[40] Green, M. B.; Schwarz, J. H.; Witten, E. - Superstring Theory: I, Cambridge, Cambridge (1987).

[41] Gasperini, $M$. - "Elementary introduction to pre-big bang cosmology and to the relic graviton background," hep-th/9907/067.

[42] Brandenberger, R. H.; Easther, R. e Maid, J, - "Nonsingular dilaton cosmology," JHEP $9808,007(1998)$.

[43] Mukhanov, V. F.; Brandenberger, R. H. - "A nonsingular universe," Phys. Rev. Lett. $68,1969(1992)$.

[44] Brandenberger, R.; Mukhanov, V.; Somborger, A. - "A cosmological theory without. singularities," Phys. Rev. D48, 1629 (1993).

[45] Brandenberger, R.; Vafa, C, "Superstrings in the early universe," Nucl. Phys. B316, $391(1989)$.

[46] Brustein, R.; Veneziano, G - "The graceful exit problem in string cosmology," Phys. Lett. B329, 429 (1994).

[47] Easther, R; Maeda, K.; Wands, D. - "Tree level string cosmology" Phys. Rev. D53, $4247(1996)$.

[48] Kaloper, N; Madden, R.; Olive, K. A. - "Towards a singularity - free inflationary universe?" Nucl. Phys. B452, 677 (1995); Kaloper, N; Madden, R.; Olive, K. A. - 
"Axions and the graceful exit problem in string cosmology" Phys. Lett. 3718, 34: (1996).

[49] Easther, $\mathrm{R}$; Maeda, K. - "One loop superstring cosmology and the nonsingular universe," Phys. Rey. D54, 7252 (1996).

[50] Starobinsky, A. A. - "A new type of isotropic cosmological models without singularity" Phys. Lett. B91, 99 (1980).

[51) Turner, M. S., Weinberg, E. J, " "Pre - Big Bang inflation requires fine tuning," Phys. Rey. D56, 4604 (1997); Coule, D. H. - "Pre-big bang model has Planck problem," Class. Quant. Grav. 15, 2803 (1998); Kaloper, N,; Linde, A, Bousso, R. - "Pre-bigbang requires the universe to be exponentially large from the very beginning" Phys. Rev. D59, 043508 (1999);

[52] Easson, D. A.;Brandenberger, R. H. "Nonsingular dilaton cosmology in the string frame," JHEP 09, 003 (1999).

[53] Overduin, F. M.; Cooperstock, F. I. - "Evolution of the scale factor with a variable cosmological term," Phys. Rev. D58, 043506 (1998).

[54] Özer, M.; Taha, M. O. - "A possible solution to the main cosmological problerns," Phys. Lett. B171, 363 (1986); "A model of the universe free of cosmological problems," Nucl. Phys. B287, 776 (1987).

[55] Abdel-Rahman, A. M. M. - "Singularity-free decaying vacum cosmologies," Phys. Rev. D45, 3497 (1992).

[56] Freese, K, Adams, F. C.; Frieman, J. A.; Mottola, M. - "Cosmology with decaying vacuum energy," Nucl. Phys. B287, 797 (1987).

[57] Birkel, M.; Sarkar, S. - Nucleosynthesis bounds on a time-varying cosmological 'constant"," Astropart. Phys. 6, 197 (1997). 
[58] Lima, J. A. S. " "Thermodynamics of decaying vacuum cosmologies," Phys. Rev. D54, $2571(1996)$.

[59] Gasperini, M, - "Decreasing vacuum temperature: a thermal approach to the cosmological constant problem," Phys. Lett. 194B, 347 (1987); "A thermal interpretation of the cosmological constant," Class. Quantum Grav. 5, 521 (1988).

[60] Gibbons, G. W., Hawking, S. W. - "Cosmological event horizons, thermodynamics, and particle creation," Phys. Rev. D15, 2738 (1977).

[61] Chen, W.; Wu, Y-S. - "Tmplications of a cosmological constant varying as $R^{-2}$," $P h y s$. Rev. D41, 695 (1990).

[62] Carvalho, J. C; Lima, J. A. S; Waga, I. - "Cosmological consequences of a timedependent cosmological term," Phys. Rev. D46, 2404 (1902).

[63] Lima, J. A. S.; Maia, J. M. F. - "Some cosmological consequences of a A-term varying as $\beta H^{2}+\alpha R^{-n}, "$ Mot. Phys. Lett. A8, 591 (1993).

[64] Waga, I. - "Decaying vacuum flat cosmological models: expressions for some observable quantities and their properties, Astrophys. J. 414, 436 (1993).

[65] Maia, J. M. F.; Lima, J. A. S. - "The deftationary universe with a time-varying cosmological term," em preparaçâo.

[66] Lima, J. A. S.; Maia, J. M. F. - "Deflationary cosmology with decaying vacunm energy density:" Phys. Rev. D49, 5597 (1994).

[67] Murphy, G. L. - "Big Bang model without singularity," Phys. Rev. D8, 4231 (1973).

[68] Barrow, J. D. - "The deflationary universe: an instability of the de Sitter universe," Phys. Lett. B180, 335 (1986).

[69] Turner, M. S. - "Coherent field oscillation phase," Phys. Reu. D28, 1243 (1983). 
[70] Barrow, J. D. - "String-Driven inflationary and deflationay cosmological models," Nucl." Phys. B310, 743 (1988).

[71] Lima, J. A. S.; Germano, A. S. M. - "On the equivalence of bulk viscosity and matter creation," Phys. Lett. A170, 373 (1992).

[72] Prigogine, I.; Géhéniau, J.; Gunzig, E.; Nardone, P. - "Thermodynamics and cosmology," Gen. Rel. Grav. 21, 767 (1989).

[73] Lima, J. A. S; Trodden, M. - "Decaying vacuum energy and deflationary cosmology in open and closed universes," Phys. Rev. D53, 4280 (1996).

[74] Olson, T. S.; Jordan, T. F. - "Ages of the universe for decreasing cosmological constants," Phys. Rev. D35, 3258 (1987).

[75] Lima, J. A. S; Maia, J. M. F.; Pires, N. - "Constraints from big bang nucleosynthesis on a time-varying cosmological 'constant'," a ser publicado nos anais do 198 Simpósio da International Astronomical Union (1999).

[76] Hosoya, A.; Sakagami, M. - "Time development of Higgs field at finite temperature," Phys. Rev. D29, 2228 (1984); Morikawa, M. - "Classical fuctuations in dissipative quantum systems," Phys. Rev. D33, 3607 (1986); Gleiser, M.; Ramos, R. O. - "Microphysical approach to nonequilibrium dynamics of quantum fields," Phys. Rev. D50, 2441 (1994); Boyanovsky, D; de Vega, H. J.; Holman, R.; Lee, D. -S.; Singh, A. "Dissipation via particle production in scalar field theories," Phys. Rev. D51, 4419 (1995).

[77] Felder, G.; Kofman, L.; Linde, A. D. - "Instant preheating," Phys. Rev. D59, 123523 (1999); idem - "Inflation and preheating in NO models," Phys. Rev. D60, 103505 (1999).

[78] Berera, A. Phys. Rev. Lett. 75, 3218 (1995); "Thermal properties of an inflationary universe," Phys. Rev. D54, 2519 (1996). 
[79] Berera; A.; Fang; L. Z. - "Thermally induced density perturbations in the inflation era." Phys. Rev. Lett. 74, 1912 (1995); Berera, A. VAND-TH-99-04, hep-ph/p904409.

[80] Lee, W; Fang, L. Z. - "Mass density perturbations from inflation with thermal disstpation;" Phys. Rev. D59, 083503 (1999).

[81] Bellini, M. - "Warm inflation and classicality conditions," Phys. Lett. 428B, 31 (1998); idem - "Towards a theory of warm inflation of the universe," Class. Quant. Grav. 16, 2393 (1999).

[82] Berera, A.; Gleiser, M; Ramos, R. O. - "Strong dissipative behavior in quantum field theory" Phys. Rev. D58, 123508 (1998): idem "A first principles warm intiation model that solves the cosmological horizon/flatness problems," Phys. Rev. Letw. 83, 264 (1999); Yokoyama, J.; Linde, A. D. - "Is warm inflation possible?," Phys. Reu. D60, 083509 (1999).

[83] Maia, J. M. F.; Lima, J. A. S. - "Extended warm inflation" Phys. Rev. D60, 101301 (1999).

[84] Berera, A.; Kephart, T. W. - "Ubiquitous inflaton in string-inspired models," Phys. Rev. Lett. 83, 1084 (1999).

[85] Oliveira, H. P.; Ramos, R. O. - "Dynamical system analysis for inflation with dissipation," Phys. Rev. D57, 741 (1998).

[86] Lucchin, F.; Matarrese, S. - "Power law inflation," Phys. Rev. D32, 1316 (1985).

[87] Amendola, L. - "Coupled quintessence," astromph/9908023.

[88] Danour, T.; Mukhanov, V. F. - "Inflation without slow roll," Phys. Rev. Lett. 80, 2441 (1998).

[89] Lima, J. A.S. " On the thermodynamic effects of an interacting cosmic scalar feld" submetido para publicaçâo. 
